\title{
Geração de Classificadores de Seqüências Genéticas Utilizando Inferência de Linguagens Regulares
}

DANiel da CRuz Gouveia Vieira

\author{
DISSERTAÇÃO APRESENTADA \\ $\mathrm{AO}$ \\ INSTITUTO DE MATEMÁTICA E ESTATÍSTICA \\ DA \\ UNIVERSIDADE DE SÃO PAULO \\ PARA \\ OBTENÇÃO DO GRAU DE MESTRE \\ EM \\ CIÊNCIA DA COMPUTAÇÃO
}

Curso: Mestrado em Ciência da Computação Área de Concentração: Ciência da Computação Orientador: Prof. Dr. Alan Mitchell Durham

Durante a elaboração deste trabalho o autor recebeu apoio financeiro da CAPES 


\section{Geração de Classificadores de Seqüências Genéticas Utilizando Inferência de Linguagens Regulares}

Este exemplar corresponde à redação final da dissertação devidamente corrigida e defendida por Daniel da Cruz Gouveia Vieira e aprovada pela comissão julgadora.

São Paulo, Julho de 2004

Banca examinadora:

$\begin{array}{ll}\text { Prof. Dr. Alan Mitchell Durham (orientador) } & \text { IME-USP } \\ \text { Prof. Dr. Junior Barrera } & \text { IME-USP } \\ \text { Dr. Cezar Bravo } & \text { POLI-USP }\end{array}$ 
A minha mãe Virginia da Cruz Gouveia Vieira 


\section{Agradecimentos}

Ao meu orientador Prof. Alan Mitchell Durham, pela orientação, amizade e incentivo principalmente nos últimos meses do período de mestrado. Ao Prof. Junior Barreira pela co-orientação no inicio deste trabalho.

Aos colegas do nosso grupo de pesquisa, em especial à Ariane Lima, pela amizade e discussões importantes, e ao André Kashiwabara, pela ajuda na preparação dos testes.

Aos meus amigos do Laboratório Bioinfo-I Processamento de Imagens do IME-USP. Dentre eles agradeço especialmente a David Pires pela amizade que fizemos e pelas importantes observações no decorrer do desenvolvimento desta dissertação.

À toda minha família, pela força que eles sempre me deram. 
Métodos computacionais vêm sendo aplicados à Biologia Molecular para a identificação de propriedades do genoma. Este projeto aborda uma perspectiva lingüística de cadeias de nucleotídeos, com o objetivo de gerar classificadores de seqüências. Desenvolvemos um sistema de aprendizado computacional no qual foram implementados algoritmos de inferência gramatical visando caracterizar conjuntos de sequiências de nucleotídeos. Tais algoritmos geram analisadores sintáticos que são utilizados para construir classificadores de seqüências. Apresentamos uma avaliação inicial desses algoritmos no problema de Biologia Molecular de identificação de fronteiras iniciais e finais de éxons. Por meio de uma amostra de "benchmark" obtivemos resultados comparáveis com um dos preditores de fronteiras existentes. 
1 Introdução 1

1.1 Organização deste documento . . . . . . . . . . . . . . . . . . 4

2 Preliminares $\quad 5$

2.1 Aprendizado Computacional . . . . . . . . . . . . . . . . . . 5

2.1.1 Modelagem do Processo de Aprendizado . . . . . . . . . . . . . 6

2.1.2 Modelo de Aprendizado PAC . . . . . . . . . . . . . . . . . . . . 7

2.2 Classificação de Bayes . . . . . . . . . . . . . . . . . . . . . . . . . 9

2.2.1 Aprendizado de um classificador de Bayes . . . . . . . . . . . . . . . . 9

2.3 Linguagens, Gramáticas e Autômatos . . . . . . . . . . . . . . . . . . . . . 11

2.3.1 A classificação de Chomsky . . . . . . . . . . . . . . . . . . . 12

2.3.2 Gramáticas e Autômatos Estocásticos . . . . . . . . . . . . . . . . . 14

2.3.3 Cadeias de Markov Ocultas . . . . . . . . . . . . . . . 16

3 Inferência Gramatical $\quad 19$

3.1 Inferência de Autômatos Finitos Determinísticos . . . . . . . . . . . . . . . 21

3.1.1 Espaço de busca de inferência regular . . . . . . . . . . . . . . . 23

3.2 Inferência de Autômatos Finitos Determinísticos Estocásticos . . . . . . . . 29

3.3 Algoritmos de inferência regular . . . . . . . . . . . . . . . . . . 30

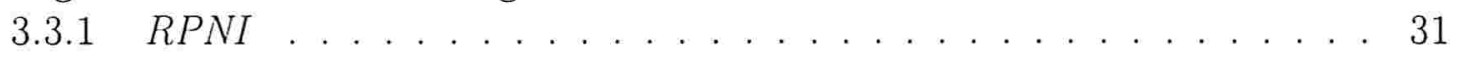

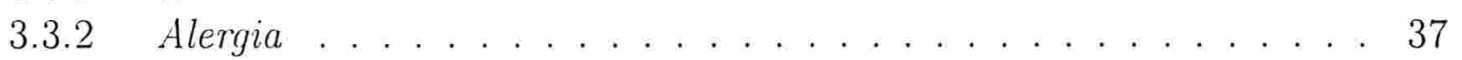

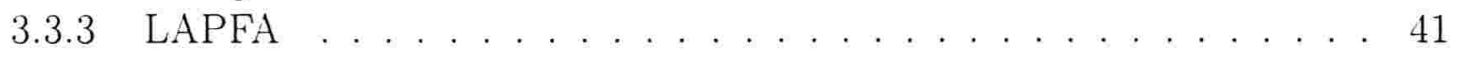

3.3.4 Amnesia . . . . . . . . . . . . . . . . . . . 44

4 Sistema de aprendizado de classificadores 53

4.1 Descrição do arcabouço . . . . . . . . . . . . . . . . . . . . . 53

4.2 Módulo de suporte aos testes dos algoritmos . . . . . . . . . . . . . . . 56 
5 Avaliação dos algoritmos $\quad 59$

5.1 Validação dos algoritmos em casos controlados . . . . . . . . . . . . . 59

5.1.1 Gramáticas alvo utilizadas . . . . . . . . . . . . . 59

5.1 .2 Análise dos parâmetros de generalização . . . . . . . . . . . . 62

5.1.3 Análise do comportamento do algoritmo à medida que a amostra de treinamento aumenta . . . . . . . . . . . . . . . . . 64

5.1 .4 Como obter um limiar . . . . . . . . . . . . . . . . . 71

5.2 Aplicação em Biologia Molecular . . . . . . . . . . . . . . . . . 74

$\begin{array}{llr}6 & \text { Conclusão } & 77\end{array}$

6.1 Trabalhos futuros . . . . . . . . . . . . . . . . . . . 78

$\begin{array}{ll}\text { A Participações em Conferências } & 81\end{array}$

Índice Remissivo $\quad 82$

Referências Bibliográficas $\quad 85$ 


\section{Lista de Figuras}

4.1 Módulos do sistema . . . . . . . . . . . . . . . . . . . . 55

5.1 Teste do parâmetro de generalização . . . . . . . . . . . . . . . . . . . 64

5.2 Teste de aprendizado da gramática alvo $G_{4} \ldots \ldots \ldots$. . . . . . . . . . . 68

5.3 Teste de aprendizado da gramática alvo $G_{\text {aleatoria }} \quad \ldots \ldots$. . . . . . . . . . 69

5.4 Teste de aprendizado da gramática alvo $G_{\text {donor }} \ldots \ldots \ldots$. . . . . . . 70

5.5 Dependência linear entre tamanho de seqüência e NLL-score . . . . . . . . 71

5.6 Desempenho da Técnica "Windowing" . . . . . . . . . . . . . . . . . 73

5.7 Histogramas de "z-scores" . . . . . . . . . . . . . . . . . . . . . . 73 



\section{Lista de Algoritmos}

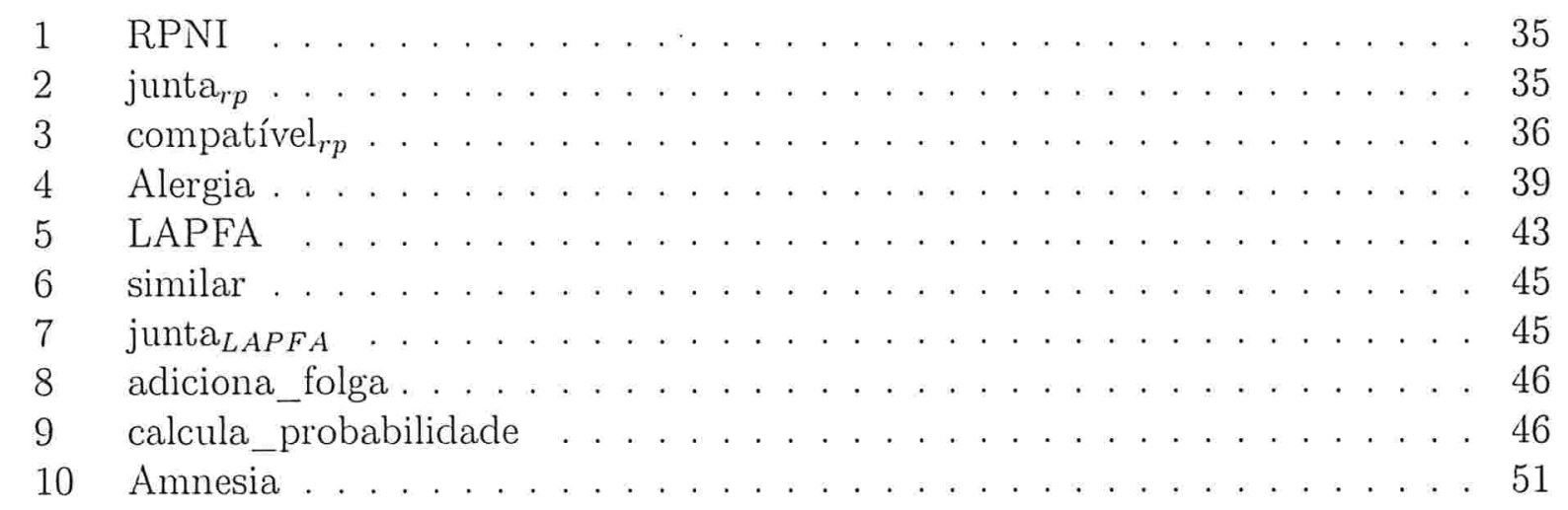




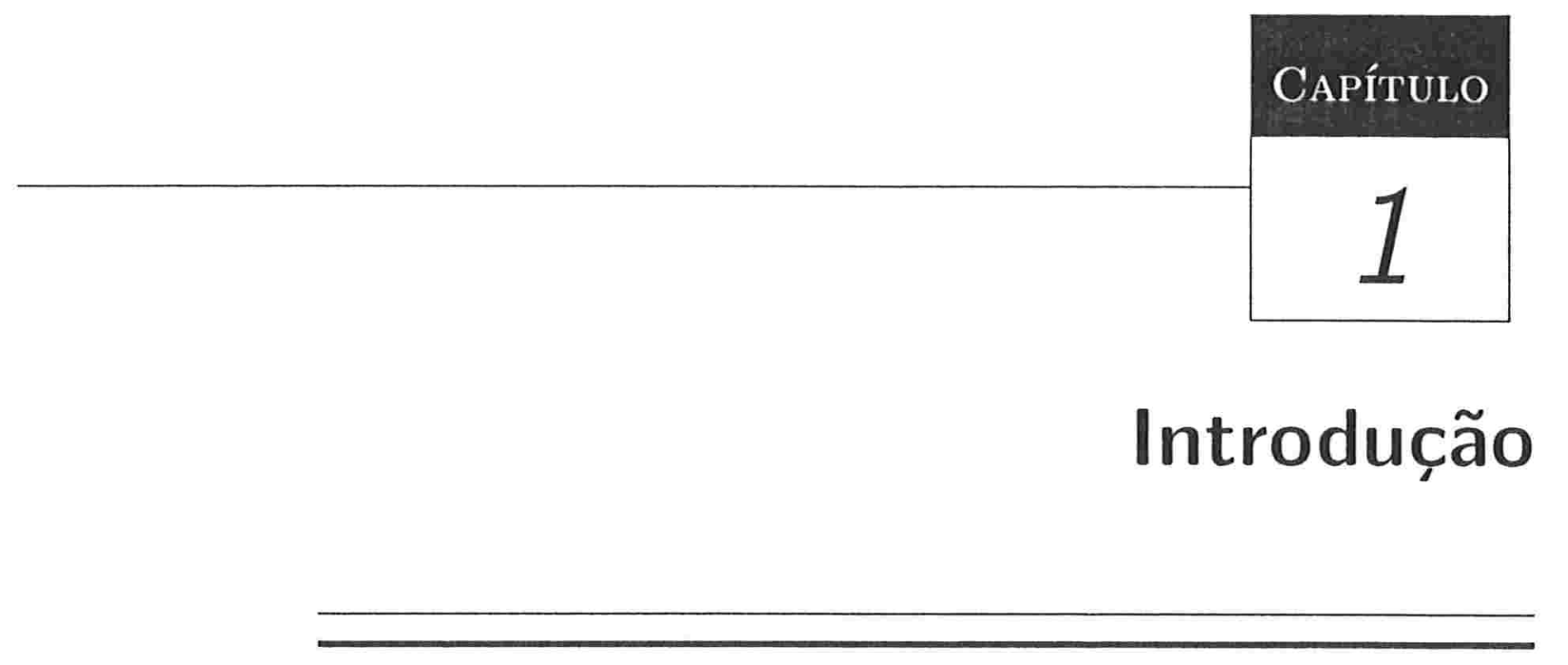

Com o desenvolvimento da tecnologia de seqüenciamento de DNA em larga escala, um número cada vez maior de trechos de DNA descaracterizados tornam-se disponíveis em bancos de dados genéticos. Devido a essa massa de dados sem significado biológico, um dos grandes desafios atuais na área da Biologia Molecular é descobrir a função do código genético. Claramente, seria inviável a análise dessa enorme base de dados sem o uso de computadores e algoritmos. A Biologia Molecular Computacional é um campo que trata do problema do "desenvolvimento e do uso das técnicas da Matemática e da Ciência da Computação para resolver problemas da Biologia Molecular" [MS97]. Apesar de ser um ramo relativamente recente, a Biologia Molecular Computacional já tem sido largamente utilizada. A própria construção dos genomas a partir dos dados de seqüenciamento tem sido feita com o auxílio de sistemas computacionais [Adi00]. O método de seqüenciamento Shotgun, por exemplo, utiliza a teoria de programação dinâmica para alinhamento dos fragmentos sobrepostos e de otimização combinatória para achar a melhor montagem [MS97]. No entanto, as aplicações em Biologia Computacional não se restringem a técnicas de alinhamento de seqüências. Em particular, algoritmos de árvores de decisão [SDFH98], teoria combinatória [SV96] e cadeias de Markov [HSF97, DEKM98, AKMSH94], entre 
outros, vêm sendo empregados para resolver problemas de encontrar genes, ou partes de genes, como éxons e regiões promotoras em longas seqüências de DNA.

A evolução dos seres vivos faz com que sistemas biológicos preservem sua estrutura e funcionalidade. As mudanças nos seres vivos são causadas por alterações nas suas moléculas de DNA. Este processo faz com que seja comum a existência de seqüências semelhantes de DNA em diferentes organismos. Quanto mais semelhantes e mais próximos os organismos estão na escala evolutiva, mais semelhantes são suas seqüências genéticas. Genes homólogos são aqueles que, apesar de pertencerem a diferentes organismos, são estruturalmente semelhantes e cumprem funções idênticas. A similaridade é usada em Biologia para descobrir características de um novo gene através da descoberta da existência de genes similares a este gene que já possuem anotações precisas de suas características [HAO93, DEKM98].

Uma vez que o DNA é definido por cadeias de 4 nucleotídeos (adenina, citosina, guanina e tinina), podemos descrever seqüências genéticas como cadeias num alfabeto de quatro letras A, C, G e T. Desta maneira, podemos caracterizar um conjunto qualquer de cadeias de DNA como uma linguagem sobre o alfabeto $\{\mathrm{A}, \mathrm{C}, \mathrm{G}, \mathrm{T}\}$. Por meio deste modelo, iremos utilizar técnicas de aprendizado computacional e inferência gramatical para, a partir de exemplos caracterizar famílias de seqüências de nucleotídeos através de gramáticas estocásticas. Estas gramáticas serão utilizadas para gerar classificadores de seqüências de nucleotídeos que, por sua vez, podem ser utilizados para investigar bancos de dados biológicos em busca de estabelecer novas anotações de seqüências por similaridade ${ }^{1}$.

\section{Por que aprendizado?}

O volume de dados levantado pelos atuais processos de sequienciamento de genomas impede a simples investigação bioquímica de todas as propriedades das seqüências. Para resolver este problema, a similaridade de genes tem desempenhado um importante papel para levantar hipóteses de propriedades em seqüências desconhecidas a partir de seqüências já investigadas. Desta maneira, passa a ter especial importância o problema de, a partir de um conjunto de seqüências, procurar criar um classificador para encontrar seqüências homólogas. Nesta formulação, temos um problema clássico de aprendizado computacional. A utilização de técnicas de aprendizado visa

\footnotetext{
${ }^{1} \mathrm{Na}$ verdade, são levantadas hipóteses sobre seqüências não anotadas, as quais, em seguida, são validadas por métodos bioquímicos.
} 
compensar a quantidade reduzida de informação e de conhecimento disponível sobre o genoma.

\section{Por que gramáticas estocásticas?}

No contexto de Aprendizado Computacional podemos escolher diversos tipos de estruturas para representar um conceito alvo como, por exemplo, redes neurais, cadeias de Markov ocultas ou gramáticas estocásticas. Optamos pelas gramáticas estocásticas, uma classe de estruturas ideal para representar famílias de cadeias de símbolos. Gramáticas têm se mostrado um instrumento promissor para modelagem de fenômenos genéticos. Searls sugeriu uma abordagem lingüística [Sea88] para identificar genes que codificam proteínas por meio de ' definite clause grammars' ' [Sea89, Sea95], originando um sistema computacional de reconhecimento de padrões sintáticos, chamado GenLang. Haas, Aaronson e Overton [HAO93] desenvolveram técnicas baseadas em gramáticas que exploram a homologia entre genes para descobrir regiões regulatórias que não estão presentes no banco de dados de seqüências de ácidos nucléicos, GenBank. Sakakibara et al. [YSRHKSH94] aplicaram gramáticas estocásticas livres de contexto para problemas de "folding", alinhamento e modelagem de famílias de seqüências de RNA transportadores. De forma geral, os autores comentam que a modelagem por gramáticas, comparada com outras técnicas, tem um potencial maior para representar a estrutura de um gene.

Este trabalho está vinculado ao projeto $\mathrm{CAGE}^{2}$ ( do inglês "Cooperation for Analysis of Gene Expression"), que une esforços multidisciplinares de químicos, estatísticos e cientistas da computação da Universidade de São Paulo com o intuito de estudar os mecanismos de expressão gênica. Nossa colaboração foi desenvolver um ambiente computacional em que se possa realizar testes de algoritmos de inferência de gramáticas regulares. Esse laboratório de inferência foi utilizado nesse trabalho para uma avaliação inicial de alguns algoritmos implementados na indetificação de fronteiras de íntrons e éxons.

\footnotetext{
${ }^{2}$ Para mais informações sobre $\circ$ projeto CAGE, consulte o sítio de internet http://www.vision.ime.usp.br/ cage.
} 


\subsection{Organização deste documento}

Esta dissertação encontra-se organizada da seguinte forma. No Capítulo 2 apresentamos definições, notações e conceitos básicos a serem utilizados no restante do documento. Revemos as noções de Aprendizado Computacional, Classificação de Bayes, Linguagens, Gramáticas e Autômatos. No Capítulo 3 apresentamos um resumo da teoria de inferência de gramáticas regulares. Descrevemos também os quatro algoritmos de inferência de gramáticas regulares implementados neste trabalho. No Capítulo 4 descrevemos o ambiente computacional desenvolvido para a realização de testes. No Capítulo 5 apresentamos uma análise dos testes realizados com os algoritmos de inferência gramatical implementados. Por último, no Capítulo 6, apresentamos um resumo das principais contribuições deste trabalho e sugestões de trabalhos futuros. 


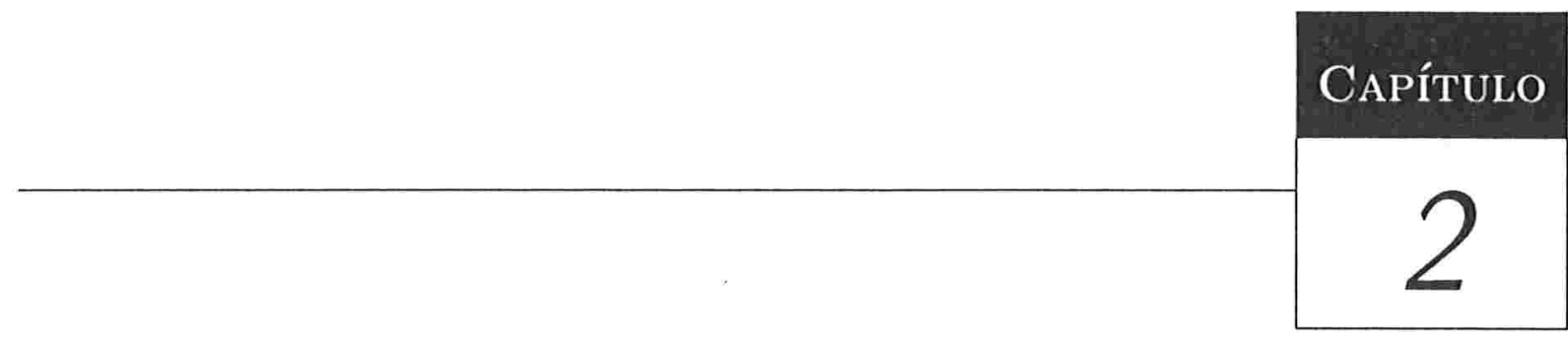

\section{Preliminares}

\subsection{Aprendizado Computacional}

A Teoria de Aprendizado Computacional estuda métodos para modelar matematicamente os processos de aprendizado. O modelo de Aprendizado Computacional que será apresentado utiliza alguns conceitos básicos da Teoria de Probabilidades, como espaço de probabilidade e distribuição de probabilidade. Uma descrição detalhada sobre essa teoria pode ser encontrada em [Bar42]. Inicialmente, iremos descrever a definição matemática do processo de aprendizado e, em seguida, iremos apresentar brevemente o conceito de identificação no limite e um dos modelos de aprendizado computacional chamado "PAC Learning". As definições descritas a seguir foram baseadas nos textos de Biggs [MA92] e Tomita [Tom96]. 


\subsubsection{Modelagem do Processo de Aprendizado}

Seja $\Sigma$ um conjunto, o alfabeto que descreve exemplos. Denotaremos por $\Sigma^{n}$ o conjunto de n-uplas de elementos de $\Sigma$ e por $\Sigma^{*}$ o conjunto de todas as seqüências finitas de elementos de $\Sigma$.

Seja $X$ um subconjunto de $\Sigma^{*}$. $X$ é denominado o espaço de exemplos e os elementos de $X$ são denominados exemplos. Um conceito $c$ sobre $X$ é um subconjunto do espaço de exemplos, que exemplificam positivamente alguma regra. De forma equivalente, um conceito pode ser definido como uma função definida por $c: X \rightarrow\{0,1\}$, onde $c(x)=1$ indica que $x$ é um exemplo positivo e $c(x)=0$ indica que $x$ é um exemplo negativo.

O conjunto $C$ de todos os possíveis conceitos é denominado espaço de conceitos. Um processo de aprendizado tem o objetivo de produzir um conceito $h$ que seja igual ou uma boa aproximação de um conceito alvo $c \in C$ que queremos aprender. O conjunto de todos os conceitos que podem ser aprendidos é denominado espaço de hipóteses e denotado por $H$.

Uma amostra de tamanho $m$ é uma seqüência de $m$ exemplos, ou seja, uma m-upla $x=$ $\left(x_{1}, x_{2}, \ldots, x_{m}\right) \in X^{m}$, que pode conter valores repetidos. Uma amostra de treinamento $s$ de tamanho $m$ é um elemento de $(X \times\{0,1\})^{m}$, ou seja,

$$
s=\left(\left(x_{1}, b_{1}\right),\left(x_{2}, b_{2}\right), \ldots,\left(x_{m}, b_{m}\right)\right)
$$

onde $b_{i}=c\left(x_{i}\right)$, indica se os exemplos são positivos ou negativos em relação ao conceito c. Dizemos que $s$ é consistente se $x_{i}=x_{j} \Rightarrow b_{i}=b_{j}, 1 \leq i, j \leq m$.

Um algoritmo de aprendizado relativo a um conceito alvo $c \in C$ é uma função $L$ que associa a cada amostra de treinamento $s$, consistente e de tamanho $m$, uma hipótese $h \in H$. O processamento de um algoritmo de aprendizado é denominado treinamento ou aprendizado. Uma característica desejável nos algoritmos de aprendizado é a capacidade de generalização, ou seja, a capacidade de associar hipóteses que consigam classificar corretamente outros exemplos além daqueles utilizados durante o treinamento.

A escolha de um conceito no espaço de hipóteses deve garantir que o conceito escolhido é aquele que melhor representa um conceito alvo. Desta maneira, podemos ver o processo 
de escolha como a minimização de uma medida de erro, medida esta que expressa a "distância" entre uma hipótese e o conceito alvo. A avaliação de uma hipótese escolhida é, em geral, realizada sobre um conjunto de exemplos de validação. O erro da hipótese sobre os dados de validação fornece uma medida do seu desempenho.

\section{Enumeração x Construção}

Podemos abordar um problema de aprendizado computacional de duas maneiras: utilizando métodos de enumeração ou métodos de construção. Na abordagem por enumeração, supomos que o espaço de hipóteses é enumerável. Seguindo uma enumeração das hipóteses, o método verifica se cada uma das hipóteses é compatível com todos os exemplos da amostra de treinamento, rejeitando-a caso não seja. Depois de rejeitar uma hipótese, a próxima é testada da mesma forma. O processo acaba quando uma hipótese compatível é encontrada ou todas as hipóteses são verificadas. Na abordagem por construção, uma hipótese é construída novamente cada vez que um exemplo da amostra de treinamento é fornecido, de tal forma que esta seja compatível com todos os exemplos já apresentados. Os algoritmos de inferência gramatical descritos na seção 3.3 utilizam métodos de construção.

\subsubsection{Modelo de Aprendizado PAC}

O modelo de aprendizado PAC (do inglês "Probably Approximately Correct") foi proposto por Valiant [Val84] em 1984. Deste então, diferentes versões foram formuladas à medida que o modelo foi utilizado na caracterização de problemas em diversas áreas. Descreveremos aqui uma versão formulada para inferência de gramáticas regulares [Pit89] e que, portanto, adapta-se melhor ao nosso projeto.

$\mathrm{O}$ aprendizado PAC é um modelo que considera apenas os algoritmos que satisfazem um determinado critério de qualidade. Informalmente, o objetivo de um algoritmo PAC é obter, com alta probabilidade, uma hipótese aproximadamente correta, quando comparada ao conceito alvo. A seguir, descreveremos sucintamente os princípios básicos deste modelo. Maiores detalhes podem ser encontrados na literatura de aprendizado computacional [Val84, MA92, Ang92, Pit89].

Suponha que $X$ define um espaço de probabilidades e que os exemplos são gerados aleatoriamente de $X$ respeitando uma distribuição de probabilidade $\mu$. $\mu$ é uma distri- 
buição arbitrária e desconhecida para o processo de aprendizado. A única restrição a $\mu$ exigida pelo modelo é que $\mu$ não sofra alterações no decorrer do tempo.

Desta maneira, podemos entender uma amostra de treinamento como sorteios independentes de elementos de $X$ segundo a distribuição $\mu$, na qual cada $x \in X$ sorteado recebe o rótulo $c(x)$.

Dado um conceito alvo $c \in C$, definimos o erro de uma hipótese $h \in H$ em relação a $c$, da seguinte forma:

$$
e r_{\mu}(h, c)=\mu\{x \in X: h(x) \neq c(x)\}
$$

O erro é a probabilidade de um exemplo obtido de $X$, de acordo com $\mu$, pertencer à diferença simétrica dos conjuntos de exemplos definidos por $h(x)$ (a hipótese em questão) e $c(x)$ (o conceito desejado).

Suponha que $X^{m}$, o conjunto de amostras de treinamento de tamanho $m$, possui a mesma estrutura do espaço de probabilidades de $X$. Denotamos $\mu^{m}$ a distribuição de probabilidades sobre $X^{m}$. Se $Y$ é um conjunto de amostras de treinamento $\left(Y \subset X^{m}\right)$, $\mu^{m}(Y)$ é 'a probabilidade de uma amostra aleatória de $m$ exemplos, obtidos de $X$, segundo a distribuição $\mu$, pertencer a $Y^{\prime}$.

Agora, seja $S(m, c)$ o conjunto de amostras de treinamento $s$ de tamanho $m$, com relação ao conceito $c$. Dizemos que um algoritmo $L$ é PAC para um espaço de hipóteses $H$ se, dados dois números reais $\epsilon$ e $\delta$ pertencentes ao intervalo $[0,1]$, existe um inteiro positivo $m_{0}=m_{0}(\epsilon, \delta)$ tal que, para qualquer conceito alvo $c$ e para qualquer distribuição de probabilidades $\mu$ sobre $X$,

sempre que $m \geq m_{0}$ temos que $\mu^{m}\left\{s \in S(m, c): e r_{\mu}(L(s), c)<\epsilon\right\}>1-\delta$.

A idéia desse modelo de aprendizado é propor um algoritmo que, dados $\delta$ e $\epsilon$, produz uma hipótese $h$ tal que, com probabilidade alta $(1-\delta)$, o erro entre $h$ e o conceito alvo $c$ seja baixo (menor que $\epsilon$ ), para qualquer $\mu$ e $c$. A condição de qualquer $\mu$ é satisfeita porque existe uma relação entre duas quantidades que a envolvem : o erro $e r_{\mu}$ e a probabilidade em relação a $\mu$ de um determinado conjunto. No modelo PAC, o aprendizado de uma hipótese com erro alto ocorre somente quando a amostra de treinamento não caracteriza 
o conceito alvo. Entretanto, uma amostra desse tipo raramente acontece e, portanto, o modelo PAC garante, com alta probabilidade, que a hipótese aprendida tem erro baixo.

\subsection{Classificação de Bayes}

Num processo de aprendizado, uma das maneiras de representar uma hipótese é através de um Classificador de Bayes [Fu82]. Um classificador de Bayes utiliza uma série de curvas de distribuição de probabilidades, cada curva correspondente a um padrão, para, dada uma entrada, decidir a qual padrão esta deve pertencer. Vejamos isso em detalhe.

Seja $X$ uma variável aleatória. Para cada padrão $\omega_{j}, j=1, \ldots, m$, suponha que a função de distribuição de probabilidade de $X$, denotada por $p\left(X \mid \omega_{j}\right)$ e a probabilidade de $\omega_{j}$ ocorrer, denotada por $P\left(\omega_{j}\right)$, são conhecidas. Baseado nessas informações, a função de um classificador é classificar minimizando a probabilidade de reconhecimento errôneo. O problema de classificação de padrões pode então ser formulado como um problema estatístico de decisão (teste de $m$ hipóteses), definindo uma função de decisão $d(X)$, na qual $d(X)=d_{i}$ significa que a hipótese $H_{i}: X \sim \omega_{i}$ foi aceita. A regra de decisão ótima que minimiza a probabilidade de reconhecimento errôneo é chamada de regra de Bayes. Neste caso a regra de decisão de Bayes é a seguinte:

$$
X \sim \omega_{i} \text { se } P\left(\omega_{i}\right) P\left(X \mid \omega_{i}\right) \geq P\left(\omega_{j}\right) P\left(X \mid \omega_{j}\right) \quad \text { para todo } j=1, \ldots, m
$$

Entretanto, como essas probabilidades não são conhecidas, temos que estimá-las através de um processo de aprendizado.

\subsubsection{Aprendizado de um classificador de Bayes}

Nosso objetivo final é a obtenção de um gerador de classificadores para seqüências de nucleotídeos. Dadas duas classes de padrões de seqüências, queremos construir um classificador que, dada uma seqüência qualquer, consiga classificar, com o menor erro possível a qual padrão ela pertence. Dentro do modelo de aprendizado computacional, nosso classificador representará um conceito, ou seja, uma função binária que associa a cada sequiência do domínio um valor 0 ou 1. Esse valor classifica cada seqüência entre as duas classes de padrões. 
A construção desse classificador é um processo que envolve inferência gramatical e classificação bayesiana. Explicaremos esse processo considerando um padrão de seqüências $C_{1}$ e um padrão de sequiências $C_{2}$ que é o complemento de $C_{1}$. Sejam $\tilde{C}_{1}$ um conjunto de exemplos positivos e $\tilde{C}_{2}$ um conjunto de exemplos negativos do padrão $C_{1}$. Utilizando um algoritmo de inferência gramatical, podemos inferir uma gramática para cada amostra de treinamento (isto é, tanto para a amostra positiva quanto para a negativa). Baseando-se nas amostras $\tilde{C}_{1}$ e $\tilde{C}_{2}$ podemos estimar probabilidades para as produções das duas gramáticas inferidas, transformando-as em duas gramáticas estocásticas $G_{1}$ e $G_{2}$ que caracterizam $C_{1}$ e $C_{2}$, respectivamente. Cada uma dessas gramáticas pode ser associada a um analisador sintático estocástico, que por sua vez é uma função que associa a cada cadeia de símbolos $x$ um valor de probabilidade $p\left(x \mid G_{i}\right)$, em que $i=1,2$. Desta maneira, podemos dizer que cada uma das gramáticas estocásticas $G_{1}$ e $G_{2}$ representa uma distribuição de probabilidade no domínio do nosso problema. Com base nessas duas distribuições, podemos classificar qualquer seqüência $x$ usando um classificador de Bayes da seguinte forma:

Se $P\left(x \mid G_{1}\right) P\left(C_{1}\right)>P\left(x \mid G_{2}\right) P\left(C_{2}\right)$ então $x \in C_{1}$ senão $x \in C_{2}$.

Em particular, na ausência de outra informação, vamos supor que $P\left(C_{1}\right)=P\left(C_{2}\right)$ (as duas classes têm a mesma probabilidade de ocorrer), o que nos dá:

Se $P\left(x \mid G_{1}\right)>P\left(x \mid G_{2}\right)$ então $x \in C_{1}$ senão $x \in C_{2}$.

A proposta de validação dos algoritmos será baseada no modelo de aprendizado PAC "Learning". Estamos interessados em desenvolver algoritmos que gerem classificadores com o menor erro possível. Mais que isso, queremos que os classificadores gerados por estes algoritmos tenham menor erro quanto maior for a amostra de treinamento inicial. No nosso caso específico, na fase de validação dos algoritmos de inferência gramatical, utilizaremos para o aprendizado duas amostras de cadeias simuladas que foram geradas por duas gramáticas estocásticas previamente conhecidas. Neste sentido, podemos apurar o erro do algoritmo fazendo com que este classifique outras cadeias, geradas pelas mesmas gramáticas estocásticas, computando a taxa de sucesso do classificador. Serão validados apenas os algoritmos que são PAC "Learning" no sentido em que, ao aumentarmos o tamanho da amostra utilizada para gerar os classificadores, a taxa de erro do classificador resultante diminui. 


\subsection{Linguagens, Gramáticas e Autômatos}

Uma gramática consiste de um conjunto de produções que, combinadas, descrevem a geração de diferentes seqüências de símbolos. A partir de uma gramática, podemos construir um algoritmo, chamado de analisador sintático, que consegue reconhecer todas as possíveis sequiências geradas pela gramática, tornando uma gramática útil tanto na caracterização de conjuntos de sequiências como no reconhecimento de categorias de seqüências de símbolos.

Nesta seção definiremos os conceitos básicos relacionados à teoria de gramáticas. Uma descrição mais detalhada tanto destas definições como da teoria de linguagens formais pode ser encontrada no trabalho de Aho [AU73, ASU86].

Seja $\Sigma$ um alfabeto finito e sejam $u, v$ e $w$ elementos de $\Sigma^{*}$, ou seja, cadeias sobre $\Sigma$. Denotaremos a cadeia vazia por $\lambda$ e o tamanho da cadeia $u$ por $|u|$. Dizemos que $u$ é um prefixo de $v$ se existe $w$ tal que $u w=v$ e que $u$ é um sufixo de $v$ se existe $w$ tal que $w u=v$. Uma linguagem $L$ é qualquer subconjunto de $\Sigma^{*}$. Diremos que uma linguagem $L_{1}$ é mais geral que uma linguagem $L_{2}$ se $L_{2} \subset L_{1}$. Denotaremos o conjunto de prefixos de $L$ por $\operatorname{Pr}(L)=\{u \mid \exists v, u v \in L\}$. O conjunto $L / u=\{v \mid u v \in L\}$ é denominado de quociente-direito ou conjunto de caudas de $L$ por $u$. Temos $L / u \neq \emptyset$ se, e somente se, $u \in \operatorname{Pr}(L)$.

Definição. 2.3.1 Uma gramática é uma quádrupla $G=\left\{V_{n}, V_{t}, P, S\right\}$ na qual:

- $V_{n}$ é um conjunto de símbolos não terminais;

- $V_{t}$ é um conjunto de símbolos terminais;

- $S \in V_{n}$ é o símbolo inicial;

- $P \in\left\{\left(V_{n} \cup V_{t}\right)^{*} V_{n}\left(V_{n} \cup V_{t}\right)^{*} \rightarrow\left(V_{n} \cup V_{t}^{*}\right)\right\}$ é o conjunto de produções. 


\subsubsection{A classificação de Chomsky}

As linguagens podem ser classificadas em quatro tipos [Cho59], ordenadas por ordem decrescente de generalidade: linguagens recursivamente enumeráveis, linguagens sensíveis ao contexto, linguagens livres de contexto e linguagens regulares.

Cada uma destas classes de linguagens é associada a um tipo de mecanismo de reconhecimento e a um tipo de gramática capaz de especificá-la.

Na seqüência definiremos as gramáticas regulares, que são as gramáticas que pretendemos abordar, bem como autômatos finitos, que são o mecanismo de reconhecimento destas gramáticas.

Definição. 2.3.2 G é uma gramática regular (GR) se suas produções são de uma das duas formas abaixo:

- $A \rightarrow b, b \in V_{t}, A \in V_{n}$

- $A \rightarrow b C, b \in V_{t}, C \in V_{n}, A \in V_{n}$

Definição. 2.3.3 Um autômato finito é uma quíntupla $M=\left(Q, \Sigma, \delta, q_{0}, F\right)$ sendo que:

- Q érum conjunto não vazio de estados;

- $\Sigma$ é um alfabeto;

- $\delta$ é a função de transição, i.e. um mapeamento de $Q \times \Sigma$ para $2^{Q}$;

- $q_{0}$ é o estado inicial; $e$

- F é um subconjunto de $Q$, denominado de conjunto de estados finais.

Para qualquer gramática regular $G$ podemos construir um autômato finito que reconhece a linguagem gerada por $G$ [ASU86]. Desta maneira, dada uma gramática regular, é fácil construir um algoritmo eficiente de geração e reconhecimento de cadeias geradas por aquela gramática. Como a maioria dos algoritmos de inferência utilizam os autômatos finitos como a classe de representação para suas hipóteses, daqui em diante nos concentraremos nas definições de autômatos finitos. 
Definição. 2.3.4 Um autômato finito determinístico (AFD) é um autômato finito que, para qualquer $q \in Q$ e para qualquer $\sigma \in \Sigma$, existe $\delta: Q \times \Sigma \rightarrow Q$ tal que $\delta(q, a)$ tem no máximo um membro.

Um reconhecimento de uma cadeia $u=a_{1} \ldots a_{l}$ por um autômato (possivelmente não-determinístico) $A$ define uma seqüência (possivelmente não única) de $l+1$ estados $\left(q^{0}, \ldots, q^{l}\right)$ tal que $q^{0}=q_{o}, q^{l} \in F$ e $q^{i+1} \in \delta\left(q^{i}, a_{i+1}\right)$, para $0 \leq i \leq l-1$. Dizemos que estes $l+1$ estados são percorridos pelo reconhecimento e que $q^{l}$ é usado como estado de reconhecimento. De forma semelhante, dizemos que as $l$ transições são exercitadas pelo reconhecimento.

Definição. 2.3.5 Um autômato $A$ é ambígüo se existe pelo menos uma cadeia $u$ na qual existe mais de um reconhecimento. Neste caso, este autômato é necessariamente não-determinístico.

Definição. 2.3.6 $A$ linguagem $L(A)$ reconhecida por um autômato $A$ é o conjunto de cadeias reconhecidas por $A$.

Definição. 2.3.7 Dois autômatos são equivalentes se eles reconhecem a mesma linguagem.

Definição. 2.3.8 Uma linguagem $L$ é regular se, e somente se, existe um AFD M tal que $L=L(M)$. Portanto a classe de linguagens regulares é a classe de linguagens reconhecidas por $A F D$ s.

Teorema 2.3.1 A classe de linguagens reconhecidas pelos autômatos finitos não-determinísticos também corresponde exatamente à classe de linguagens regulares.

Um estado $q$ de um autômato $A$ é denominado útil se existe uma cadeia $u$ em $L(A)$ na qual o estado $q$ é percorrido em algum reconhecimento de $u$. Caso contrário, o estado $q$ é denominado inútil.

Denotaremos por $A(L)=\left(Q, \Sigma, \delta, q_{0}, F\right)$ o AFD que tem o menor número de estados para uma linguagem $L$ dada. $A(L)$ é denominado também autômato canônico, e pode ser definido como segue: 
- $Q=\{L / u \mid u \in \operatorname{Pr}(L)\}$

- $q_{0}=L / \lambda$,

- $F=\{L / u \mid u \in L\}$,

- $\delta(L / u, a)=L / u a$ em que $u, u a \in \operatorname{Pr}(L)$.

Todo autômato determinístico que reconhece exatamente $L$ e contém o menor número de estados para esta linguagem é isomorfo a $A(L)$. Logo, para qualquer linguagem regular $L$ existe um único $A F D$ canônico que reconhece $L$.

\subsubsection{Gramáticas e Autômatos Estocásticos}

Uma gramática estocástica é uma gramática na qual associamos uma probabilidade a cada uma das produções. Formalmente:

Definição. 2.3.9 Uma gramática estocástica é uma quádrupla $G_{s}=\left\{V_{n}, V_{t}, P_{s}, S\right\}$ sendo que:

- $V_{n}, V_{t}, S$ têm o mesmo significado que em gramáticas não estocásticas.

- $P \in\left\{\left(V_{n} \cup V_{t}\right)^{*} V_{n}\left(V_{n} \cup V_{t}\right)^{*} \rightarrow\left(V_{n} \cup V_{t}^{*}\right), p\right\}$ é o conjunto de produções. A cada produção está associada uma probabilidade $p, 0 \leq p \leq 1$.

- para cada $A \in V_{n}$ e para cada $\left\{A \rightarrow \alpha_{i}, p_{i}\right\} \in P_{s}, \sum_{i} p_{i}=1$.

Dada uma linguagem $L$ gerada por uma gramática estocástica $G_{s}$, podemos associar a cada cadeia $x$ desta linguagem um valor $p\left(x \mid G_{s}\right)$ ao qual chamaremos de probabilidade da cadeia $x$ dada $G_{s}$. Esta probabilidade é calculada multiplicando-se os valores das probabilidades das produções utilizadas na derivação de $x^{1}$. O valor $p\left(x \mid G_{s}\right)$ pode ser utilizado para caracterizar o grau de certeza de que $x$ pertence a $L\left(G_{s}\right)$, ou seja, podemos dizer que uma gramática estocástica é uma representação de uma distribuição de probabilidade.

\footnotetext{
${ }^{1}$ no caso de gramáticas estocásticas ambíguas, este valor é a soma dos valores calculados para cada uma das possíveis derivações de $x$.
} 
Definição. 2.3.10 Um autômato finito estocástico (AFE) é uma quádrupla $P=$ $\left(Q_{P}, \Sigma_{P}, \pi_{P}, M_{P}\right)$ sendo que:

- $Q_{P}$ é um conjunto não vazio de estados;

- $\Sigma_{P}$ é um alfabeto;

- $\pi_{P}: Q_{P} \rightarrow[0,1]$ é uma distribuição de probabilidades sobre $Q_{P}$;

- $M_{P}: Q_{P} \times Q_{P} \times \Sigma_{P} \rightarrow[0,1]$ é uma matriz de probabilidades de transição na qual

$$
\sum_{i \in Q_{p}} \pi_{P}=1 \quad \text { e } \forall i \in Q_{P} \sum_{j \in Q_{P}, \sigma \in \Sigma_{p}} M_{P}(i, j, \sigma)=1
$$

Para qualquer cadeia $w=w_{1} \ldots w_{n} \in \Sigma_{P}^{*}$ a probabilidade de $w$ ser gerada por $P=$ $\left(Q_{P}, \Sigma_{P}, \pi_{P}, M_{P}\right)$ é calculada da seguinte forma:

$$
P\left(w_{1} \ldots w_{n}\right)=\sum_{\left\langle i_{0}, \ldots, i_{n}\right\rangle \in Q_{P}^{n+1}} \pi_{P}\left(i_{0}\right) \cdot \prod_{j=0}^{n-1} M_{P}\left(i_{j}, i_{j+1}, w_{j+1}\right)
$$

Portanto, para qualquer exemplo de tamanho $n, P$ define uma distribuição de probabilidade sobre $\Sigma_{P}^{n}$.

Não é difícil perceber que, assim como os autômatos finitos estão associados às gramáticas regulares, os AFEs representam a mesma classe de linguagens que as GREs. A definição de AFE pode ser restringida para que o autômato seja determinístico no sentido em que qualquer estado não tenha mais de uma transição de saída com mesmo símbolo. Segue a definição dessa classe de autômatos.

Definição. 2.3.11 Um autômato finito determinístico (AFD) estocástico é uma quíntupla $M=\left(Q_{P}, \Sigma_{P}, \pi_{P}, \tau, \gamma\right)$ sendo que:

- $Q_{P}$ é um conjunto não vazio de estados;

- $\Sigma_{P}$ é um alfabeto finito;

- $\tau: Q \times \Sigma \rightarrow Q$ é a função de transição; 
- $\gamma: Q \times \Sigma \rightarrow[0,1]$ é a função de probabilidade do próximo símbolo;

- $\pi_{P}: Q_{P} \rightarrow[0,1]$ é a distribuição de probabilidade inicial sobre sobre os estados iniciais;

- as funções $\gamma$ e $\pi$ devem satisfazer as seguintes condições: $\sum_{\sigma \in \Sigma} \gamma(q, \sigma)=1$ e $\sum_{q \in Q} \pi(q, \sigma)=1 ; e$

- A função de transição $\tau$ é definida em todos os estados q e símbolos $\sigma$ nos quais $\gamma(q, \sigma)>0$ e em nenhum outro par estado-símbolo.

Um AFD estocástico pode gerar cadeias de tamanho infinito. Porém, como nosso estudo está voltado para a prática, abordaremos apenas as distribuições de probabilidade sobre cadeias de tamanho finito. Se $P_{M}$ é a distribuição de probabilidade de um AFE $M$ sobre cadeias de tamanho infinito, então denotaremos por $P_{M}^{N}$, para qualquer $N \geq 0$, a probabilidade induzida das cadeias com tamanho $N$. A probabilidade de $M$ gerar uma cadeia $u=u_{1} u_{2} \ldots u_{N}$ em $\Sigma^{N}$ é

$$
P_{M}^{N}(u)=\sum_{q^{0} \in Q} \pi\left(q^{0}\right) \prod_{i=1}^{N} \gamma\left(q^{i-1}, u_{i}\right)
$$

dado que $q^{i+1}=\tau\left(q^{i}, u_{i}\right)$.

Neste trabalho, concentraremos os esforços no aprendizado de AFD estocásticos. A definição da classe mais geral de AFE foi introduzida para traçarmos um paralelo entre a classe dos autômatos e as Cadeias de Markov ocultas, descritas na próxima seção.

\subsubsection{Cadeias de Markov Ocultas}

Conforme mencionado previamente, técnicas de HMM são utilizadas em diversos problemas de modelagem de bioseqüências e, portanto, nos mostra o escopo em que algoritmos de inferência gramatical podem ser aplicados. Todo conhecimento necessário às cadeias de Markov ocultas que se supõe nesse texto pode ser encontrado no tutorial de Rabiner [Rab89]. Reveremos apenas sua definição para podermos relacionar esse modelo à classe de autômatos finitos estocásticos. As cadeias de Markov ocultas são definidas de 
forma semelhante aos autômatos finitos estocásticos, exceto que a geração dos símbolos está associada com os estados e não com as transições.

Definição. 2.3.12 Uma cadeia de Markov oculta (HMM) é uma quíntupla $P=\left(Q_{P}, \Sigma_{P}, \pi_{P}, M_{P}, L_{P}\right)$ sendo que:

- $Q_{P}$ é um conjunto não vazio de estados;

- $\Sigma_{P}$ é um alfabeto;

- $\pi_{P}: Q_{P} \rightarrow[0,1]$ é uma distribuição de probabilidades sobre $Q_{P}$;

- $M_{P}: Q_{P} \times Q_{P} \rightarrow[0,1]$ é uma matriz de probabilidades de transição; $e$

- $L_{P}: Q_{P} \times \Sigma_{P} \rightarrow[0,1]$ é uma matriz de probabilidades de emissão de símbolos para cada estado de $Q_{P}$.

Além disso, temos

$$
\sum_{i \in Q_{p}} \pi_{P}=1 \quad \text { e } \forall i \in Q_{P} \sum_{j \in Q_{P}} M_{P}(i, j)=1 \quad \text { e } \forall i \in Q_{P} \sum_{\sigma \in \Sigma_{p}} M_{P}(i, \sigma)=1
$$

Para qualquer cadeia $w=w_{1} \ldots w_{n} \in \Sigma_{P}^{*}$ a probabilidade de $w$ ser gerada por $P=$ $\left(Q_{P}, \Sigma_{P}, \pi_{P}, M_{P}\right)$ é calculada da seguinte forma:

$$
P\left(w_{1} \ldots w_{n}\right)=\sum_{\left\langle i_{0}, \ldots, i_{n}\right\rangle \in Q_{P}^{n+1}} \pi_{P}\left(i_{0}\right) \cdot \prod_{j=0}^{n-1} L_{P}\left(i_{j}, w_{j+1}\right) M_{P}\left(i_{j}, i_{j+1}\right)
$$

Portanto, para qualquer exemplo de tamanho $n, P$ define uma distribuição de probabilidade sobre $\Sigma_{P}^{n}$.

Teorema 2.3.2 Qualquer cadeia de Markov oculta pode ser simulada por um autômato finito estocástico com o mesmo número de estados.

Para qualquer cadeia de Markov oculta $P=\left(Q_{P}, \Sigma_{P}, \pi_{P}, M_{P}, L_{P}\right)$ construímos um autômato finito $A=\left(Q_{A}, \Sigma_{A}, \pi_{A}, M_{A}\right)$ da seguinte forma: 
- $Q_{A}=Q_{P}, \quad \Sigma_{A}=\Sigma_{P}, \quad \pi_{A}=\pi_{P}$ e

- $\forall i, j \in Q_{A}, \forall \sigma \in \Sigma_{A} \quad M_{A}(i, j, \sigma)=M_{P}(i, j) \cdot L_{P}(i, \sigma)$

Demonstraremos a seguir, que $P$ e $Q$ definem a mesma distribuição sobre $\Sigma_{P}^{n}$ para qualquer $n$.

$$
\begin{gathered}
A\left(w_{1} \ldots w_{n}\right)=\sum_{\left\langle i_{0}, \ldots, i_{n}\right\rangle \in Q_{A}^{n+1}} \pi_{A}\left(i_{0}\right) \cdot \prod_{j=0}^{n-1} M_{A}\left(i_{j}, i_{j+1}, w_{j+1}\right) \\
=\sum_{\left\langle i_{0}, \ldots, i_{n}\right\rangle \in Q_{P}^{n+1}} \pi_{P}\left(i_{0}\right) \cdot \prod_{j=0}^{n-1} L_{P}\left(i_{j}, w_{j+1}\right) M_{P}\left(i_{j}, i_{j+1}\right) \\
=P\left(w_{1} \ldots w_{n}\right)
\end{gathered}
$$

O problema de treinamento de HMM é definido como o problema de aproximar uma distribuição arbitrária e de origem desconhecida por distribuições geradas por HMMs [AW90]. Em vez de passar por um processo de aprendizado, o treinamento de HMM utiliza métodos que, dado um HMM e um conjunto de cadeias, estimam novamente as probabilidades das transições do HMM de tal forma a maximizar a probabilidade do modelo. Apesar do sucesso de HMM em problemas práticos, como o resultado da estimação depende da configuração inicial das probabilidades de transição do HMM, o algoritmo de treinamento garante a convergência somente para um máximo local. Abe e Warmuth [AW90] estudaram o problema de treinar HMMs e, a partir da suposição de que $R P \neq N P$, provaram que HMMs não podem ser treinados em tempo polinomial no tamanho do alfabeto.

Essa desvantagem do modelo HMM, somada ao fato de que o treinamento baseia-se em uma arquitetura do modelo pré-estabelecida, motiva o emprego de algoritmos que inferem a estrutura e estimam as probabilidades das transições de um autômato finito estocástico. 


$\overline{3}$

\section{Inferência Gramatical}

Apesar do campo de inferência gramatical tratar de problemas de uma área relativamente específica, este usa técnicas de vários domínios e intercepta diversas disciplinas. Pesquisadores de inferência gramatical vêm de diversas áreas da Ciência da Computação: Aprendizado Computacional, Lingüística, Teoria da Computação e Reconhecimento de Padrões. Do ponto de vista prático, inferência gramatical já foi aplicada, por exemplo, em problemas de reconhecimento de voz e linguagem natural, Biologia Computacional e Criptografia. Para maiores informações, tanto do ponto de vista teórico quanto de aplicações consulte os artigos apresentados nos cinco colóquios internacionais de inferência gramatical já realizados [CO94b, MH96, HS98, Oli00, AFvZ02].

Definiremos inferência gramatical como um processo de inferência indutiva que tem o objetivo de construir uma gramática que gera uma linguagem desconhecida a partir de uma amostra finita de cadeias desta linguagem [Sak95]. O processo de inferência pode receber também uma amostra negativa.

Entre as classes de gramáticas, estaremos interessados apenas em inferência de gramáticas regulares por alguns motivos. Em primeiro lugar, o mecanismo de reconhecimento cor- 
respondente à classe de linguagens regulares é o mais eficiente entre todos os mecanismos das outras classes de linguagens da hierarquia de Chomski [ASU86]. O fato dos autômatos finitos reconhecerem em tempo linear é interessante na medida em que pretendemos aplicar os classificadores em conjuntos de bioseqüências potencialmente grandes. Além disso, apesar da classe de linguagens regulares ser a mais limitada na hierarquia de Chomski, a extensa utilização de HMM em Biologia Molecular e a equivalência entre esse modelo e gramáticas regulares estocásticas [DEKM98] nos indica que gramáticas regulares têm potencial de modelar com sucesso uma série de problemas que foram abordados por HMMs.

Para o problema de inferência de linguagens regulares, precisamos definir a classe de hipóteses utilizada pelo algoritmo de inferência para que este possa indicar como sua conjectura consegue representar a linguagem alvo. Como toda linguagem gerada por uma gramática regular pode ser reconhecida por um autômato finito determinístico (AFD), há uma equivalência em inferência de gramáticas regulares e inferência de AFDs [DEKM98]. Dessa forma, nas seções seguintes, trataremos o problema de inferência gramatical utilizando a estrutura de autômatos finitos determinísticos.

O problema de inferência de AFDs pode ser dividido em aprendizado ativo de AFDs, no qual existem mecanismos para que o algoritmo interaja com o autômato alvo, e em aprendizado passivo de AFDs, no qual o algoritmo de aprendizado não tem controle sobre os dados que recebe. Para o nosso modelo de aprendizado, como vamos ter acesso a apenas amostras de seqüências, abordaremos apenas os resultados de aprendizado passivo de AFDs. Detalhes sobre aprendizado ativo de AFDs podem ser obtidos em [Pit89, Sak95].

De fato, estamos interessados no aprendizado de linguagens regulares estocásticas. Um AFD estocástico representa uma distribuição de probabilidades de seqüências de uma determinada linguagem $L$ e, com isso, através da comparação de probabilidades, consegue distinguir dentre duas seqüências quaisquer qual é a seqüência mais característica à linguagem $L$. Em problemas práticos, quando um classificador de apenas uma gramática inferida classifica um número de seqüências maior que o desejável, podemos limitar esse conjunto, selecionando apenas as seqüências que possuem probabilidade maior que um certo limiar. Essa formulação de AFDs estocásticos com limiar permite controlar o nível de generalização da hipótese inferida pelo algoritmo de inferência, o que não seria possível num modelo não estocástico. 
Esse problema pode ser dividido em duas partes: inferência da estrutura da gramática e estimação das probabilidades das regras de transição. Como os métodos dos algoritmos de inferência de gramáticas estocásticas baseiam-se nos métodos de inferência de gramáticas não estocásticas, descreveremos os principais resultados teóricos e métodos de inferência de autômatos determinísticos na Seção 3.1 para depois explicar a inferência de autômatos finitos determinísticos estocásticos na Seção 3.2.

\subsection{Inferência de Autômatos Finitos Determinísticos}

Nessa seção, para o problema de inferência de linguagens regulares, o espaço de conceitos é a classe de autômatos finitos determinísticos e o espaço de hipóteses é igual ao espaço de conceitos. O problema de inferência pode ser caracterizado como inferência exata ou aproximada. Na inferência exata o critério de sucesso de um algoritmo é identificar exatamente a linguagem gerada por algum AFD alvo. Na inferência aproximada, o critério de sucesso é menos rigoroso, uma hipótese inferida que represente uma aproximação da linguagem gerada pelo AFD alvo é suficiente. Inicialmente, explicaremos o modelo de identificação no limite, um caso de inferência exata, e em seguida abordaremos identificação PAC, um caso de inferência aproximada.

\section{Identificação no limite}

O modelo de identificação no limite foi proposto por Gold [Gol67] em seu estudo teórico de inferência de linguagens formais. Antes de definir identificação no limite é necessário explicar os conceitos de apresentação completa e apresentação positiva. Uma apresentação completa de uma linguagem reconhecida por um AFD alvo $M$ dado é definida como uma seqüência infinita de exemplos tal que para cada cadeia $w \in L(M)$, o exemplo $(w, 1)$ aparece pelo menos uma vez na seqüência, para cada $w \in \Sigma^{*}-L(M)$, o exemplo $(w, 0)$ aparece pelo menos uma vez na seqüência, e não existe erro na classificação dos exemplos. Consideraremos também uma apresentação de apenas exemplos positivos do AFD $M$. Uma apresentação positiva de $M$ é igual a uma apresentação completa de $M$, exceto que a seqüência contém todas e apenas as cadeias que fazem parte da linguagem $L(M)$.

Identificação no limite considera o aprendizado como um processo infinito, fornecendo um modelo em que uma apresentação completa (positiva) do AFD alvo $M$ é 
apresentada para o algoritmo de inferência $A$. A cada novo exemplo uma hipótese é inferida. Se o algoritmo $A$ apresentar uma mesma hipótese após um número finito de passos e essa hipótese for equivalente a $M$, então dizemos que $A$ identifica no limite $M$ a partir de apresentação completa (positiva).

Gold iniciou o estudo de inferência gramatical [Gol67] mostrando que existe uma diferença fundamental no que pode ser aprendido a partir de apresentação completa versus apresentação positiva. AFDs podem ser identificados no limite a partir de apresentação completa. Em contrapartida, nenhuma classe de linguagem que contém todas linguagens finitas e pelo menos uma linguagem infinita é identificada no limite a partir de apresentação positiva. Como corolário a classe de AFDs não é identificada no limite a partir de apresentação positiva. O problema é que nenhum exemplo positivo pode refutar uma hipótese tão geral. Ambos os resultados são baseados no critério de identificação no limite, o qual não leva em conta o custo computacional para encontrar uma solução. No caso de apresentação completa, a solução baseia-se na técnica de identificação por enumeração, o que é insatisfatório para o ponto de vista de eficiência computacional. Angluin provou que a classe de AFDs não é identificável no limite em tempo polinomial [Ang92].

Os resultados teóricos citados acima ajudam a compreender a dificuldade do problema de inferência de gramáticas regulares, porém, na prática dificilmente encontraremos problemas para aprender uma linguagem infinita ou amostras de treinamentos com infinitas seqüências. Como a intenção desse trabalho está voltada para a prática, no contexto de aprendizado computacional, modelaremos o espaço de exemplos $X$ como um subconjunto de $\Sigma^{n}$ em vez de $\Sigma^{*}$. O modelo de aprendizado PAC nos oferece uma abordagem mais interessante para problemas práticos.

\section{Identificação PAC}

Nesse modelo consideraremos um critério menos rigoroso para inferência bem sucedida. O objetivo dos algoritmos de inferência PAC é produzir, com alta probabilidade, um AFD que classifica cadeias aproximadamente igual ao AFD alvo. Suponha agora que existe uma distribuição arbitrária e desconhecida $D$ de cadeias pertencentes a $\Sigma^{*}$. Um algoritmo de inferência PAC $A$ pode sortear independentemente cadeias de acordo com a distribuição $D$, e para cada cadeia $w$ sorteada, $A$ sabe se $w \in L(M)$ ou não, sendo $M$ o $\mathrm{AFD}$ alvo. O critério de qualidade $\mathrm{PAC}$ assegura que $A$ produz, com alta probabilidade, um AFD que classifica com erro baixo uma 
amostra escolhida aleatoriamente de acordo com a distribuição $D$. Mesmo com um critério menos rigoroso, Kearns e Valiant [KV89] demonstraram que aprendizado de AFDs no modelo PAC é tão difícil quanto quebrar protocolos criptográficos baseados em suposições mais fortes que a suposição $P \neq N P$.

\subsubsection{Espaço de busca de inferência regular}

O espaço de busca de inferência de gramáticas regulares pode ser caracterizado por um reticulado completo construído a partir de uma amostra positiva. Na literatura de inferência gramatical, essa caracterização também é conhecida como método de junção de estados. Veremos algumas definições formais que ajudam a modelar essa teoria. Uma descrição mais detalhada da teoria do espaço de busca pode ser encontrada em [PD94].

\section{Reticulados}

Nesta seção, recordaremos alguns conceitos e definições da Teoria dos Reticulados [PY73, Sza84] que serão utilizados ao longo do capítulo.

Definição. 3.1.1 Considere um conjunto $\mathcal{L}$. Uma relação binária $\preceq$ em $\mathcal{L}$ é chamada de uma relação de ordem parcial se as seguintes restrições valem:

- Reflexiva: $\forall X \in \mathcal{L}, X \preceq X$.

- Anti-simétrica: $\forall X, Y \in \mathcal{L}$, se $X \preceq Y$ e $Y \preceq X$ então $X=Y$.

- Transitiva: $\forall X, Y, Z \in \mathcal{L}$, se $X \preceq Y$ e $Y \preceq Z$ então $X \preceq Z$.

Definição. 3.1.2 Um conjunto $\mathcal{L}$ munido com uma relação de ordem parcial $\preceq$ é um conjunto parcialmente ordenado e ele é denotado por $(\mathcal{L}, \preceq)$, ou simplesmente por $\mathcal{L}$ quando a relação de ordem está claramente definida pelo contexto.

Definição. 3.1.3 Seja $(\mathcal{L}, \preceq)$ um conjunto parcialmente ordenado. Dados $A, B \in \mathcal{L} e$ $\mathcal{X} \subset \mathcal{L}$, dizemos que $B$ é um limitante superior de $\mathcal{X}$, se para todo $X \in \mathcal{X}$ temos $X \preceq B$ e que $A$ é um limitante inferior de $\mathcal{X}$, se para todo $X \in \mathcal{X}$ temos $A \preceq X$. 
Definição. 3.1.4 Sejam $(\mathcal{L}, \preceq)$ um conjunto parcialmente ordenado e $\mathcal{X} \subset \mathcal{L}$. Se $\mathcal{X}$ tem $u m$ limitante superior $B \in \mathcal{L}$, o menor elemento do conjunto de limitantes superiores de $\mathcal{X}$, se existe, é denominado de supremo de $\mathcal{X}$ em $\mathcal{L}$ e é denotado por $\vee \mathcal{X}$. Similarmente, se $\mathcal{X}$ tem um limitante inferior $A \in \mathcal{L}$, o maior elemento do conjunto dos limitantes inferiores de $\mathcal{X}$, se existe, é denominado de ínfimo de $\mathcal{X}$ em $\mathcal{L}$ e é denotado por $\wedge \mathcal{X}$.

Definição. 3.1.5 Um conjunto parcialmente ordenado $\mathcal{L}$ é um reticulado se, e somente se, qualquer conjunto de dois elementos possui um infimo e um supremo em $\mathcal{L}$.

Dois elementos do reticulado completo $\mathcal{L}$ são importantes: o maior elemento $I$ e o menor elemento $O$, definidos por $O \preceq X \preceq I$ para todo $X \in \mathcal{L}$. Eles são denominados de elementos universais.

Definição. 3.1.6 Um reticulado $\mathcal{L}$ é:

- completo se, e somente se, qualquer subconjunto de $\mathcal{L}$ possui um ínfimo e um supremo. Qualquer reticulado finito é um reticulado completo.

- distributivo se, e somente se, $X \wedge(Y \vee Z)=(X \wedge Y) \vee(X \wedge Z), \quad \forall X, Y, Z \in \mathcal{L}$.

- complementado se, e somente se, todos os seus elementos possuem complemento. $O$ complemento de um elemento $X$ em um reticulado $\mathcal{L}$ com $O$ e $I$ é um elemento $Y \in \mathcal{L}$ tal que $X \wedge Y=O$ e $X \vee Y=I$, e é denotado por $X^{c}$.

- Booleano se, e somente se, ele é distributivo e complementado.

\section{Derivação de autômatos}

Informalmente, um autômato é derivado de um dado autômato $A$, quando ele é consequência da junção de pelo menos dois estados de $A$. Veremos mais adiante que quanto maior for o número de junções de estados em um autômato, mais geral deve ser a linguagem reconhecida por ele. O processo de junção de estados, que será explicado formalmente a seguir, tem um papel importante no processo de inferência de autômatos, porque é uma maneira de controlar o grau de generalização de uma hipótese. Segue abaixo 
uma explicação formal de como juntar estados de um autômato para obter um autômato derivado.

Para qualquer conjunto $S$, uma partição $\pi$ é um conjunto de subconjuntos disjuntos não vazios de $S$ cuja união é $S$. Seja $s$ um elemento de $S$ e seja $B(s, \pi)$ o único elemento, ou bloco, de $\pi$ que contém $s$. Dizemos que $\pi_{i}$ refina $\pi_{j}$ se, e somente se, cada bloco de $\pi_{j}$ é uma união de um ou vários blocos de $\pi_{i}$.

Se $A=\left(Q, \Sigma, \delta, q_{0}, F\right)$ é um autômato, o autômato $A / \pi=\left(Q^{\prime}, \Sigma, \delta^{\prime}, B\left(q_{0}, \pi\right), F^{\prime}\right)$ derivado de $A$ em relação à partição $\pi$ de $Q$ é definido da seguinte forma:

- $Q^{\prime}=Q / \pi=\{B(q, \pi) \mid q \in Q\}$

- $F^{\prime}=\left\{B \in Q^{\prime} \mid B \cap F \neq \emptyset\right\} ; \mathrm{e}$

- $\delta^{\prime}: Q^{\prime} \times \Sigma \rightarrow 2^{Q^{\prime}}: \forall B, B^{\prime} \in Q^{\prime}, \forall a \in \Sigma, B^{\prime} \in \delta^{\prime}(B, a) \Longleftrightarrow \exists q, q^{\prime} \in Q, q \in B$, $q^{\prime} \in B^{\prime}$ e $q^{\prime} \in \delta(q, a)$.

Dizemos que os estados de $Q$ pertencentes ao mesmo bloco $B$ da partição $\pi$ são juntados e que o processo de junção de estados é a derivação do autômato $A$ resultando no $A / \pi$.

\section{Amostras de linguagens e autômatos correspondentes}

Definição. 3.1.7 Uma amostra positiva $I_{+}$é estruturalmente completa em relação a um autômato $A$ que reconhece $L$, se existe um reconhecimento $R C\left(I_{+}, A\right)$ de $I_{+}$tal que:

- Toda transição de A é exercitada.

- Todo elemento de F é usado como estado de reconhecimento.

Seja $I_{+}=\left\{u_{1}, \ldots, u_{m}\right\}$ uma amostra positiva, sendo que $u_{i}=a_{i, 1} \ldots a_{i,\left|u_{i}\right|}, 1 \leq i \leq$ $M=\left|I_{+}\right|$.

Definição. 3.1.8 $O$ autômato canônico maximal em relação a $I_{+}$denotado por $A C M\left(I_{+}\right)=\left(Q, \Sigma, \delta, q_{0}, F\right)$ é construído da seguinte forma: 
- $\Sigma$ é o alfabeto no qual $I_{+}$está definido;

- $Q=\left\{v_{i, j}|1 \leq i \leq M, 1 \leq j \leq| u_{i} \mid, v_{i, j}=a_{i, 1} \ldots a_{i, j}\right\} \cup\{\lambda\}, q_{0}=\lambda$;

- $F=I_{+}$;

- $\delta(\lambda, a)=\left\{v \mid v=a_{i, 1}, a=a_{i, 1}, 1 \leq i \leq M\right\} ; e$

- $\delta\left(v_{i, j}, a\right)=\left\{v_{i, j+1} \mid v_{i, j+1}=v_{i, j} a_{i, j+1} e a=a_{i, j+1}\right\}, 1 \leq i \leq M, 1 \leq j \leq\left|u_{i}\right|-1$.

Conseqüentemente, a linguagem que o $\operatorname{ACM}\left(I_{+}\right)$reconhece é exatamente igual a $I_{+}$ e $A C M\left(I_{+}\right)$é o autômato que tem o maior número de estados úteis para o qual $I_{+}$é estruturalmente completa. Note que o $A C M\left(I_{+}\right)$pode ser não-determinístico.

Definição. 3.1.9 O autômato da árvore de prefixos de $I_{+}$denotado por $A A P\left(I_{+}\right)$ é o $\operatorname{ACM}\left(I_{+}\right) / \pi_{I_{+}}$em que a partição $\pi_{I_{+}}$é definida como:

$$
B\left(q, \pi_{I_{+}}\right)=B\left(q^{\prime}, \pi_{I_{+}}\right) \text {se, e somente se, } \operatorname{Pr}(q)=\operatorname{Pr}\left(q^{\prime}\right)
$$

Note que o $A A P\left(I_{+}\right)$e o $A C M\left(I_{+}\right)$reconhecem a mesma linguagem, entretanto, o $A A P\left(I_{+}\right)$é um autômato determinístico.

Definição. 3.1.10 O autômato que reconhece todas cadeias sobre um alfabeto $\Sigma$ e é o menor autômato para o qual cada amostra de $\Sigma^{*}$ é estruturalmente completa é denominado de autômato universal e denotado por $U A$.

\section{Reticulado de Autômatos}

Seja $P(A)$ o conjunto de partições do conjunto de estados de um autômato $A$. O número de blocos da partição $\pi_{i}$ é denotado por $r\left(\pi_{i}\right)$ ou simplesmente $r_{i}$. Sejam $\pi_{1}=$ $\left\{B_{11}, \ldots, B_{r_{i}}\right\}$ e $\pi_{2}$ duas partições de $P(A)$. Dizemos que $\pi_{2}$ deriva diretamente de $\pi_{1}$ se a partição $\pi_{2}$ for construída a partir de $\pi_{1}$ da seguinte forma:

$$
\pi_{2}=\left\{B_{1 j} \cup B_{1 k}\right\} \cup\left(\pi_{1} \backslash\left\{B_{1 j}, B_{1 k}\right\}\right) \quad \text { para quaisquer } j, k \text { entre } 1 \text { e } r_{1}, j \neq k \text {. }
$$


Esta operação de derivação define uma relação de ordem parcial $\preceq \operatorname{em} P(A)$, no sentido em que $\pi_{i} \preceq \pi_{j}$ se, e somente se, $\pi_{i}$ refina $\pi_{j}$. Para as partições $\pi_{1}$ e $\pi_{2}$ temos $\pi_{1} \preceq \pi_{2}$. Estendendo a notação para autômatos, dizemos que $A / \pi_{i}$ refina $A / \pi_{j}$ e que $A / \pi_{j}$ deriva de $A / \pi_{i}$. Por construção, temos que:

$$
A / \pi_{i} \preceq A / \pi_{j} \quad \text { se } \quad L\left(A / \pi_{i}\right) \subseteq L\left(A / \pi_{j}\right)
$$

O conjunto de autômatos derivados do autômato $A$, parcialmente ordenados pela relação $\preceq$, é um reticulado Booleano, denotado por $\operatorname{Ret}(A)$, em que:

- o autômato universal $A U$ é o maior elemento;

- o autômato $A$ é o menor elemento.

Definição. 3.1.11 A profundidade de um autômato $A / \pi$ no reticulado $\operatorname{Ret}(A)$ é dada por $N-r(\pi)$, sendo que $N$ é o número de estados de $A$.

Conseqüentemente, as profundidades dos autômatos $A$ e $A U$ no $\operatorname{Ret}(A)$ são iguais a 0 e $N-1$, respectivamente.

Considere um problema de inferência regular no qual queremos inferir um autômato desconhecido $A$ e possuímos somente uma amostra positiva $I_{+}$gerada por $A$. Ao construir o $A A P\left(I_{+}\right)$a partir de $I_{+}$temos um autômato que reconhece exatamente $I_{+}$. Como não temos garantia de que a linguagem representada por $I_{+}$é igual a $L(A)$, queremos de alguma forma generalizar o $A A P\left(I_{+}\right)$. O reticulado formado por todas as possíveis derivações do $A A P\left(I_{+}\right)$fornece uma representação interessante para controlar o grau de generalização de possíveis hipóteses, porque uma sequiência sucessiva de derivações do $A A P\left(I_{+}\right)$resulta numa seqüência de autômatos que reconhecem linguagens cada vez mais gerais. O teorema a seguir enuncia uma condição que garante a presença do autômato desconhecido neste reticulado.

Teorema 3.1.1 Seja $I_{+}$uma amostra positiva de uma linguagem regular qualquer $L e$ seja $A(L)$ o autômato canônico que reconhece $L$. Se a amostra $I_{+}$for estruturalmente completa em relação a $A(L)$ então $A(L)$ pertence ao $\operatorname{Ret}\left(A A P\left(I_{+}\right)\right)$. 
Conseqüentemente, supondo a presença de uma amostra positiva estruturalmente completa, o problema de inferência de gramáticas regulares pode ser visto como uma busca em um reticulado completo para o qual o autômato de árvore de prefixos construído a partir da amostra positiva é o menor elemento.

\section{Direcionando a busca pelo autômato desconhecido}

Muitos dos algoritmos de inferência regular utilizam esta caracterização do espaço de busca para orientarem-se no processo de inferência [CO94a, CO99, Dup96, Lan99, Ron95]. Destes, os que requerem apenas amostra positiva de treinamento, utilizam algum método heurístico para apresentar um autômato do reticulado como solução. Tais algoritmos procuram generalizar de alguma forma a informação contida na amostra positiva. Dada uma amostra positiva $I_{+}$gerada por um autômato desconhecido $A$, ao construir o $A A P\left(I_{+}\right)$, cada algoritmo utiliza sua heurística para escolher quais estados serão juntados e, assim, após sucessivas derivações do $A A P\left(I_{+}\right)$, apresentar sua hipótese $H$. Diremos neste caso que o algoritmo percorre um caminho no reticulado, com extremos $A A P\left(I_{+}\right)$e $H$. Veremos este processo em mais detalhes na Seção 3.3.

Suponha agora que uma amostra negativa $I_{-}$da linguagem desconhecida está disponível. O problema de inferência pode ser formulado como a identificação de um autômato $H$ que reconhece todas as cadeias de $I_{+}$e nenhuma cadeia de $I_{-}$. Um autômato com esta característica é denominado de autômato compatível às amostras positiva e negativa. Entretanto, diversos autômatos podem ser compatíveis com ambas as amostras, inclusive o $A C M\left(I_{+}\right)$. Como desejamos generalizar de alguma forma a informação contida em $I_{+}$, estamos interessados no autômato compatível com as amostras positiva e negativa que contém o menor número de estados. Em outras palavras, entre todos os autômatos compatíveis, queremos aquele que generalize o máximo possível. Chamaremos este problema, que Gold já demonstrou ser NP-completo [Gol78], de problema de consistência do AFD minimal. Tal problema está relacionado com a caracterização do espaço de busca através do conceito de conjunto de fronteira, que definiremos a seguir.

Definição. 3.1.12 Uma anticadeia $\overline{a . s}$ num reticulado de autômatos é um conjunto de autômatos tal que nenhum elemento de $\overline{a s}$ tem uma relaçăo de ordem parcial $\preceq$ com outro elemento de $\overline{a s}$. 
Definição. 3.1.13 Um autômato $A$ está na profundidade máxima de um reticulado de autômatos em relação a uma amostra negativa $I_{-}$, se não existe um autômato $A^{\prime}$ que possa ser derivado de $A$ tal que $L\left(A^{\prime}\right) \cap I_{-}=\emptyset$.

Definição. 3.1.14 $O$ conjunto de fronteira $C F_{\text {AAP }}\left(I_{+}, I_{-}\right)$é a anticadeia do $\operatorname{Ret}\left(A A P\left(I_{+}\right)\right)$na qual cada elemento está na máxima altura.

Dessa forma o conjunto de fronteira de um reticulado é o conjunto de autômatos que corresponde ao limite de generalização controlado pela amostra negativa. O problema de consistência do AFD minimal pode ser caracterizado como o processo de inferir o menor $A F D$ do conjunto de fronteira. Na seção 3.3.1 descreveremos o algoritmo RPNI, que resolve o problema de consistência do AFD minimal.

\subsection{Inferência de Autômatos Finitos Determinísticos Es- tocásticos}

Uma linguagem estocástica é uma linguagem com uma distribuição de probabilidade nos seus elementos [AS83]. Estaremos interessados agora em aprender distribuições geradas por AFDs estocásticos. Suponha que existe um AFD estocástico $M$ desconhecido que gera exemplos de acordo com sua distribuição $D$. Inferência de linguagens regulares estocásticas tem o objetivo de inferir uma hipótese que represente uma aproximação da distribuição $D$. Em nossa modelagem, consideraremos como espaço de hipóteses a classe de AFDs estocásticos.

Descreveremos a seguir um modelo de aprendizado formulado por D. Ron et al. [MKS94] que é relacionado ao modelo de aprendizado PAC descrito na seção 2.1.2. A diferença significativa entre os dois modelos está na definição de erro da hipótese. Como nesse novo modelo o objetivo é aprender distribuições, a definição de erro da hipótese deve basear-se numa métrica de distância entre distribuições. Das diversas medidas de distância possíveis, como por exemplo as distâncias quadrática e de variação, os autores do modelo escolheram a divergência de Kullback-Leibler que é definida da seguinte forma: 


$$
D_{K L}\left[P_{M}^{N}\right]\left[P_{M^{\prime}}^{N}\right] \stackrel{\text { def }}{=} \sum_{r \in \Sigma^{N}} P_{M}^{N}(r) \log \frac{P_{M}^{N}(r)}{P_{M^{\prime}}^{N}(r)}
$$

sendo que $P_{M}^{N}$ e $P_{M^{\prime}}^{N}$ são distribuições de cadeias de tamanho $N$ que os AFD estocásticos $M$ e $M^{\prime}$ geram, respectivamente.

De forma parecida ao modelo PAC, dizemos que a hipótese $\widehat{M}$ é uma hipótese $\epsilon$-boa em relação ao AFD estocástico alvo $M$, que pode gerar cadeias de tamanho infinito, se para todo $N>0$

$$
\frac{1}{N} D_{K L}\left[P_{M}^{N}\right]\left[P_{\bar{M}}^{N}\right] \leq \epsilon
$$

Note que a divergência de Kullback-Leibler entre distribuições, geradas por cadeias de Markov de ordem finita é proporcional ao tamanho das cadeias sobre as quais a distância é computada. Portanto, para obter uma medida independente do tamanho das cadeias é necessário dividir a divergência de Kullback-Leibler pelo tamanho $N$ das cadeias.

O modelo exige que, para todo $\delta>0$ e $\epsilon>0$ dados, o algoritmo de aprendizado infere, com probabilidade pelo menos $1-\delta$, uma hipótese $\epsilon$-boa $\widehat{M}$ em relação ao AFD alvo $M$.

Infelizmente, Kearns et al. [MKS94] mostraram que existe grandes evidências que o problema de aprendizado de AFDs estocásticos é difícil. Baseado nesse resultado, D. Ron, em sua tese de doutorado, estudou subclasses de AFDs estocásticos, motivada por aplicações práticas na modelagem de sequiêncais naturais como linguagens naturais e escritas à mão. O resultado desse estudo foi a elaboração de dois algoritmos de inferência de subclasses de AFD estocásticos, apresentados na Seção 3.3.

\subsection{Algoritmos de inferência regular}

Conforme dito anteriormente, estamos interessados em algoritmos de inferência de gramáticas regulares estocásticas. Entretanto, não são todos os algoritmos que inferem gramáticas com probabilidades em suas produções. Para os algoritmos que inferem gramáticas não estocásticas, será necessário utilizar um algoritmo de estimação de probabilidades em seguida. Este algoritmo apenas associa probabilidades às produções de uma 
gramática fornecida como parâmetro. Estas probabilidades são estimadas com base na amostra positiva de treinamento.

Na literatura de inferência gramatical encontramos os seguintes algoritmos de inferência de gramáticas regulares: Alergia [CO94a], Rlips [CO99], RPNI [Dup96], GIG [Dup94], Exbar [Lan99], Ed-beam [Lan99], LAPFA [Ron95] e Amnesia [Ron95].

Devido ao tempo limitado para a realização desse trabalho decidimos implementar quatro desses algoritmos. Para limitar o escopo de pesquisa dos algoritmos a serem implementados descartamos algoritmos que utilizam a abordagem de oráculos pelo fato de desconhecermos em Biologia Molecular uma fonte de informações que desempenhe esse papel. Os algoritmos Alergia, RPNI, LAPFA e Amnesia foram escolhidos para serem implementados por apresentarem resultados teóricos ou práticos importantes. Descrevemos a seguir as principais características de cada algoritmo implementado que acaba por justificar o motivo da escolha de cada um.

\subsubsection{RPNI}

O algoritmo RPNI (do inglês "Regular Positive and Negative Inference") proposto por Oncina e García [OG92] e, independentemente, por Lang [Lan92] é baseado no algoritmo de Trakhtenbrot e Barzdin [TB73], um dos primeiros algoritmos de inferência gramatical. Nossa implementação e os comentários sobre o algoritmo descritos abaixo foram baseados no pseudo-código apresentado no artigo de Dupont [Dup96].

O algoritmo RPNI é o único dos algoritmos implementados que infere um autômato sem probabilidades nas transições. Apesar dessa característica indesejada, o RPNI possui resultados interessantes tanto do ponto de vista teórico quanto prático. Estes resultados positivos, que apresentaremos a seguir, somados ao fato do RPNI ser um dos poucos algoritmos que utilizam amostras positiva e negativa são características determinantes para sua escolha. Para que este pudesse ser integrado ao arcabouço do sistema, ele teve que ser adaptado para produzir um autômato estocástico.

O algoritmo RPNI requer uma amostra de treinamento positiva $I_{+}$e uma negativa $I_{-}$. Como foi explicado na seção 3.1.1, qualquer autômato derivado do $A A P\left(I_{+}\right)$reconhece uma linguagem que inclui $I_{+}$. Nesse sentido, qualquer autômato pertencente ao $\operatorname{Ret}\left(A A P\left(I_{+}\right)\right)$constitui uma possível generalização do $A A P\left(I_{+}\right)$. O algoritmo $R P N I$ 
tem como objetivo encontrar um autômato do $\operatorname{Ret}\left(A A P\left(I_{+}\right)\right)$que generaliza o máximo possível a amostra positiva de treinamento e ao mesmo tempo seja consistente com a amostra negativa.

Esse algoritmo, na teoria, possui uma característica importante. Se a amostra de treinamento for suficientemente "representativa", o RPNI identifica no limite qualquer linguagem regular em tempo polinomial. Além disso, nesse caso particular, o autômato inferido é a solução do problema de consistência do AFD minimal. Segundo Dupont, mesmo que a amostra não seja característica, este algoritmo oferece uma boa generalização da amostra de treinamento [Dup96]. Isso é validado experimentalmente em [Dup96].

Veremos a seguir como o algoritmo RPNI garante obter a solução para o problema de consistência do AFD minimal. Para isso, introduziremos uma variação do modelo de identificação no limite e a noção de amostra característica, a qual garante ao RPNI a identificação correta da linguagem desconhecida.

\section{Identificação no limite e amostra característica}

Na seção 3.1 vimos o paradigma de identificação no limite a partir de apresentação completa, um modelo de aprendizado baseado numa amostra de treinamento com infinitos exemplos. Gold formulou também um paradigma de identificação para amostras de treinamento fixas, chamado de identificação no limite a partir de amostra dada [Gol78]. Neste modelo, o conjunto de dados $D$ consiste de uma amostra positiva $I_{+}$e uma negativa $I_{-}$e é denotado por $D=\left(I_{+}, I_{-}\right)$. Segue a definição de Gold [Gol78]:

Definição. 3.3.1 Um método de inferência $M$ identifica uma linguagem $L$ a partir de amostra dada se existe uma amostra $D^{c}=\left(I_{+}^{c}, I_{-}^{c}\right)$ tal que para qualquer conjunto $D=\left(I_{+}, I_{-}\right)$, com $I_{+} \supseteq I_{+}^{c}$ e $I_{-} \supseteq I_{-}^{c}$, a hipótese $H(D)$ proposta pelo método $M$ é correta, isto é $L(H(D))=L$. A amostra $D^{c}$ é denominada característica para a linguagem $L$ e o método $M$.

Apesar de caracterizarem a amostra de treinamento de maneira diferente, os dois modelos de identificação no limite são equivalentes [Dup96]. Note que a definição acima não estabelece um critério de como especificar uma amostra característica, ela apenas fornece uma caracterização geral do método de inferência. Dada uma linguagem regular 
$L$, representada pelo autômato canônico $A(L)$, veremos como especificar uma amostra característica para a linguagem $L$ e o algoritmo RPNI. Para isto, introduziremos os conceitos de prefixos curtos e núcleo da linguagem definidos por Oncina e Garcia [OG92].

Definição. 3.3.2 O conjunto de prefixos curtos $P c(L)$ de uma linguagem $L$ é definido como

$$
\operatorname{Pc}(L)=\left\{x \in \operatorname{Pr}(L) \mid \nexists u \in \Sigma^{*} \operatorname{com} L / u=L / x \text { e } u<x\right\}
$$

sendo que o símbolo " $<$ " representa a ordem padrão, na qual uma cadeia u é menor que uma cadeia $x$ se, e somente se, $|u|<|x|$ ou $|u|=|x|$ e u é anterior a $x$ na ordem alfabética.

Pela definição de autômato canônico, sabemos que o número de estados do $A(L)$ para uma linguagem $L$ é igual ao número de caudas $L / x$ de cadeias $x$ que pertencem ao conjunto de prefixos de $L$. O conjunto de prefixos curtos é uma maneira de representar esse conjunto de caudas, no qual cada elemento indica um estado. Portanto, existem tantos prefixos curtos quanto estados no $A(L)$.

Definição. 3.3.3 $O$ núcleo $N(L)$ da linguagem $L$ é definido como

$$
N(L)=\{\lambda\} \cup\{x a \mid x \in S p(L), a \in \Sigma, x a \in \operatorname{Pr}(L)\}
$$

O núcleo é constituído da cadeia vazia e dos prefixos da linguagem correspondentes aos prefixos curtos estendidos de um símbolo. Os elementos do núcleo representam as transições de $A(L)$ porque eles são construídos a partir da concatenação dos prefixos curtos, que representam os estados, com símbolos. Não obstante, os elementos do núcleo que também pertencem à linguagem representam os estados finais do $A(L)$.

Definição. 3.3.4 Uma amostra $D^{c}=\left(I_{+}^{c}, I_{-}^{c}\right)$ é característica para a linguagem $L e$ para o algoritmo RPNI se satisfaz as seguintes condições:

1. $\forall x \in N(L)$, se $x \in L$ então $x \in I_{+}^{c}$ senão $\exists u \in \Sigma^{*}$ tal que $x u \in I_{+}^{c}$

2. $\forall x \in P c(L), \forall y \in N(L)$ se $L / x \neq L / y$ então $\exists u \in \Sigma^{*}$ tal que $\left(x u \in I_{+}^{c}\right.$ e $\left.y u \in I_{-}^{c}\right)$ ou $\left(x u \in I_{-}^{c}\right.$ e $\left.y u \in I_{+}^{c}\right)$. 
A condição 1 garante que cada elemento do núcleo que também pertence à linguagem está em $I_{+}^{c}$ e que cada elemento pertencente ao núcleo e não pertencente à linguagem é prefixo de uma cadeia em $I_{+}^{c}$. Como as transições de $A(L)$ são representadas pelos elementos do $N(L)$, a condição 1 implica que as cadeias de $I_{+}^{c}$ exercitam todas as transições de $A(L)$. Além disso, como os elementos da intersecção do núcleo e da linguagem pertencem a $I_{+}^{c}$, todo estado final de $A(L)$ é usado como estado de reconhecimento. Dessa forma, a condição 1 garante que uma amostra característica é estruturalmente completa e, conseqüentemente, o $A(L)$ pertence ao $\operatorname{Ret}\left(A A P\left(I_{+}^{c}\right)\right)$ pelo teorema 3.1.1.

A condição 2 garante que a presença de certas cadeias em $D^{c}$ evita a junção de estados no $A A P\left(I_{+}^{c}\right)$ que não correspondem ao mesmo estado no $A(L)$. Quando um elemento $x$ do conjunto de prefixos curtos e um elemento $y$ do núcleo não tem o mesmo conjunto de caudas, eles necessariamente correspondem a estados distintos no autômato canônico. Neste caso, a junção de um estado correspondente a $x$ com um outro estado correspondente a $y$ no $A A P\left(I_{+}^{c}\right)$ é incompatível devido à presença de $x u$ em $I_{+}^{c}$ e $y u$ em $I_{-}^{c}$ ou vice-versa. Como vários sufixos $u$ podem satisfazer as condições 1 e 2 , várias amostras características podem existir para uma mesma linguagem.

Dupont demonstrou os seguintes teoremas [Dup96]:

Teorema 3.3.1 O algoritmo RPNI identifica no limite a classe de linguagens regulares.

Teorema 3.3.2 Quando a amostra de treinamento contém uma amostra característica para a linguagem $L$, o autômato canônico $A(L)$ é o $A F D$ que possui o menor número de estados pertencente ao $C F_{A A P}\left(I_{+}, I_{-}\right)$. Conseqüentemente, $A(L)$ é a solução para o problema de consistência do AFD minimal.

Enquanto o teorema 3.3.1 garante a existência de um AFD notável no conjunto de fronteira se a amostra de treinamento é característica, o teorema 3.3.1 garante que este AFD pode ser inferido pelo RPNI. A complexidade polinomial do RPNI e o teorema 2 não contradizem o fato do problema de consistência do AFD minimal ser NP-dificil. Isto porque este resultado é para o caso geral e o RPNI garante a identificação somente quando recebe uma amostra de treinamento que contém uma amostra característica. 


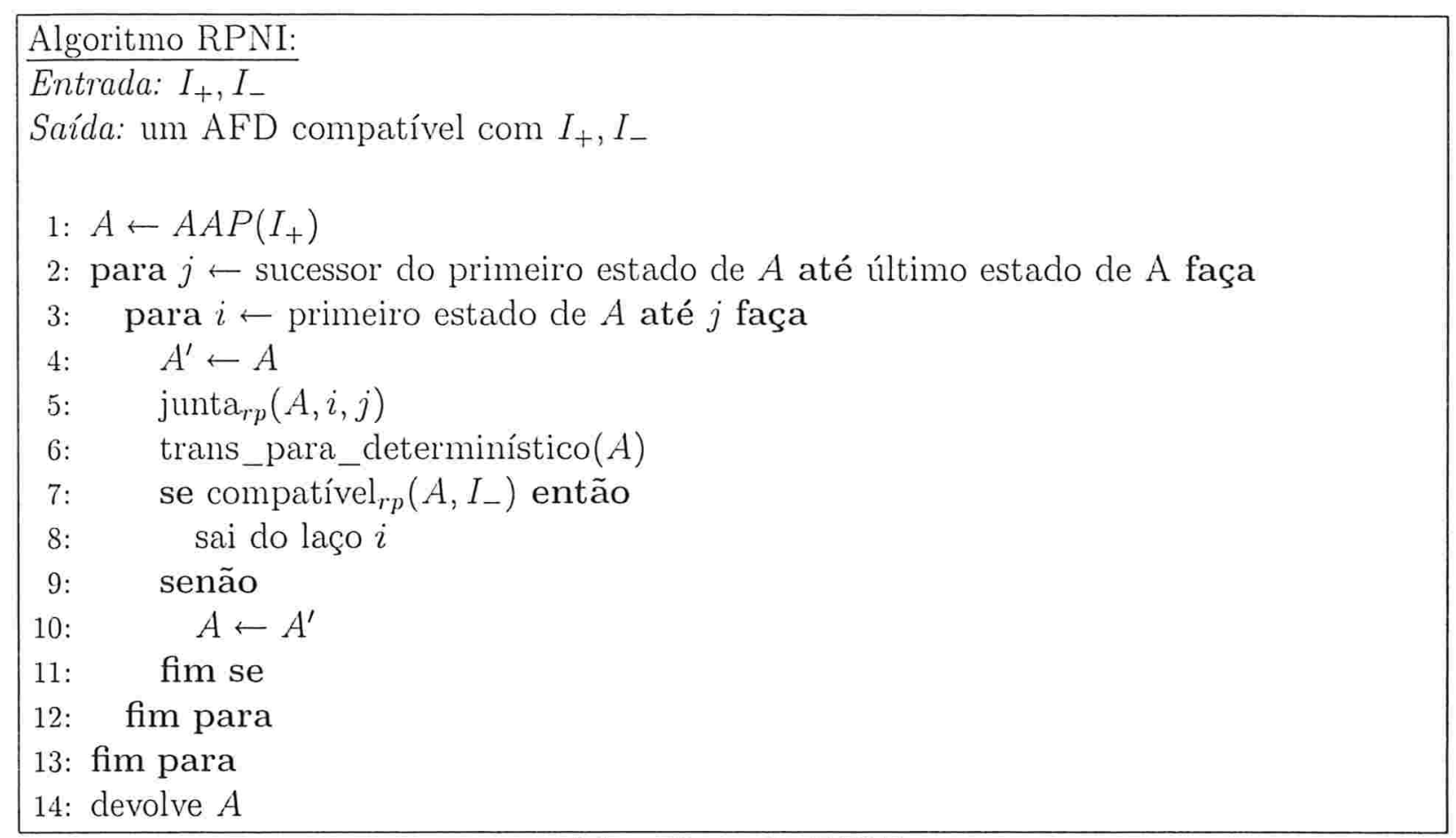

Algoritmo 1: RPNI

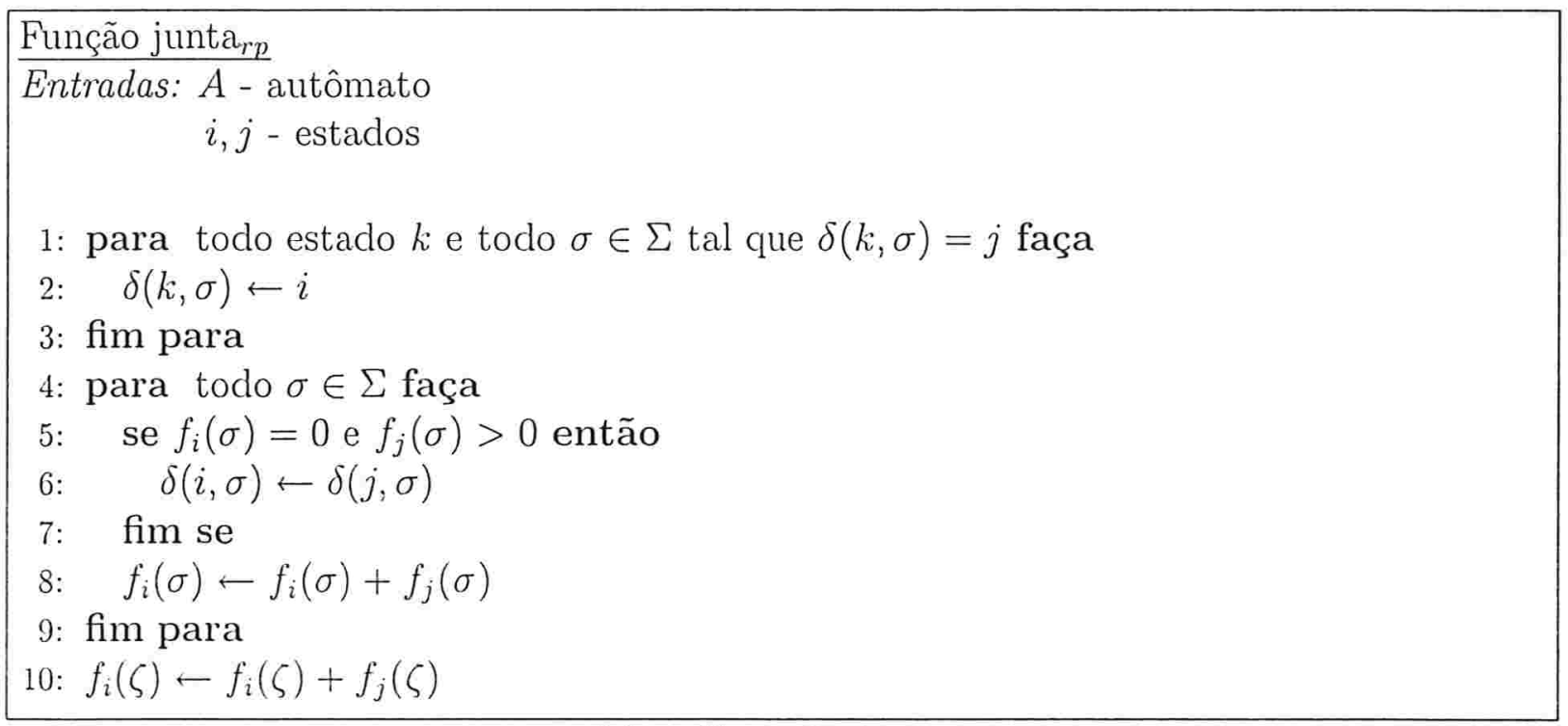

Algoritmo 2: junta $_{r p}$ 
Função compatível ${ }_{r p}$ :

Entradas: $A$ - autômato determinístico

$I$ - amostra

Saída: valor booleano

1: para cada seqüência $S[1 . . n]$ de $I$ faça

2: $\quad q \leftarrow q_{0}$ \{lembre-se de que $q_{0}$ é o estado inicial $\}$

3: $\quad i \leftarrow 1$

4: $\quad$ enquanto $q \neq \emptyset$ e $i \leq$ tamanho $[S]$ faça

5: $\quad q \leftarrow \delta(q, S[i])$

6: $\quad i \leftarrow i+1$

7: fim enquanto

8: $\quad$ se $i>\operatorname{tamanho}[S]$ e $q \in F$ então

9: devolve falso $\{A$ reconhece pelo menos uma seq de I, logo $A$ não é compatível $\}$ 10: fim se

11: fim para

12: devolve verdadeiro $\{$ nenhuma seq. de I foi reconhecida por $\mathrm{A}, \log$ o $A$ é compatível

Algoritmo 3: compatível $_{r p}$

\section{Linhas gerais do algoritmo}

O RPNI, cujo pseudo-código encontra-se no Algoritmo 1, necessita de uma amostra positiva e uma negativa para realizar uma busca ordenada no $\operatorname{Ret}\left(A A P\left(I_{+}\right)\right)$. O algoritmo inicia construindo o $A A P\left(I_{+}\right)$, no qual cada um dos estados corresponde a um prefixo. Note que, pelo método de construção do autômato da árvore de prefixos, cada prefixo é único. Os prefixos são ordenados de acordo com a ordem padrão. A ordem padrão também pode ser aplicada numa partição do conjunto de estados do $A A P\left(I_{+}\right)$, no qual cada bloco é representado pelo estado com o menor prefixo.

Esse algoritmo foi adaptado para transformar a gramática inferida numa gramática estocástica. Essa adaptação consite em estimar as probabilidades das transições de acordo com a amostra de treinamento. Dessa forma, na construção do $A A P\left(I_{+}\right)$, em cada estado são armazenadas as freqüências em que as seqüências da amostra de treinamento passaram pelas transições de saída. Denotaremos por $f_{i}(a)$ o número de seqüiências que passam pela transição $\delta(i, a), f_{i}(\zeta)$ o número de seqüências que acabam no estado $i$, e $n_{i}$ o número de seqüências que chegam no estado $i$, ou seja $n_{i}=\sum_{a \in \Sigma \cup \zeta} f_{i}(a)$. Além disso, denotaremos por $p_{i}(a)$ a probabilidade de ao estar no estado $i$ utilizar a transição $\delta(i, a)$, e $p_{i}(\zeta)$ a 
probabilidade de ao estar no estado $i$ utilizar $i$ como estado final. As probabilidades $p_{i}(a)$ e $p_{i}(\zeta)$ são estimadas pelas razões $f_{i}(a) / n_{i}$ e $f_{i}(\zeta) / n_{i}$ respectivamente.

Por meio de dois laços aninhados, que utilizam a ordem padrão para percorrer os pares de estados do autômato $A$, o $R P N I$, a cada iteração, realiza as seguintes operações. Primeiramente, uma cópia $A^{\prime}$ do autômato $A$ é feita. Em seguida, os estados correntes $i$ e $j$ de $A$ são juntados e o autômato $A^{\prime}$ é transformado num autômato determinístico através das funções junta e transf_para_determinístico respectivamente. Após estas operações, se $A$ for compatível em relação à amostra negativa então a última operação de junção é aceita e o laço mais interno é interrompido. Senão, como a última junção de estados não foi bem sucedida, o autômato $A$ recupera suas configurações anteriores à última junção, que estão armazenadas em $A^{\prime}$.

A função junta $a_{r p}$, Algoritmo 2, baseia-se no processo de junção de estados descrito na seção 3.1.1. A verificação da compatibilidade de um autômato em relação a uma amostra é feita por meio da função compatível ${ }_{r p}$ (veja o Algoritmo 3). Lembramos que um autômato é compatível em relação a uma amostra $I_{-}$se este não reconhece nenhuma seqüência de $I_{-}$.

\subsubsection{Alergia}

Os resultados teóricos do algoritmo $R P N I$ mostram que a presença de uma amostra negativa é importante para determinar o grau de generalização no processo de inferência. Entretanto, na prática, não são em todos os problemas de aprendizado que temos amostras negativa e positiva. Daí a necessidade de implementar algoritmos que utilizam somente amostra positiva.

O algoritmo Alergia, criado por Carrasco e Oncina [CO94b] segue as mesmas diretrizes do $R P N I$. Após construir o $A A P\left(I_{+}\right)$o Alergia segue um caminho no $\operatorname{Ret}\left(A A P\left(I_{+}\right)\right)$por meio do processo de junção de estados. A diferença principal para o RPNI é que o Alergia utiliza apenas amostra de treinamento positiva. Este algoritmo supõe que a linguagem desconhecida $L$ possui uma distribuição de probabilidade nos seus elementos e que as amostras de treinamento de $L$ consistem de exemplos positivos que aparecem repetidamente de acordo com a distribuição de $L$. Na ausência de amostra negativa, o Alergia utiliza um critério estatístico baseado nas freqüências das seqüências da sua amostra de 
treinamento para decidir quando generalizar. Dois estados são juntados somente se estes geram, dentro de uma incerteza estatística, a mesma linguagem estocástica.

Os autores do Alergia testaram sua performance com diferentes gramáticas-alvo [CO94b]. Para cada uma delas, amostras de diferentes tamanhos eram geradas e fornecidas como amostra de treinamento para o algoritmo. Experimentalmente, constataram que o tempo de convergência do algoritmo cresce linearmente em função do tamanho da amostra de treinamento. Além disso, quando a amostra de treinamento era suficientemente grande, o Alergia sempre inferia a estrutura da gramática-alvo corretamente. Nada foi dito em relação à precisão da estimação das probabilidades de transição.

\section{Linhas gerais do algoritmo}

O algoritmo Alergia, cujo pseudo-código encontra-se no Algoritmo 4 primeiramente constrói o autômato de árvore de prefixos a partir da amostra de treinamento positiva $I_{+}$. Ao construí-lo, em cada estado são armazenadas as frequiências em que as seqüências da amostra de treinamento passaram pelas transições de saída, da mesma forma que é feito no algoritmo RPNI.

Em seguida, o algoritmo compara todos os estados dois a dois, utilizando dois laços aninhados. A ordem seguida pelos laços é a ordem padrão utilizada pelo algoritmo RPNI e definida na seção 3.3.1. A cada iteração, o Alergia verifica se dois estados são "compatíveis". Se forem, os dois são juntados através da função junta, o autômato resultante torna-se determinístico através da função trans_para_determinístico e o laço mais interno é interrompido. As funções junta e trans_para_determinístico são iguais as funções de mesmo nome do algoritmo RPNI. Após o término dos dois laços aninhados, o Alergia calcula as probabilidades das transições por meio das frequiências armazenadas em cada estado e devolve o autômato estocástico que foi inferido.

O algoritmo compatível al utiliza o seguinte critério para deduzir se dois estados são compatíveis. Suponha que $I_{+}$é uma amostra estruturalmente completa. Pelo teorema 3.1.1 sabemos que $\mathrm{A}(\mathrm{L})$ está no $\operatorname{Ret}\left(A A P\left(I_{+}\right)\right)$e que existe uma partição $\tilde{\pi}$ dos estados do $A A P\left(I_{+}\right)$que corresponde a $A(L)$. Dois estados quaisquer $q_{i}$ e $q_{j}$ são equivalentes $\left(q_{i} \equiv q_{j}\right)$ se $q_{i}$ e $q_{j}$ pertencem ao mesmo bloco da partição $\tilde{\pi}$. Pela forma que o $A A P\left(I_{+}\right)$ é construído, estados equivalentes possuem probabilidades de transição iguais e estados de destino equivalentes: 


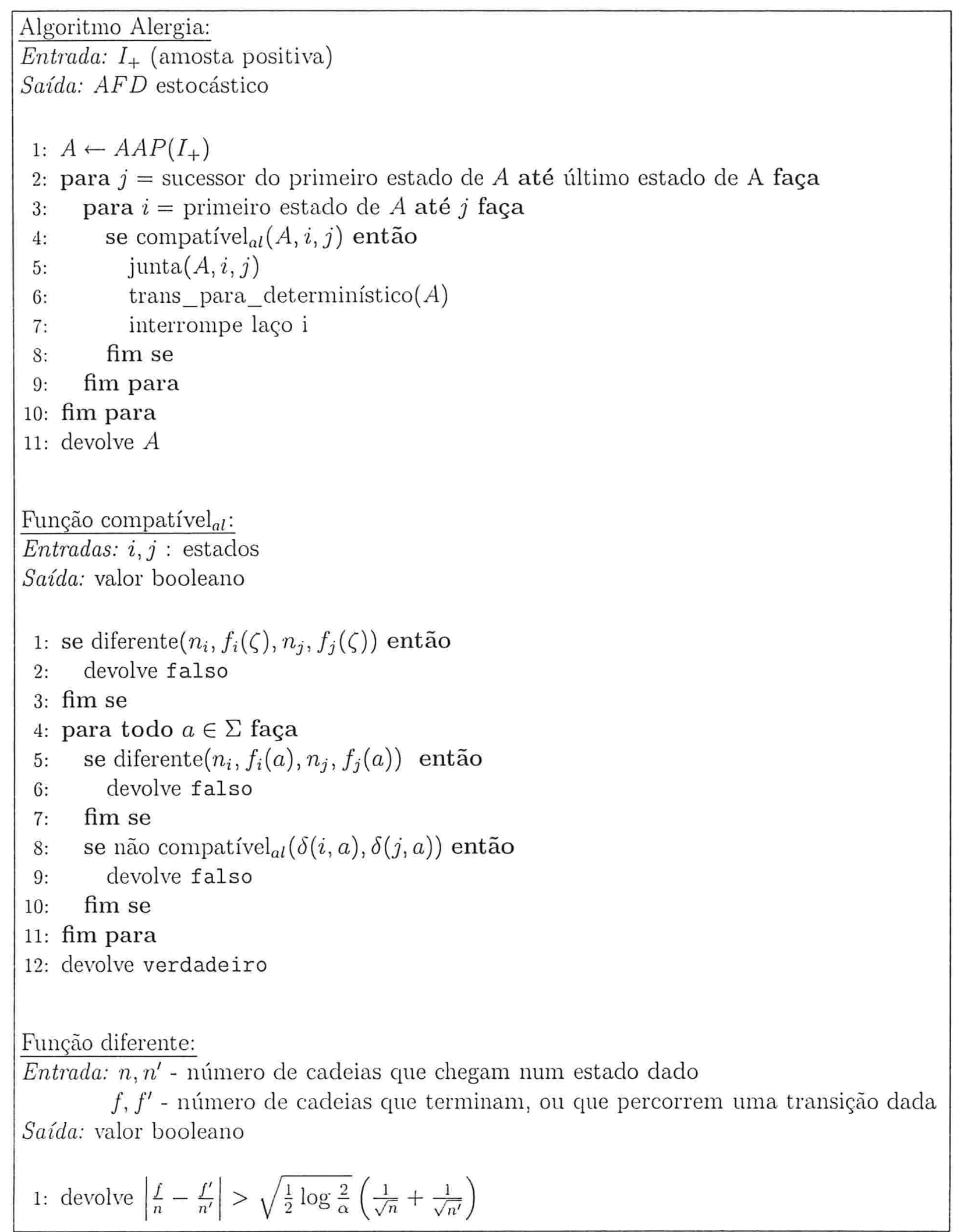




$$
\left(q_{i} \equiv q_{j}\right) \Rightarrow \forall a \in \Sigma\left\{\begin{array}{l}
p_{i}(a)=p_{j}(a) \\
\delta_{i}(a) \equiv \delta_{j}(a)
\end{array}\right.
$$

O descumprimento de uma dessas duas condições proporciona um critério para rejeitar a equivalência de estados. Entretanto, devido às variações dos dados amostrais, a equivalência de estados deve ser aceita, se a diferença de $p_{i}(a)$ para $p_{j}(a)$ estiver dentro de um intervalo de confiança. O algoritmo Alergia verifica isto por meio da função compativel cl $_{\text {. }}$ Esta utiliza a função diferente para averiguar se $p_{i}(a)$ é aproximadamente igual a $p_{j}(a)$ para $\forall a \in \Sigma \cup \zeta$, e utiliza a recursão para verificar se os estados de destino são equivalentes também. Veja a função compatível al no Algoritmo 4.

O critério que verifica se as probabilidades de transição para cada símbolo de dois estados são aproximadamente iguais, baseia-se num teste de hipótese. Para cada estado $i$ do $A A P\left(I_{+}\right)$e para cada $a \in \Sigma \cup \zeta$, definimos uma variável aleatória de Bernoulli $X$ que assume o valor 1 quando $\delta(i, a)$ é utilizado e 0 caso contrário.

Um intervalo de confiança para uma variável aleatória de Bernoulli com probabilidade de sucesso $p$ e frequiências observadas $f$ de $n$ possibilidades é dado pelo limite de Hoeffding [Hoe63]:

$$
\begin{gathered}
\left|p-\frac{f}{n}\right|<\eta_{\alpha}(m) \text { com probabilidade maior que }(1-\alpha) \\
\text { sendo que } \eta_{\alpha}(m)=\sqrt{\frac{1}{2 n} \log \frac{2}{\alpha}} \text { e } \alpha>0
\end{gathered}
$$

Consistentemente, para cada par de variáveis de Bernoulli com probabilidades $p$ e $p^{\prime}$, com probabilidade maior que $(1-\alpha)^{2}$,

$$
\begin{aligned}
& \left|\frac{f}{n}-\frac{f^{\prime}}{n^{\prime}}\right|<\eta_{\alpha}(m)+\eta_{\alpha}\left(m^{\prime}\right) \text { se } p=p^{\prime} \\
& \left|\frac{f}{n}-\frac{f^{\prime}}{n^{\prime}}\right|>\eta_{\alpha}(m)+\eta_{\alpha}\left(m^{\prime}\right) \text { se }\left|p-p^{\prime}\right|>2 \eta_{\alpha}(m)+2 \eta_{\alpha}\left(m^{\prime}\right)
\end{aligned}
$$

Esse é o teste de hipóteses implementado na função diferente do Algoritmo 4. Note que o parâmetro $\alpha$ determina o grau de generalização do algoritmo. Quanto maior 
for o valor de $\alpha$, menor é o intervalo de confiança, menos estados serão compatíveis e, conseqüentemente, menor será o nível de generalização.

\subsubsection{LAPFA}

Dana Ron formulou um algoritmo de aprendizado de distribuições geradas por autômatos finitos acíclicos determinísticos estocásticos, chamado LAPFA ( do inglês "Learn Acyclic Probabilistic Finite Automata") [MKS94]. Esse algoritmo baseia-se no modelo de aprendizado de distribuições descrito na seção 3.2. Como foi dito na Seção 3.2, a dificuldade em aprender AFD estocásticos e a necessidade de resolver problemas práticos motivou Ron a estudar essa subclasse de autômatos. Segundo a autora do algoritmo, o LAPFA tem o objetivo de modelar distribuições de seqüências curtas.

\section{Restringindo a classe de hipóteses}

Esse algoritmo baseia-se numa definição de AFD estocástico um pouco diferente da definição apresentada na Seção 2.3.2. Supomos agora a existência de um estado final $q_{f} \notin Q$ e um símbolo de fim de cadeia $\zeta \notin \Sigma$. A função de transição $\tau$ e a função de probabilidade do próximo símbolo $\gamma$ são definidas de maneira diferente, $\tau: Q \times \Sigma \cup\{\zeta\} \rightarrow$ $Q \cup\left\{q_{f}\right\}$ e $\gamma: Q \times \Sigma \cup\{\zeta\} \rightarrow[0,1]$. Além disso, são feitas duas exigências em $\tau$ e $\gamma$. Primeiro, para cada $q \in Q$ tal que $\gamma(q, \zeta)>0, \tau(q, \zeta)=q_{f}$. Segundo, $q_{f}$ pode ser alcançado por qualquer estado $q$ que pode ser alcançado a partir do estado inicial $q_{0}$.

Definição. 3.3.5 Para $0 \leq \mu \leq 1$, dois estados $q_{1}$ e $q_{2}$ em $Q$ são $\mu$-distintos se existe uma cadeia u para a qual $\left|P_{q_{1}}^{M}(u)-P_{q_{2}}^{M}(u)\right| \geq \mu$. Um AFD estocástico é $\mu$-distinto se para cada par de estados em $M$ os dois são $\mu$-distintos.

Como dito anteriormente, esse algoritmo considera como classe de hipótese a subclasse de autômatos finitos determinísticos acíclicos (AFDA) estocásticos. A profundidade de um AFDA estocástico é definida como sendo o comprimento do caminho mais longo do estado $q_{0}$ até $q_{f}$. De fato, o algoritmo utiliza um AFDA estocástico de níveis como estrutura para realizar o processo de inferência. Nesse tipo de autômato, cada estado pertence a um único nível $d$, sendo que o estado inicial $q_{0}$ é o único estado no nível 0 e o 
estado final $q_{f}$ é o único estado no nível $D$, dado que $D$ é a profundidade do autômato. Além disso, todas as transições de um estado no nível $d$ devem chegar em estados do nível $d+1$, a não ser para as transições rotuladas com o símbolo de final de cadeia $\zeta$. Denotaremos o conjunto de estados pertencentes ao nível $d$ por $Q_{d}$.

Teorema 3.3.3 Para cada AFDA estocástico com $n$ estados e profundidade $D$, existe um AFDA estocástico de níveis equivalente com no máximo $n(D-1)$ estados.

Considerando essa subclasse de autômatos, Ron obteve o seguinte resultado:

Teorema 3.3.4 Para cada parâmetro $0<\mu \leq 1$ dado, para cada AFDA estocástico $\mu$-distinto dado, para cada parâmetro de segurança $0<\delta \leq 1$ e de aproximação $\epsilon>0$ dados, o algoritmo LAPFA devolve um AFDA estocástico $\widehat{M}$ como hipótese, tal que com probabilidade pelo menos $1-\delta, \widehat{M}$ é uma hipótese $\epsilon$-boa em relação a $M$. O tempo de execução do algoritmo é polinomial em $\frac{1}{\epsilon}, \log \frac{1}{\delta}, \frac{1}{\mu}, n, D$ e $|\Sigma|$.

Descreveremos apenas as linhas gerais da demonstração desse teorema, que econtra-se em detalhes na tese de Dana Ron [MKS94]. Inicialmente, a noção de uma amostra $\epsilon$-boa em relação ao autômato alvo $M$ é definida e o parâmetro $m_{0}$ do algoritmo LAPFA é definido em função dos parâmetros $\epsilon$ e $\delta$ do modelo de aprendizado:

$$
m_{0}=\frac{|\Sigma| n^{2} D^{2}+2 D \ln (8(|\Sigma|+1))+\ln \frac{1}{\delta}}{\epsilon^{2}}
$$

Em seguida, é provado que com alta probabilidade uma amostra gerada por $M$ é boa. Por último, é demonstrado que se o algoritmo LAPFA recebe uma amostra $\epsilon$-boa então ele infere um AFDA estocástico como hipótese com as propriedades enunciadas no teorema.

\section{Linhas gerais do algoritmo}

Assim como os outros algoritmos já apresentados, o primeiro passo do LAPFA (Algoritmo 5) é a construção do autômato da árvore de prefixos $A A P\left(I_{+}\right)$a partir da amostra de treinamento $I_{+}$. Para cada estado $i$ desse autômato e para cada $\sigma \in \Sigma, m_{i}(\sigma)$ é o número de cadeias de $I_{+}$que passam pela transição de saída de $i$ rotulada por $\sigma$. Se $i$ não 


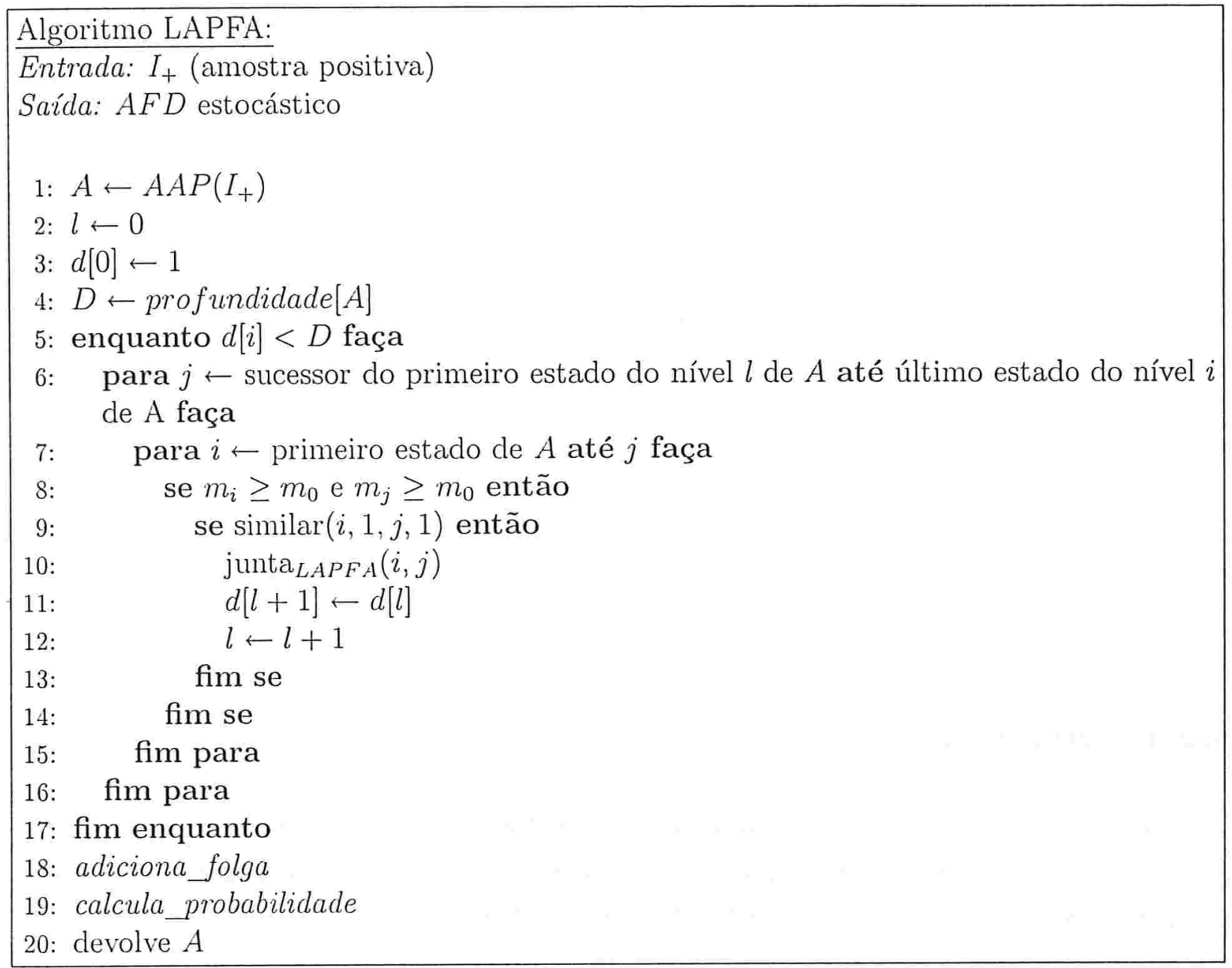


tem transição de saída rotulada por $\sigma$ então definimos $m_{i}(\sigma)=0$. Além disso, denotamos $\sum_{\sigma} m_{i}(\sigma)$ por $m_{i}$

Para cada nível do autômato, o LAPFA testa todos os pares $i$ e $j$ de estados do nível em análise para verificar se esses possuem a seguinte propriedade: dado um limiar $m_{0}$ (parâmetro de entrada) ambas as contagens $m_{i}$ e $m_{j}$ devem ser maiores ou iguais a $m_{0}$ e os estados devem ser similares. Essa última verificação é feita por meio da função similar, veja Algoritmo 6. Caso essas duas verificações sejam verdadeiras, o algoritmo junta $i$ e $j$ e todos os pares de estados que eles alcançam. Se $i$ e $j$ são juntados em um novo estado $k$ temos $m_{k}(\sigma)=m_{i}(\sigma)+m_{j}(\sigma)$.

Após todos os níveis serem analisados, o algoritmo chama a rotina adiciona_folga (Algoritmo 8). Essa função, inicialmente, junta todos os estados finais em um único estado $q_{f}$. Depois, para cada nível $d$ do autômato todos os estados $k$ no nível $d$ tais que $m_{k}<m_{0}$ são juntados em um estado denominado pequeno(d). Por último, para cada estado $k$ e para cada $\sigma$ tais que $m_{k}(\sigma)=0$, se $\sigma=\zeta$ então uma transição, rotulada por $\zeta$ é adicionada de $k$ a $q_{f}$ e se $\sigma \in \Sigma$ então uma transição rotulada por $\sigma$ é adicionada de $k$ a pequeno $(d+1)$ sendo que $d$ é o nível do estado $k$.

Finalmente, a função calcula_probabilidade, Algoritmo 9 é chamada. Note que $\gamma_{\text {min }}$, um parâmetro de entrada do algoritmo é a probabilidade mínima de qualquer transição do autômato.

\subsubsection{Amnesia}

O algoritmo Amnesia, foi originalmente apresentado na tese de doutorado de D. Ron [Ron95]. Uma segunda versão, na qual nosso trabalho baseou-se, foi apresentada, com significativas melhoras, no artigo de D. Ron et al. [DR96].

O Amnesia baseia-se no modelo de aprendizado de AFDs estocásticos descrito na seção 3.2, que tem como objetivo aprender distribuições. Segundo a autora, este é um algoritmo de aprendizado de distribuições de Cadeias de Markov de alcance variável. Esse processo de Markov pode ser descrito por uma subclasse de AFD estocásticos denominada de autômatos de sufixos estocásticos, a qual é utilizada como classe de hipóteses do modelo.

Esse algoritmo possui uma característica em especial que o distingue bastante dos demais. Ele é o único que não utiliza a estrutura de autômatos no decorrer do processo 


\section{Função similar: \\ Entradas: $i, j$ : estados $p_{i}, p_{j}:$ reais}

Saída: valor booleano

1: se $\left|p_{i}-p_{j}\right| \geq \mu / 2$ então

2: devolve falso

3: senão se $p_{i}<\mu / 2$ e $p_{j}<\mu / 2$ então

4: devolve verdadeiro

5: senão

6: para todo $\sigma \in \Sigma \cup \zeta$ faça

7: $\quad p_{i}^{\prime} \leftarrow p_{i} m_{i}(\sigma) / m_{i}$

8: $\quad p_{j}^{\prime} \leftarrow p_{j} m_{j}(\sigma) / m_{j}$

9: $\quad$ se $\operatorname{similar}\left(\tau(i, \sigma), p_{i}^{\prime}, \tau(j, \sigma), p_{j}^{\prime}\right)$ então

10: devolve falso

11: $\quad$ fim se

12: fim para

13: fim se

14: devolve verdadeiro \{chamadas recursivas acabaram, logo são similares\}

Algoritmo 6: similar

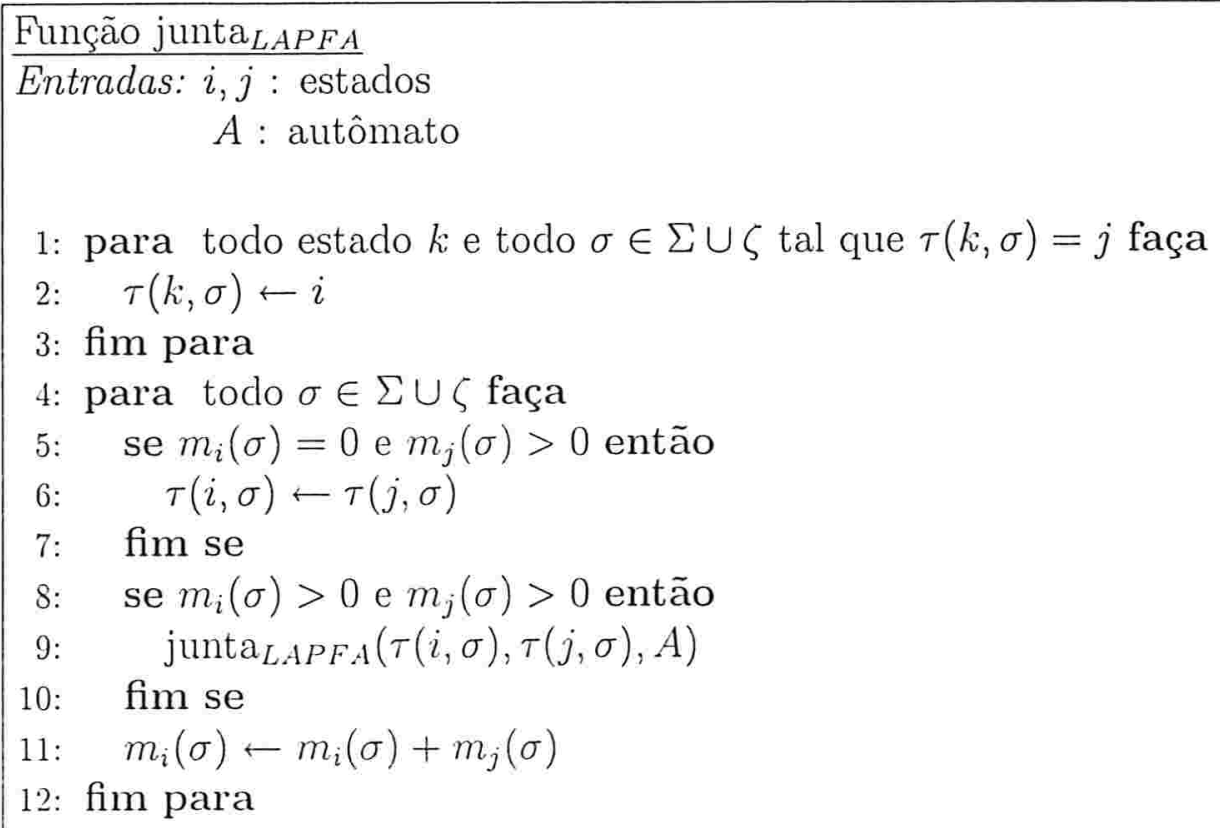




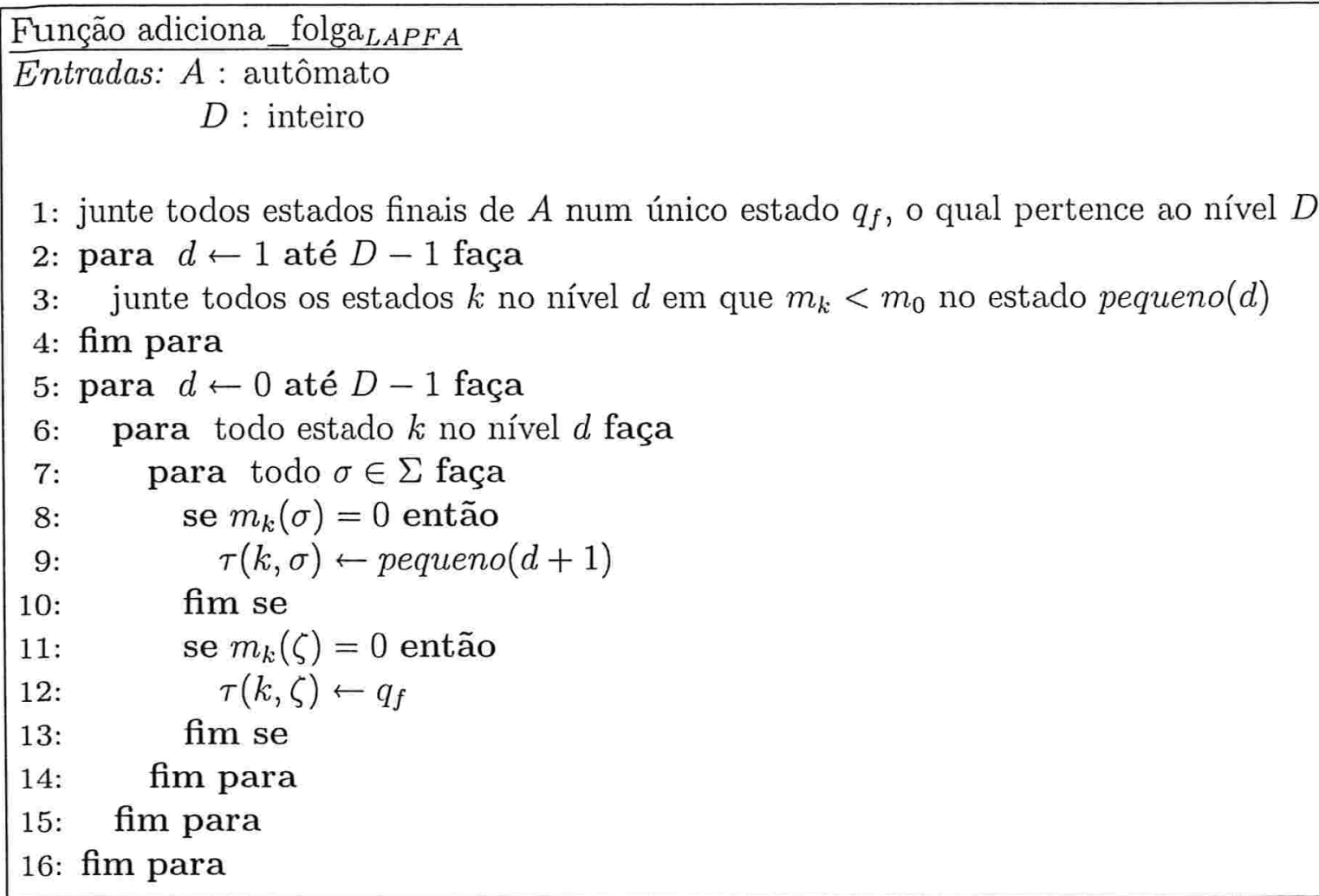

Algoritmo 8: adiciona_folga

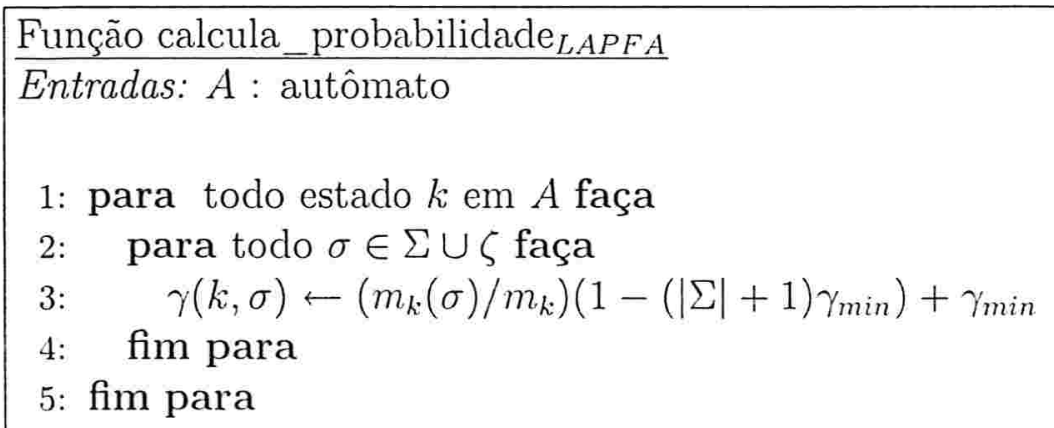

Algoritmo 9: calcula_probabilidade 
de inferência. A hipótese que o Amnesia infere pertence à classe de Árvores de Sufixos Preditoras que depois é transformada em um AFD estocástico.

Além de se mostrar útil em problemas práticos, como na modelagem de DNA de E.coli, esse algoritmo possui um resultado teórico importante. Apesar do aprendizado de distribuições geradas por AFD estocásticos ser difícil, Ron mostrou que seu modelo restrito pode ser aprendido considerando o modelo de aprendizado tipo PAC da Seção 3.2 .

\section{Restringindo a classe de hipóteses}

Para o entendimento do algoritmo é necessária a formalização das estruturas de autômatos de sufixos estocásticos e árvore de sufixos preditora. Iniciaremos a seção com algumas definições básicas para depois definirmos essas duas estruturas reconhecedoras de cadeias.

Para qualquer inteiro $N, \Sigma^{N}$ denota todas as cadeias de tamanho $N$ e $\Sigma^{\leq N}$ denota 0 conjunto de todas cadeias de tamanho até $N$. Para qualquer cadeia $u=u_{1} \ldots u_{l}, u_{i} \in \Sigma$, usaremos a seguinte notação:

- O sufixo mais longo de u diferente de u é denotado por sufixo $(u)=u_{2} \ldots u_{l-1} u_{l}$

- O conjunto de todos os sufixos de u é denotado por $\operatorname{Sufixo}^{*}(u)=\left\{u_{i} \ldots u_{l} \mid 1 \leq\right.$ $i \leq l\} \cup\{\lambda\}$.

- Uma cadeia $u^{\prime}$ é um sufixo próprio de $u$ se este for sufixo de $u$, mas diferente de $u$.

- Um conjunto de cadeias $S$ é denominado um conjunto de sufixos livres se $\forall u \in$ $S, \operatorname{Sufixo^{*}}(u) \cap S=\{u\}$.

Definição. 3.3.6 Um autômato de sufixo estocástico (ASE) $M$ é um AFD estocástico com as seguintes propriedades:

- Cada estado em $M$ é rotulado por uma cadeia de tamanho finito em $\Sigma^{*}$; 
- O conjunto de cadeias que rotulam os estados é um conjunto de sufixos livres;

- Para cada dois estados $q^{1}, q^{2} \in Q$ e para cada símbolo $\sigma \in \Sigma$, se $\tau\left(q^{1}, \sigma\right)=q^{2}$ e $q^{1}$ é rotulado por uma cadeia $s^{1}$, então $q^{2}$ é rotulado por uma cadeia $s^{2}$ na qual é um sufixo de $s^{1} \cdot \sigma$.

Para qualquer $L \geq 0$ dado, a subclasse de ASE na qual cada estado é rotulado por uma cadeia de tamanho no máximo $L$ é denotada por $L$-ASE.

Definição. 3.3.7 Uma árvore de sufixos preditora (ASP), sobre um alfabeto $\Sigma$, é uma árvore de grau $|\Sigma|{ }^{1}$ Cada aresta da árvore é rotulada por um único símbolo de $\Sigma$, de forma que de cada nó interno parte exatamente uma aresta rotulada por cada símbolo. Os nós das árvores são rotulados por pares $\left(u, \gamma_{u}\right)$ em que u é a cadeia associada com o caminho que começa neste nó e acaba na raiz da árvore e $\gamma_{u}: \Sigma \rightarrow[0,1]$ é a função de probabilidade do próximo símbolo relacionada com u. Além disso, é necessário que para cada cadeia u rotulando um nó na árvore, $\sum_{\sigma \in \Sigma} \gamma_{u}(\sigma)=1$.

Teorema 3.3.5 Para cada $L-A S E M=(Q, \Sigma, r, \gamma, \pi)$ existe uma $A S P T_{M}$ equivalente, de máxima profundidade $L$ e com no máximo $L .|Q|$ nós.

Restringindo o espaço de hipóteses, Ron obteve o seguinte resultado teórico:

Teorema 3.3.6 Para cada ASE alvo $M$ e para cada parâmetro de segurança $0<\delta<1$ $e$ de aproximação $0<\epsilon<1$, o algoritmo Amnesia devolve uma ASE $\widehat{T}$ como hipótese tal que, com probabilidade pelo menos $1-\delta$ :

- $\widehat{T}$ é uma hipótese $\epsilon$-boa em relação a $M$.

- O número de nós em $\widehat{T}$ é no máximo $|\Sigma| . L$ vezes o número de estados em $M$.

O tempo de execução do algoritmo é polinomial em $L, n,|\Sigma|, \frac{1}{\epsilon}$ e $\frac{1}{\delta}$.

\footnotetext{
${ }^{1}$ Grau de uma árvore é o máximo grau dos nós na árvore.
} 


\section{Linhas gerais do algoritmo}

Descreveremos a seguir o funcionamento do algoritmo. Seja $M=(Q, \Sigma, r, \gamma, \pi)$ o $L$-ASE alvo e seja $|Q| \leq n$. Em vez de trabalhar com autômatos no processo de inferência, o algoritmo Amnesia utiliza a estrutura de árvores de sufixo preditora como espaço de hipóteses. Para isto, o algoritmo baseia-se no Teorema 3.3.5 que garante a existência um árvore de sufixo preditora $T$, de tamanho limitado por $L \cdot|Q|$, que é equivalente a $M$. Após construir a função de probabilidade empírica $\widetilde{P}$ baseada na amostra de treinamento, o algoritmo utiliza $\widetilde{P}$ para construir uma árvore de sufixo $\bar{T}$, que com alta probabilidade é uma sub-árvore de $T$. Com base em $\bar{T}$ e $\widetilde{P}$ a hipótese $\widehat{T}$ é inferida. Primeiro definiremos formalmente $\widetilde{P}$ e depois explicaremos a construção de $\bar{T}$.

Denotaremos por $P$ a distribuição de probabilidade das cadeias geradas por $M$. Seja $S$ uma amostra de cadeias geradas por $M$, definiremos a seguir a função de probabilidade empírica $\widetilde{P}$ baseada em $S$. Se a amostra consiste de apenas uma cadeia $r$ de tamanho $m$, temos que para qualquer cadeia $u$ de tamanho até $L, \chi_{j}(u)$ é definido como 1 se $r_{j-|u|+1} \ldots r_{j}=u$ e 0 caso contrário. Seja

$$
\widetilde{P}(u)=\frac{1}{m-L} \sum_{j=L}^{m-1} \chi_{j}(u)
$$

e, para qualquer símbolo $\sigma$, seja

$$
\widetilde{P}(\sigma \mid u)=\frac{\sum_{j=L}^{m-1} \chi_{j+1}(u \sigma)}{\sum_{j=L}^{m-1} \chi_{j}(u)}
$$

Para uma amostra de treinamento com $m^{\prime}$ cadeias $r^{1}, \ldots, r^{m^{\prime}}$, cada uma de tamanho $l \geq L+1$, então para qualquer cadeia $u$ de tamanho no máximo $L, \chi_{j}^{i}(u)$ é definido como 1 se $r_{j-|u|+1}^{i} \ldots r_{j}^{i}=u$ e 0 caso contrário. Seja

$$
\widetilde{P}(u)=\frac{1}{m^{\prime}(l-L)} \sum_{i=1}^{m^{\prime}} \sum_{j=L}^{l-1} \chi_{j}^{i}(u)
$$

e para qualquer símbolo $\sigma$, seja 


$$
\widetilde{P}(\sigma \mid u)=\frac{\sum_{i=1}^{m^{\prime}} \sum_{j=L}^{l-1} \chi_{j+1}(u \sigma)}{\sum_{i=1}^{m^{\prime}} \sum_{j=L}^{l-1} \chi_{j}(u)}
$$

A construção da árvore de sufixos preditora $\bar{T}$ segue um procedimento "top-down". A árvore é inicializada com apenas um nó (rotulado pelo símbolo de final de cadeia $\lambda$ ) e nós são inseridos como filhos de uma folha da árvore somente se estes possuem uma determinada característica em relação à amostra, conforme a linha 5 do Algoritmo ??. As cadeias dos nós que possivelmente podem ser inseridos na árvore são armazenadas em $\bar{S}$. O conjunto $\bar{S}$ é inicializado com as cadeias dos possíveis filhos da raiz.

Enquanto houver cadeias em $\bar{S}$ o algoritmo executa os seguintes passos. A cada iteração, uma cadeia $u$ é removida de $\bar{S}$ e um nó $v$ rotulado por $u$ é adicionado como folha de $\widehat{T}$ se a seguinte condição for verdadeira. A probabilidade empírica da cadeia $u, \widetilde{P}(u)$, é não negligente e, para um símbolo $\sigma$, a probabilidade empírica de observar $\sigma$ após $u, \widetilde{P}(\sigma \mid u)$, difere substancialmente da probabilidade empírica de observar $\sigma$ depois de sufixo(u), $\widetilde{P}(\sigma \mid \operatorname{sufixo}(u))$. Note que sufixo(u) é a cadeia rotulando o pai do nó de $v$. A regra de decisão para inserir $v$ é portanto dependente da razão entre $\widetilde{P}(\sigma \mid u)$ e $\widetilde{P}(\sigma \mid \operatorname{sufixo}(u))$. Um nó é adicionado somente quando esta razão é substancialmente maior que 1. Em cada iteração ainda, se o tamanho da cadeia $u$ for menor que $L$, o algoritmo insere cada sufixo de $u$ de tamanho $|u|+1 \mathrm{em} \bar{S}$ caso este tenha probabilidade significante na amostra.

Após completar a construção de $\bar{T}$, o algoritmo define a estrutura de $\widehat{T}$ como sendo a árvore $\bar{T}$ com o acréscimo dos nós necessários para que esta tenha todos os nós internos com grau máximo. Depois, o algoritmo define a função de probabilidade do próximo símbolo para cada nó baseado em $\widetilde{P}$.

O algoritmo de aprendizado recebe como parâmetro de entrada o tamanho máximo $L$ das cadeias que rotulam os estados do ASE alvo $M$, um limite superior $n$ do número de estados em $M$, e um parâmetro de aproximação $0<\epsilon<1$. A partir dos três parâmetros de entrada, o algoritmo calcula outros quatro, que são utilizados no processo de inferência, da seguinte forma:

$$
\begin{aligned}
& \epsilon_{2}=\frac{\epsilon}{48 L} \\
& \gamma_{\text {min }}=\frac{\epsilon_{2}}{|\Sigma|}
\end{aligned}
$$




$$
\begin{aligned}
& \epsilon_{0}=\frac{\epsilon}{2 n L \log \left(1 / \gamma_{\min }\right.} \\
& \epsilon_{1}=\frac{\epsilon_{2} \gamma_{\min }}{8 n \epsilon_{0}}
\end{aligned}
$$

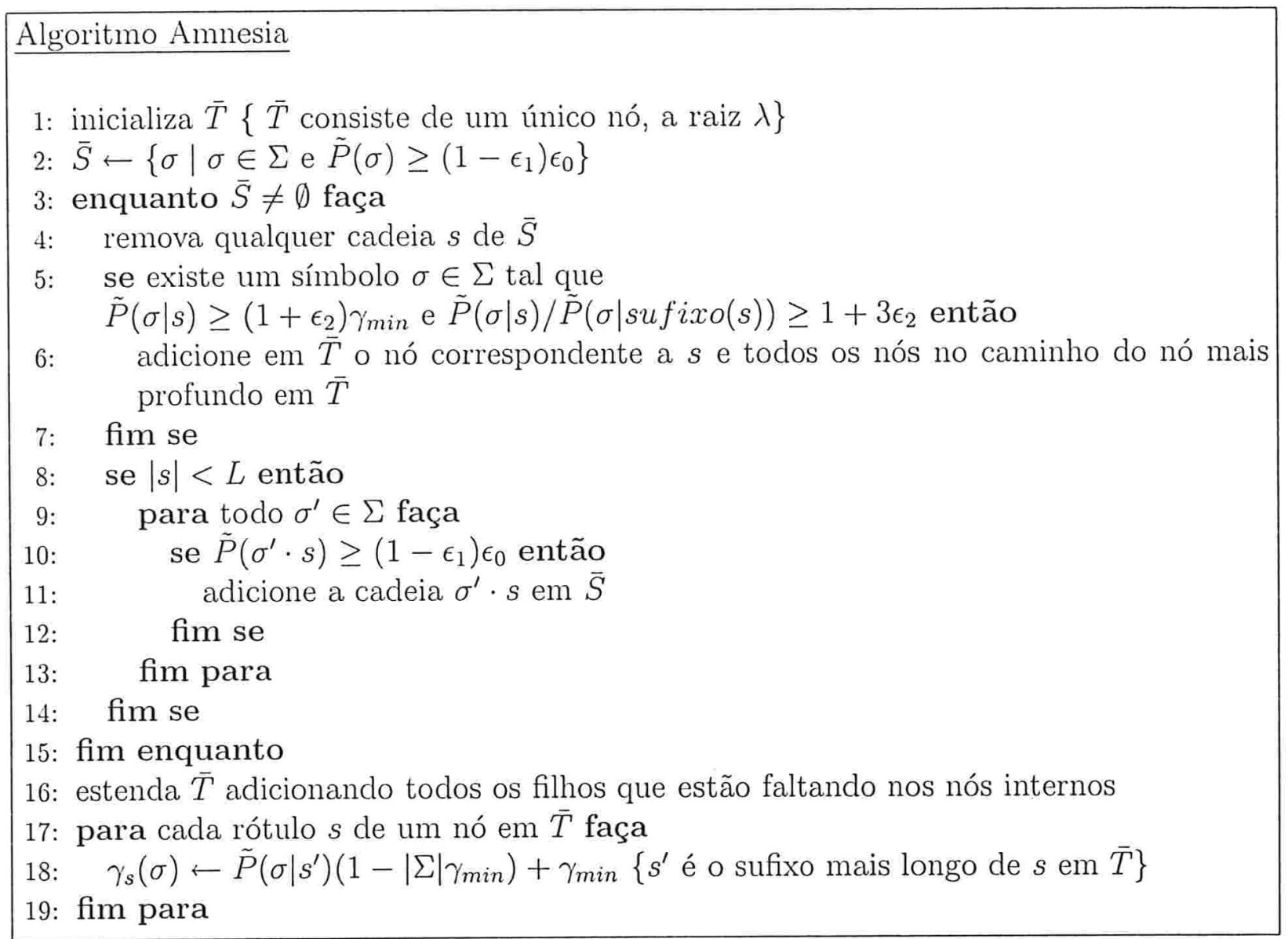

Algoritmo 10: Amnesia 



$\overline{4}$

\section{Sistema de aprendizado de classificadores}

Um dos objetivos deste trabalho foi desenvolver um ambiente computacional em que se possa realizar testes, de forma automática, para a análise do comportamento dos algoritmos de inferência gramatical implementados. Os quatro algoritmos de inferência foram implementados de forma modular para serem integrados no arcabouço modular de um sistema de geração automática de classificadores, desenvolvido por Ariane Machado [Lim02]. Além disso, um módulo de suporte de testes foi elaborado, não somente para executar os testes apresentados no Capítulo 5 mas também para que seja utilizado em trabalhos futuros.

\subsection{Descrição do arcabouço}

O arcabouço do sistema de geração automática de classificadores tem como objetivo criar um sistema para facilitar a implementação e validação de algoritmos de inferência 
gramatical. No trabalho elaborado por Ariane [Lim02], foram desenvolvidos módulos de inferência gramatical e geradores de analisadores sintáticos baseados em gramáticas livres de contexto. Para a implementação desse sistema, foi escolhido o paradigma de programação orientada a objetos com o intuito de facilitar a reutilização de código, a flexibilidade de implementação e uma possível expansão. Nossa tarefa foi implementar esses módulos direcionados a gramáticas regulares. A escolha desse paradigma permitiu que esses módulos fossem desenvolvidos separadamente, reutilizando parte do código já existente, para depois serem integrados ao sistema. Esse sistema, um dos projetos do grupo de pesquisa CAGE, foi desenvolvido em $\mathrm{C}++$ e documentado com o auxílio da ferramenta Doxygen ${ }^{1}$. Segue uma descrição resumida de cada módulo.

\section{Gerador de Seqüências (GS)}

O GS, módulo desenvolvido por Caetano Jimenez Carezzato, tem o objetivo de gerar exemplos de seqüências a partir de uma gramática estocástica. O programa permite configurar a semente usada para gerar as seqüências pseudo-aleatórias, tamanho máximo e número de seqüências a serem geradas.

\section{Inferidor de Gramáticas (IG)}

Módulo que implementa um algoritmo de inferência gramatical. Um IG deve ser capaz de, dado um conjunto de seqüências positivas e/ou um conjunto de seqüências negativas, inferir uma gramática e devolver sua descrição. Alguns algoritmos de inferência também possuem parâmetros de entrada que controlam o grau de generalização. Dependendo do algoritmo de inferência, a gramática inferida pode, ou não, ser estocástica. Neste trabalho, todos os IGs implementados forneciam como saída gramáticas estocásticas e por isso não foi necessário a utilização do módulo Estimador de Probabilidades.

\section{Estimador de Probabilidades (EP)}

Este módulo estima as probabilidades das produções de uma gramática não estocástica de acordo com uma amostra. Um EP deve receber um conjunto de seqüências, uma gramática não estocástica e, após o processo de estimação, fornecer a descrição da gramática estocástica.

\footnotetext{
${ }^{1}$ Doxygen é um sistema de documentação para algumas linguagens, entre elas $\mathrm{C}++$. Essa ferramenta permite, a partir de um conjunto de códigos fonte documentados, gerar a documentação on-line em HTML ou um manual de referência em LaTeX.
} 
Gerador de analisadores sintáticos (GAna) Este módulo tem o objetivo de implementar analisadores sintáticos. Ele recebe como entrada uma gramática estocástica e devolve o código de um analisador sintático correspondente à gramática de entrada.

\section{Gerador de Classificadores (GC)}

Pode-se gerar um classificador considerando uma ou várias gramáticas, cada uma representando uma família de seqüências. O GC recebe como entrada o nome do classificador a ser gerado e um conjunto de nomes de analisadores gerados pelo GAna. Como saída, ele gera o código em $\mathrm{C}++$ do classificador e um Makefile. O código gerado, após ser compilado, torna-se um programa que recebe como entrada um conjunto de seqüências e um limiar que, na ausência de um valor, assume $-\infty$ como valor padrão. Além do resultado da classificação de cada seqüência, o classificador devolve, em um arquivo texto de saída, o maior valor de probabilidade, para cada sequiência, entre todas as gramáticas consideradas em sua construção.

Dada uma seqüência $s$, sua classificação é feita da seguinte forma. Inicialmente, o classificador apura a gramática $G^{*}$ que devolve a maior probabilidade de reconhecer $s$ e então compara esse valor com o limiar. Se $p\left(s \mid G^{*}\right)$ for maior que o limiar então a seqüência $s$ é classificada como sendo da família representada por $G^{*}$. Caso contrário, s recebe o rótulo de não classificada. Note que, dessa forma, um classificador gerado a partir de uma única gramática rotula as sequências de entrada como classificadas ou não, de acordo com o limiar.

A utilização desses módulos na seqüência, descrita na Figura 4.1, demonstra o processo de geração de um classificador.

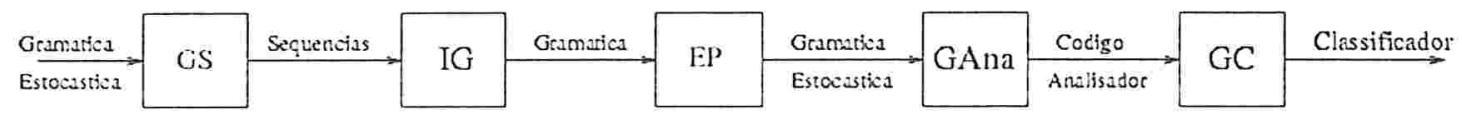

Figura 4.1: Módulos do sistema. 


\subsection{Módulo de suporte aos testes dos algoritmos}

Antes de aplicar os algoritmos implementados em problemas de Biologia Molecular, é importante estudar o comportamento desses algoritmos para domínios de sequiências que são geradas por uma gramática alvo conhecida. Nessa simulação, temos como ponto de partida uma gramática-alvo $G_{A}$ conhecida e, utilizando o módulo $G S$, amostras positivas de treinamento e validação são geradas. As amostras negativas, tanto de treinamento quanto de validação, são geradas após um conjunto de seqüências aleatórias serem filtradas pelo classificador da gramática-alvo. As amostras de treinamento são utilizadas para gerar os classificadores e depois estes são testados através das amostras de validação. O total de seqüências da amostra positiva de validação, que não foram corretamente classificadas, é o número de falsos negativos, e o total de seqüências da amostra negativa, que foram classificadas como pertencentes a linguagem alvo, é o número de falsos positivos. O erro total do algoritmo é a soma do total de falsos positivos e negativos.

A intenção de realizar essas simulações para aprender uma gramática alvo é a de estudar o comportamento desses algoritmos e comparar a performace das taxas de erro em basicamente três aspectos. Em primeiro lugar, é importante comparar a taxa de erro dos algoritmos para diferentes gramáticas alvo. Além disso, necessitamos compreender o impacto dos parâmetros de generalização dos algoritmos de inferência no resultado dos classificadores. Para se ter uma idéia, os algoritmos LAPFA e Amnesia possuem três parâmetros, os quais, dependendo da configuração de entrada, geram classificadores com taxas de erro bem diferentes. Por último, analisamos a taxa de erro dos algoritmos à medida que a amostra de treinamento aumenta.

Para que estes aspectos dos algoritmos possam ser estudados foi criado um conjunto de programas que, quando combinados, geram tais testes. A seguir descrevemos os principais programas implementados e, no Capítulo 5, apresentamos alguns resultados obtidos a partir deles.

\section{Gerador Aleatório de Gramáticas Regulares}

Lang [Lan92] realizou um estudo empírico do aprendizado de autômatos finitos determinísticos gerados aleatoriamente. Utilizando métodos próprios, implementamos essa idéia nesse programa, que é capaz de gerar uma gramática regular aleatória para 
que seja usada como gramática alvo num problema de aprendizado controlado. A partir de uma semente usada para gerar valores de probabilidade pseudo-aleatórias e um número inteiro $n$, o Gerador Aleatório de Gramáticas Regulares gera uma gramática regular com $n$ símbolos não terminais em que as regras de produção são criadas aleatoriamente.

\section{Validação Cruzada}

A validação cruzada é um método de validação de algoritmos de aprendizado utilizado, geralmente, quando o tamanho da amostra é limitado e pequeno. Numa $k$-validação cruzada, a amostra disponível é particionada em $k$ subconjuntos de tamanhos aproxidamente iguais. O aprendizado é realizado $k$ vezes, cada vez um subconjunto da amostra é desprezado para o treinamento e utilizado na apuração do erro. O programa desenvolvido recebe como parâmetro de entrada uma amostra de sequiências e o parâmetro $k$. Como saída, fornece $k$ amostras.

\section{Gera Amostra de Validação}

Esse programa é capaz de gerar as amostras de validação positiva e negativa correspondentes a uma gramátiva alvo. Ele recebe um arquivo com sequiências aleatórias e uma gramática e devolve dois arquivos, um com seqüências positivas e outro com negativas. Essas sequiências de entrada são classificadas em positivas ou negativas pelo classificador que é gerado a partir da gramática alvo de entrada. A amostra de entrada é gerada, normalmente, por uma gramática que gera os símbolos do alfabeto em questão com a mesma probabilidade.

\section{Gera Classificadores}

Esse programa é capaz de executar a seqüência de programas, IG, GAna e GC para gerar classificadores a partir de uma amostra de treinamento. Caso necessário, pode-se determinar um intervalo da amostra de treinamento e um tamanho de incremento para que o programa gere classificadores a partir de subconjuntos, cada vez maiores, da amostra de treinamento. Pode-se configurar as seguintes opções do programa: algoritmo de inferência; valores dos parâmetros de generalização; utilização de amostra de treinamento negativa no aprendizado; amostra de treinamento positiva; amostra de treinamento negativa; tamanho inicial da amostra de treinamento; tamanho final da amostra de treinamento; e incremento da amostra de treinamento. 


\section{Combina Parâmetros}

Esse programa tem o objetivo de fornecer uma análise da taxa de erro dos classificadores provenientes dos resultados de inferência de um algoritmo, executado com combinações diferentes de seus parâmetros de entrada. As combinações possíveis são definidas por meio de três parâmetros de entrada para cada parâmetro de generalização do algorimo de inferência: valor inicial, valor final e tamanho do incremento. Todas as combinações possíveis, dentro da faixa estabelecida, são geradas e para cada combinação o programa Gera Classificador é executado para gerar o classificador correspondente.

\section{Testa Classificadores}

Considerando um conjunto de classificadores, esse programa é capaz de apurar o erro de cada um deles para uma determinada amostra de teste. Dada uma amostra positiva, uma negativa, um conjunto de classificadores e um limiar, os totais de falsos positivos e de falsos negativos são apurados para cada classificador e impressos numa tabela.

"Windowing Technique" O "Windowing Technique" [SMBMH94, HK96], um método geralmente utilizado em modelos de HMM, apresenta uma solução para a definição de um limiar. Esse programa fornece uma série de gráficos como saída que auxiliam na determinação do limiar. Na Seção 5.1 .4 explicamos em detalhes esse método. 


Capítulo

\section{Avaliação dos algoritmos}

Os algoritmos serão avaliados basicamente de duas formas: em casos controlados nos quais a família que se deseja aprender é representada por sequiências que são geradas por uma gramática alvo conhecida e num problema de Biologia Molecular com seqüências naturais. Veremos que os testes elaborados para os casos controlados foram motivados pela aplicação dos algoritmos no problema de definição de fronteiras iniciais e finais de éxons, apresentada na Seção 5.2. O objetivo principal desses testes é comparar os quatro algoritmos implementados entre si.

\subsection{Validação dos algoritmos em casos controlados}

\subsubsection{Gramáticas alvo utilizadas}

Os testes controlados apresentados neste trabalho baseiam-se em três gramáticas alvo. Uma gramática simples para uma validação inicial dos algoritmos, uma gramática cuja 
as regras de produção foram definidas aleatóriamente, e por último uma gramática que gera seqüências semelhantes as seqüências da aplicação em Biologia Molecular. A seguir, apresentamos cada uma delas.

$G_{4}$

Essa gramática é composta de 4 símbolos não terminais e 11 produções, das quais 2 são recursivas. Ela é uma gramática trivial que pode ser equiparada a uma Cadeia de Markov de alcance 1. As probabilidades das produções foram atribuídas de forma que as seqüências geradas tivessem um tamanho médio de 30 bases.

$<A>\rightarrow a<A>[0.4]$

$<A>\rightarrow g<G>[0.6]$

$<G>\rightarrow g<G>[0.6]$

$<G>\rightarrow c<C>[0.39]$

$<G>\rightarrow \lambda[0.01]$

$<C>\rightarrow g<G>[0.7]$

$<C>\rightarrow t<T>[0.2]$

$<C>\rightarrow \lambda[0.1]$

$<T>\rightarrow a<A>[0.6]$

$<T>\rightarrow c<C>[0.2]$

$<T>\rightarrow \lambda[0.2]$

$G_{\text {aleatoria }}$

Essa gramática, constituída por 10 símbolos não terminais e 36 produções, foi construída utilizando-se o programa Gera Gramática Aleatórias. As seqüências geradas por ela variam muito de tamanho, possuindo um comprimento médio de 12 bases.

$$
\begin{aligned}
& <1>\rightarrow a<8>[0.153846] \\
& <1>\rightarrow c<1>[0.615385] \\
& <1>\rightarrow t<8>[0.230769] \\
& <2>\rightarrow t<6>[0.666667] \\
& <2>\rightarrow \lambda[0.333333] \\
& <3>\rightarrow c<5>[0.434783] \\
& <3>\rightarrow g<9>[0.130435]
\end{aligned}
$$


$<3>\rightarrow t<7\rangle[0.391304]$

$<3>\rightarrow \lambda[0.043478]$

$<4>\rightarrow a<3>$ [0.133333]

$<4>\rightarrow c<10>[0.100000]$

$<4>\rightarrow g<10>[0.200000]$

$<4>\rightarrow t<9>[0.266667]$

$<4>\rightarrow \lambda[0.300000]$

$<5>\rightarrow a<8>[0.117647]$

$<5>\rightarrow g<4>[0.294118]$

$<5>\rightarrow t<3>[0.235294]$

$<5>\rightarrow \lambda[0.352941]$

$<6>\rightarrow a<7>[0.304348]$

$<6>\rightarrow c<3>[0.260870]$

$<6>\rightarrow t<6>[0.347826]$

$<6>\rightarrow \lambda[0.086957]$

$<7>\rightarrow c<8>[0.250000]$

$<7>\rightarrow g<7>[0.208333]$

$<7>\rightarrow t<8>[0.250000]$

$<7>\rightarrow \lambda[0.291667]$

$<8>\rightarrow a<3>[0.714286]$

$<8>\rightarrow t<5>[0.142857]$

$<8>\rightarrow \lambda[0.142857]$

$<9>\rightarrow c<4>[0.600000]$

$<9>\rightarrow g<6>[0.266667]$

$<9>\rightarrow \lambda[0.133333]$

$<10>\rightarrow a<5>[0.391304]$

$<10>\rightarrow c<2>[0.260870]$

$<10>\rightarrow g<10>[0.086957]$

$<10>\rightarrow \lambda[0.260870]$

$G_{\text {donor }}$

Apresentaremos na Seção 5.2 uma aplicação dos algoritmos no problema de identificação de fronteiras entre íntrons e éxons. A intenção de criar a gramática 
$G_{\text {donor }}$ foi a de realizar testes controlados numa gramática alvo que simulasse essas sequiências naturais antes de aplicar os algoritmos no problema biológico. Para isso, as produções dessa gramática foram elaboradas tendo como base a seqüência de consenso de sítios donor. A gramática é formada por 9 símbolos não terminais e 22 produções e foi construída para gerar seqüências com exatamente 9 símbolos.

$$
\begin{aligned}
& <1>\rightarrow a<2>[0.45] \\
& <1>\rightarrow c<2>[0.50] \\
& <1>\rightarrow g<2>[0.05] \\
& <2>\rightarrow a<3>[0.90] \\
& <2>\rightarrow t<3>[0.10] \\
& <3>\rightarrow c<4>[0.05] \\
& <3>\rightarrow g<4>[0.90] \\
& <3>\rightarrow t<4>[0.05] \\
& <4>\rightarrow g<5>[1] \\
& <5>\rightarrow t<6>[1] \\
& <6>\rightarrow a<7>[0.45] \\
& <6>\rightarrow g<7>[0.55] \\
& <7>\rightarrow a<8>[0.90] \\
& <7>\rightarrow c<8>[0.03] \\
& <7>\rightarrow g<8>[0.03] \\
& <7>\rightarrow t<8>[0.04] \\
& <8>\rightarrow a<9>[0.04] \\
& <8>\rightarrow c<9>[0.06] \\
& <8>\rightarrow g<9>[0.90] \\
& <9>\rightarrow c[0.06] \\
& <9>\rightarrow g[0.04] \\
& <9>\rightarrow t[0.9]
\end{aligned}
$$

\subsubsection{Análise dos parâmetros de generalização}

Como esperado, nos testes de aprendizado de uma gramática alvo, constatamos que resultados positivos dos classificadores dependem dos valores dos parâmetros de entrada 
dos algoritmos de inferência. Devido a isso um estudo preliminar desses parâmetros torna-se importante.

Com exceção do RPNI que não possui parâmetro de entrada, o teste dos parâmetros de generalização foi aplicado para cada algoritmo implementado conforme a seguinte metodologia. Um conjunto de 1000 seqüências geradas pela gramática alvo $G_{\text {aleatoria }}$ formam a amostra de treinamento. Como já foi apresentado, os algoritmos LAPFA e Amnesia possuem 3 parâmetros de entrada e o Alergia apenas 1. Para cada algoritmo de inferência e parâmetro de entrada repetimos os seguintes passos. A partir da amostra gerada o algoritmo de inferência em análise é treinado várias vezes. Cada treinamento é realizado com um valor diferente do parâmetro em análise e para os outros parâmetros, caso se aplique, são atribuídos valores fixos. Os classificadores construídos a partir de cada gramática inferida classificam seqüências, de uma amostra de teste, como pertencentes ou não à família gerada por $G_{\text {aleatoria }}$ de acordo com um limiar. Ao classificar uma amostra de teste o erro do classificador é calculado por meio dos falsos positivos e falsos negativos. A porcentagem ou taxa de falsos negativos é a razão entre o número de falsos negativos e o tamanho da amostra positiva de teste; a taxa de falsos positivos é a razão entre o número de falsos positivos e o tamanho da amostra negativa de teste.

Um parâmetro de generalização tem o objetivo de controlar a compensação entre falsos positivos e falsos negativos. Se a gramática inferida reconhece exatamente a amostra de treinamento, a taxa de falsos positivos é zero, porém a taxa de falsos negativos tende a ser alta. À medida que inferimos uma gramática mais geral, o número de falsos negativos tende a cair e, em contrapartida, os falsos positivos tendem a aumentar.

No caso do algoritmo Alergia, seu único parâmetro de entrada $\alpha$ controla o nível de generalização da hipótese inferida. Analisando a maneira como o Algoritmo 4 decide se junta estados, notamos que quanto maior for o valor de $\alpha$ menor será o nível de generalização. Todos os testes realizados com gramáticas alvo comprovaram, na prática, a importância do parâmetro $\alpha$ na generalização da gramática inferida. Como ilustração, o gráfico da Figura 5.1 mostra a compensação entre falsos negativos e positivos à medida que diferentes valores de $\alpha$ são utilizados na inferência de gramáticas.

Esse comportamento de falsos positivos e falsos negativos não foi verificado nos testes realizados com os parâmetros dos algoritmos LAPFA e Amnesia. Na verdade esses dois algoritmos inferem gramáticas que possuem uma característica complicadora na realização 


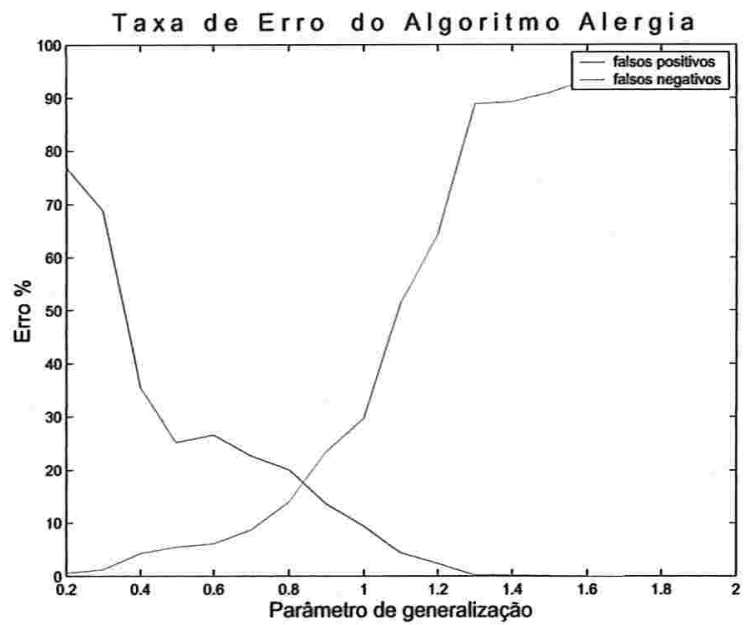

Figura 5.1: Teste do parâmetro de entrada $\alpha$ do algoritmo Alergia. O gráfico mostra a taxa de falsos positivos e falsos negativos para uma faixa de valores do parâmetro $\alpha$.

desse tipo de teste. Primeiro, a gramática inferida por eles não são bons classificadores na medida que ela atribui uma probabilidade diferente de 0 para qualquer seqüencia. Segundo que a probabilidade atribuída pela gramática a uma seqüência dependo de seu tamanho e por isso o método de classificação utilizada nesse teste torna-se ineficiente. Nesse caso, acreditamos que o ideal é utilizar um classificador utilizando a técnica "Windowing", a ser apresentada na Seção 5.1.4.

Gostaríamos de ressaltar que em problemas de Biologia Molecular em particular é melhor ter menos falsos positivos do que falsos negativos. Como em geral o custo do processo de validação bioquímica é alto, um número de falsos positivos elevado inviabilizaria financeiramente uma validação das seqüências identificadas como positivas.

\subsubsection{Análise do comportamento do algoritmo à medida que a amostra de treinamento aumenta}

Conforme vimos no Capítulo 3, de maneira geral os algoritmos implementados neste trabalho tendem a inferir melhores hipóteses à media que a amostra de treinamento aumenta. Os autores dos algoritmos comentam que essa característica, dependendo do 
algoritmo, é averiguada por uma validação experimental ou garantida por um modelo teórico. A teoria na qual o RPNI está inserido garante que, se a amostra de treinamento contém uma amostra característica, esse algoritmo identifica no limite a linguagem da gramática alvo. Os autores do Alergia constataram experimentalmente que, para amostras suficientemente grandes, esse algoritmo infere a estrutura da gramática alvo corretamente. Por último, os algoritmos LAPFA e Amnesia estão inseridos num modelo derivado do modelo de aprendizado PAC. O objetivo dos testes desta Seção é, portanto, verificar como se comporta o processo de aprendizado dos quatro algoritmos à medida que a amostra de treinamento aumenta.

Em problemas práticos, raramente dispõe-se de amostras com número de seqüências suficiente para realizar testes dessa natureza. Em contrapartida, nos testes em casos controlados, podemos gerar amostras de tamanho suficientemente grandes que possibilitam esta análise. Por isso, os testes de aprendizado em domínios de seqüências geradas por uma gramática alvo tornam-se importantes para entendermos, por exemplo, qual é um tamanho razoável da amostra de treinamento com o qual um algoritmo de inferência obtém a convergência ou se ele consegue uma aproximação satisfatória com amostras de tamanhos menores. Além disso, a partir dessa avaliação, podemos verificar a aplicabilidade dos algoritmos em problemas de aprendizado de famílias de seqüências biológicas, restritos a amostras de treinamento pequenas.

Não é difícil perceber que essas respostas dependem, principalmente, da complexidade da máquina geradora das seqüências da família que se quer aprender. Por isso, aplicamos este teste em três gramáticas alvos: a $G_{4}, G_{\text {aleatoria }}$ e $G_{d o n o r}$.

\section{Metodologia}

Sabemos que o RPNI é um algoritmo que necessita, além da amostra positiva, de uma amostra negativa de treinamento. Como a intenção destes testes é comparar os algoritmos entre si, elaboramos uma metodologia de teste na qual a amostra negativa colaborasse na construção dos classificadores dos algoritmos que utilizam apenas amostra positiva de treinamento. Além disso, a definição dessa metodologia, com amostras de treinamento positivas e negativas, foi motivada pela aplicação prática descrita na seção 5.2.

Inicialmente, duas amostras de treinamento suficientemente grandes são geradas: uma positiva e outra negativa. Para um tamanho inicial de ambas amostras, cada algoritmo 
de inferência é treinado. No caso do RPNI, tanto a amostra positiva quanto a negativa são utilizadas para que seja inferida uma gramática que é então utilizada na construção de um classificador binário. Este, por sua vez, classifica seqüências como pertencentes ou não à família, representada pela gramática alvo em questão, de acordo com um limiar 0 . No caso dos outros três algoritmos, para cada um deles, as amostras positiva e negativa são utilizadas para inferir duas gramáticas, $G_{+}$e $G_{-}$, respectivamente. Um classificador é construído a partir dessas duas gramáticas e classificará uma seqüência $s$ como pertencente à família se $p\left(s \mid G_{+}\right)>p\left(s \mid G_{-}\right)$ou não pertencente à família, caso contrário. Esse classificador de Bayes não considera as probabilidades dos padrões positivo e negativo porque supomos nesse teste que $p\left(G_{+}\right)=p\left(G_{-}\right)$. Esse processo é repetido $n$ vezes, sendo que cada vez o tamanho da amostra é incrementado e a inferência é realizada considerando a amostra de treinamento anterior acrescida das novas seqüências determinadas pelo novo tamanho. Os classificadores construídos são então testados com uma amostra de teste que contém exemplos positivos e negativos. O resultado de cada classificador é o número de falsos positivos e falsos negativos.

Para que o resultado do teste não dependa da representatividade de uma única amostra de treinamento, todo esse processo de construção dos classificadores foi repetido para nove amostras de treinamento geradas de maneira independente. Dessa forma, para um determinado algoritmo e um tamanho de amostra, o número de falsos positivos do classificador correspondente é a média dos 9 resultados de falsos positivos. De forma análoga, a média de falsos negativos também é calculada. Os gráficos dessa seção, em vez de mostrarem o erro absoluto, mostram a percentagem do erro. A percentagem ou taxa de falsos negativos é a razão entre o número de falsos negativos e o tamanho da amostra positiva de teste; a taxa de falsos positivos é a razão entre o número de falsos positivos e o tamanho da amostra negativa de teste; e a taxa de erro total é a soma de falsos negativos e falsos positivos dividido pelo tamanho da amostra de teste.

Antes de executar esse teste, foi necessário determinar os valores dos parâmetros de entrada dos algoritmos. Os valores foram escolhidos após a análise de um teste em que se fixa um tamanho de amostra de treinamento e os parâmetros de entrada são combinados. Para executar esse teste foi utilizado o programa Combina Parâmetros. Os resultados dos classificadores são então analisados e para cada algoritmo ecolhemos a combinação de parâmetros que resultou no menor erro total. 
Descrevemos a seguir os resultados dos testes realizados para as três gramáticas alvo consideradas neste trabalho.

\section{Análise dos resultados de $G_{4}$}

A Figura 5.2 mostra um gráfico para cada algoritmo de inferência com o resultado do aprendizado da gramática $G_{4}$. Para essa gramática os quatro algoritmos apresentaram uma boa performance, convergindo para uma taxa de erro total menor que $5 \%$ para amostras positivas e negativas de 150 seqüências. Para um tamanho de amostra igual a 500, a percentagem do erro total não tem diferença significativa entre os algoritmos. Essa taxa varia de 0,34\% para o algoritmo alergia a 1,68\% para o LAPFA. Além de ter a menor taxa de erro para amostras grandes, o Alergia destaca-se dos demais algoritmos nesse teste porque obtém uma percentagem de erro de apenas $3,59 \%$ para uma amostra de 20 sequiências. Embora os gráficos não mostrem, esse foi executado para amostras de tamanho 10000. Nenhum dos classificadores gerados a partir de gramáticas inferidas pelo RPNI convergiu para erro total igual a 0.

\section{Análise dos resultados de $G_{\text {Aleatoria }}$}

O resultado dos testes para essa gramática pode ser visto na Figura 5.3. Os resultados menos expressivos do aprendizado da $G_{\text {Aleatoria }}$, uma gramática com mais símbolos não terminais e regras de produção que a $G_{4}$, mostram que a família das seqüências geradas por ela é mais díficil de ser aprendida. Podemos notar que as taxas de erro dos algoritmos convergiram para amostras de tamanho entre 600 e 2600 seqüências. O RPNI, apesar de obter as maiores taxas de erro total para amostra de tamanho até 800 seqüências, é o único algoritmo que converge para uma taxa de erro de 0 com 2600 seqüências de treinamento.

\section{Análise dos resultados de $G_{d o n o r}$}

A Figura 5.4 mostra os resultados obtidos para o aprendizado de $G_{\text {donor }}$. Os algoritmos de inferência Alergia e LAPFA destacaram-se dos demais nesse teste. Ambos convergiram para uma taxa de erro total abaixo dos $3 \%$ para amostras com 500 seqüências. O LAPFA 

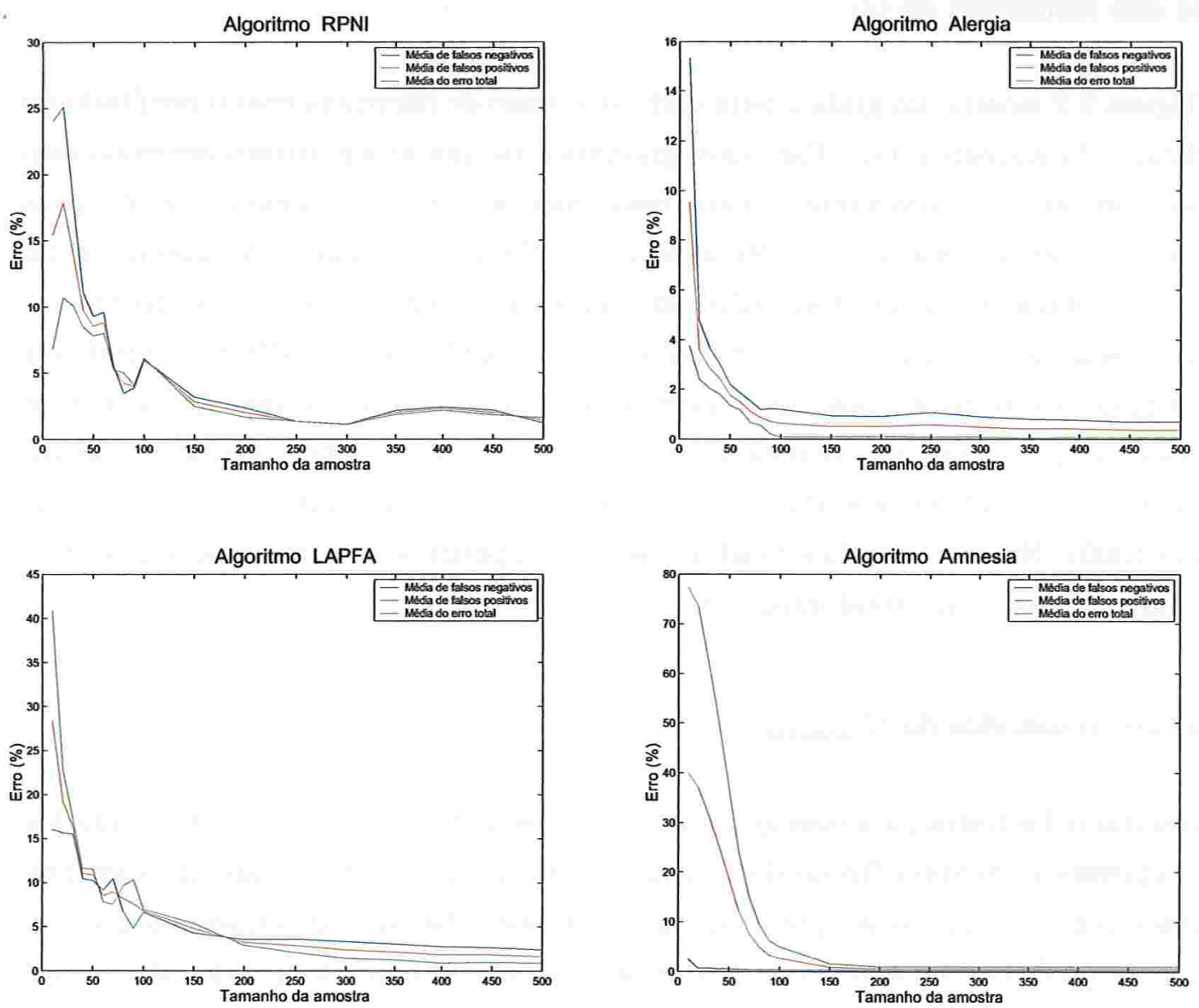

Figura 5.2: Testes de aprendizado da gramática alvo $G_{4}$. O gráfico de cada algoritmo de inferência mostra a taxa de falsos positivos, falsos negativos e erro total da média do resultado de 9 classificadores para cada tamanho de amostra. Os algoritmos de inferência foram treinados com os seguintes paramêtros: o Alergia com $\alpha=0,11$, o LAPFA com $m_{0}=4, \mu=0,4$, e $\gamma_{\min }=0,001$, e por último, o Amnesia com $L=3, n=1$ e $\epsilon=0,1$. 

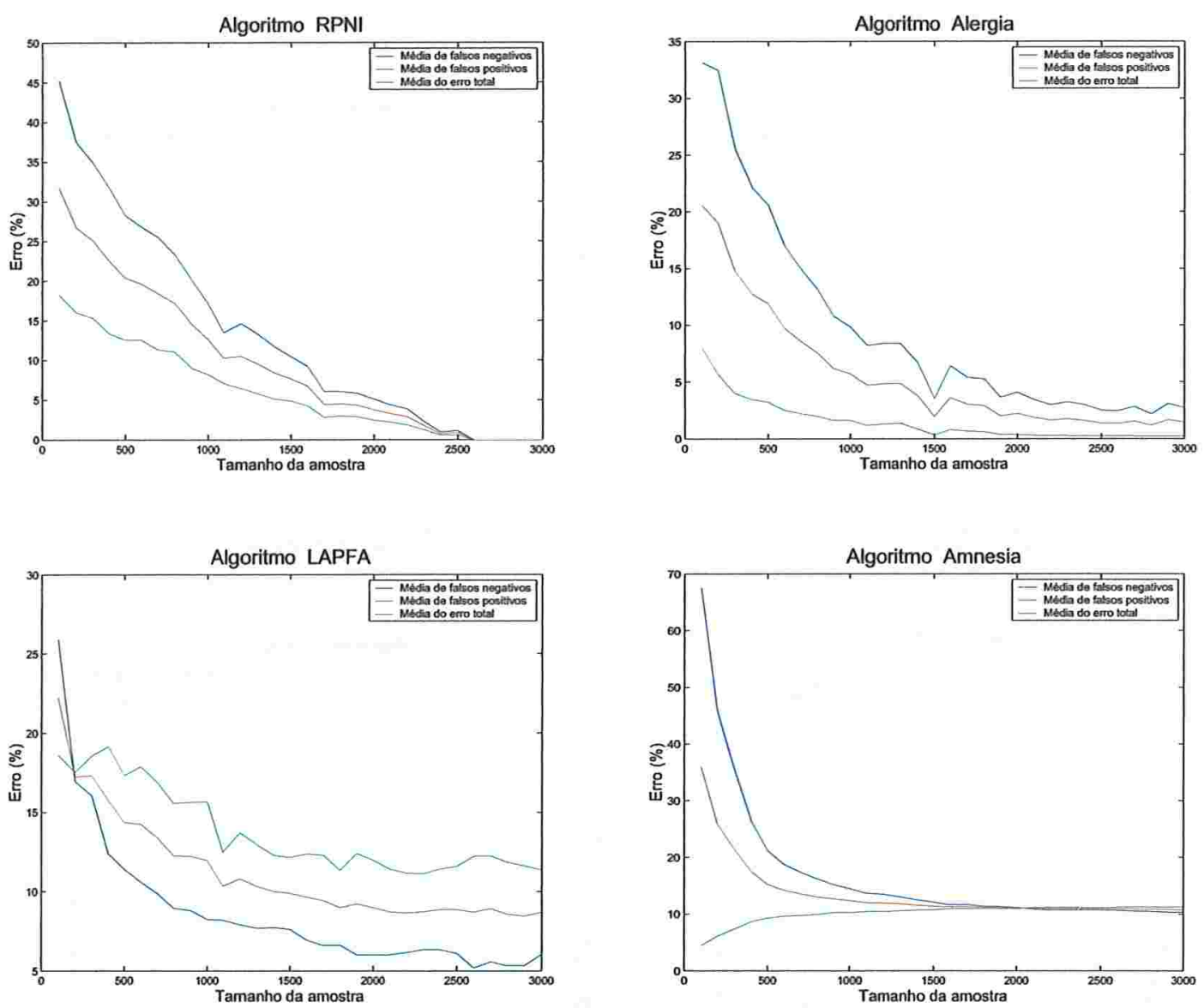

Figura 5.3: Testes de aprendizado da gramática alvo $G_{a}$ leatoria. Taxa de falsos positivos, falsos negativos e erro total da média do resultado da 9 classificadores para cada tamanho de amostra. Os algoritmos de inferência foram treinados com os seguintes paramêtros: o Alergia com $\alpha=0,11$, o LAPFA com $m_{0}=2, \mu=0,2$, e $\gamma_{\min }=0,01$, e por último, o Amnesia com $L=3, n=5$ e $\epsilon=0,1$. 
em particular obteve um resultado bom logo com amostras de tamanho 100. Apesar do gráfico não mostrar, o algoritmo RPNI também obteve uma boa performance ao zerar a taxa de erro para uma amostra de tamanho 10000 seqüências. O Amneisa, entretanto, não obteve resultados sequer satisfatórios para nenhum tamanho de amostras até 10000 seqüências.
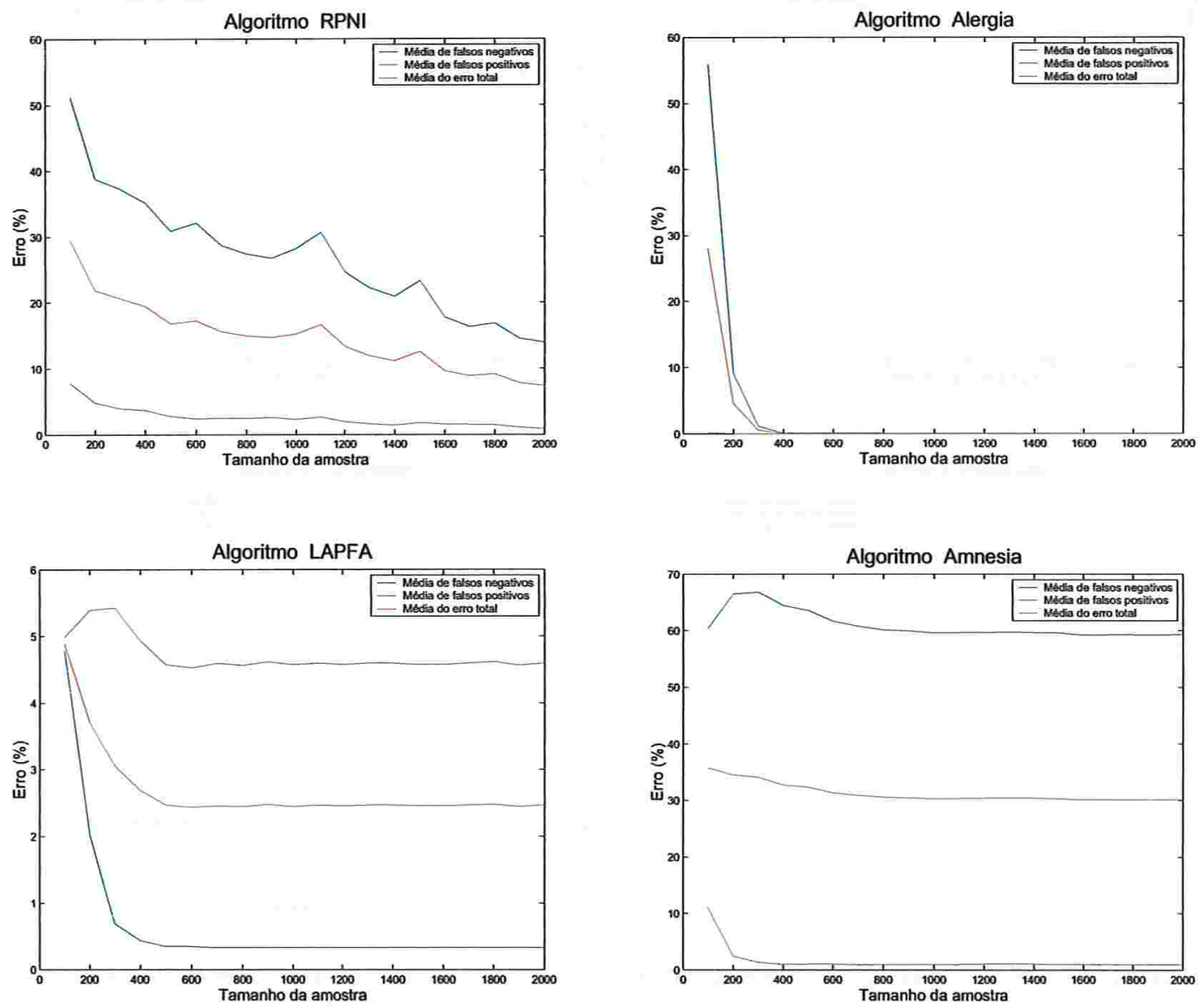

Figura 5.4: Testes de aprendizado da gramática alvo $G_{\text {donor. }}$. Taxa de falsos positivos, falsos negativos e erro total da média do resultado de 9 classificadores para cada tamanho de amostra. Os algoritmos de inferência foram treinados com os seguintes paramêtros: o Alergia com $\alpha=0,01$, o LAPFA com $m_{0}=8$, $\mu=1$, e $\gamma_{\min }=0,05$, e por último, o Amnesia com $L=3, n=10$ e $\epsilon=0,4$. 


\subsubsection{Como obter um limiar}

Uma das dificuldades enfrentadas na validação dos algoritmos foi a atribuição de um valor de limiar para o classificador. Quando um classificador é gerado a partir de apenas uma gramática inferida, a classificação deve ser feita, obrigatoriamente, utilizando um limiar. Um limiar nulo faz com que o classificador classifique como positiva todas as seqüências reconhecidas pela gramática e como negativa caso contrário. Esse é o limiar natural para os algoritmos Alergia e RPNI. Entretanto, os algoritmos Amnesia e LAPFA inferem gramáticas que sempre reconhecem seqüências com probabilidade estritamente maior que zero e, por isso, não faz sentido aplicar um limiar igual a zero. A escolha do limiar nesses casos não é uma tarefa trivial, principalmente porque a probabilidade de cada seqüência atribuída por uma gramática, depende de seu tamanho; ou seja, se as seqüências das amostras de teste não possuem o mesmo tamanho, o classificador gerado pelo GC não funciona corretamente.

Para resolver esse problema, o primeiro passo é linearizar a probabilidade da seqüência $p$ aplicando o logaritmo em $p$ e multiplicando o resultado por -1 , para transformá-lo em positivo. Assim como a literatura de HMM, denominaremos essa transformação por "NLL-score". A dependência linear entre o tamanho das seqüências e seus "NLL-score" pode ser observada na Figura 5.5.

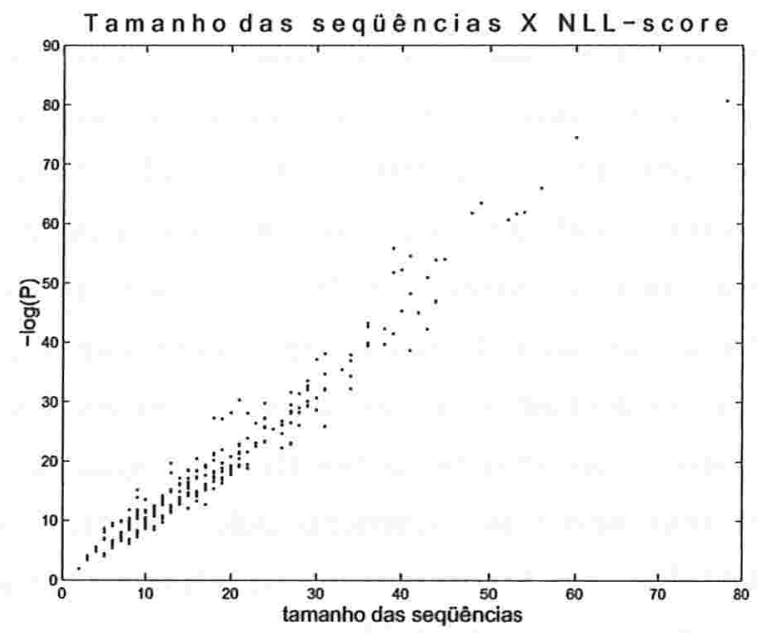

Figura 5.5: Gráfico com os "NLL-score" de seqüências reconhecidas por uma gramática estocástica 
Uma maneira de tratar esse viés entre "NLL-score" e tamanho da seqüência é considerar o "z-score", que corresponde ao número de desvios-padrão que cada "NLL-score" está afastado da média de "NLL-score" de seqüências de mesmo tamanho. Para calcular a média e desvio-padrão de cada tamanho de seqüência, utilizamos um método estatístico chamado técnica de "Windowing" [SMBMH94, HK96], a qual pode ser descrita pelo seguinte procedimento:

1. Para $k$ maior ou igual ao menor tamanho de seqüência, encontre o tamanho mínimo $e_{k} \geq k$ tal que o intervalo de tamanho $\left[k, e_{k}\right]$ contém ao menos $K$ seqüências ( $K$ deve ser pelo menos 500). Para todos esses intervalos na amostra, calcule a média do tamanho das seqüências $t_{k}$, a média $\mu_{k}$ e o desvio-padrão $\sigma_{k}$ dos "NLL-scores".

2. Construa uma curva de média e outra de desvio-padrão dos "NLL-score" para todos os tamanhos de seqüências da amostra, interpolando linearmente os tamanhos que não são representados pelos intervalos construídos.

3. Para cada seqüência $x$ de tamanho $j$ da amostra, calcule $z(x)=\frac{N L L(x)-\mu_{j}}{\sigma_{j}}$. Se o "z-score" da seqüência for maior que um limiar $l$, considere-a como pertencente à família. Esse limiar não é fixo para todos os problemas e deve ser definido observando o histograma de "z-score".

Essa técnica foi testada num problema de aprendizado simulado, no qual o objetivo era classificar as seqüências de uma família caracterizada pela gramática alvo $G_{4}$. A partir de uma amostra positva de treinamento, o algoritmo LAPFA inferiu uma gramática $G$. A Figura 5.6 mostra os "NLL-scores", calculados por $G$, das seqüências de uma amostra de validação e as curvas de média e desvio-padrão, construídas pela técnica de "Windowing". Podemos notar que as seqüências que não pertencem à família formam uma linha de pontos vermelhos e os "NLL-score" das seqüências positivas encontram-se geralmente abaixo dessa linha. Os histogramas do "z-score" das seqüências positivas e negativas, representados na Figura 5.7, mostram que, ao normalizar as seqüências pelo "z-score", os dois grupos de seqüências podem ser distingüidos mais facilmente por um limiar. Nesse teste, para um limiar de 1,8 , obtivemos uma taxa de erro de $0,74 \%$. 


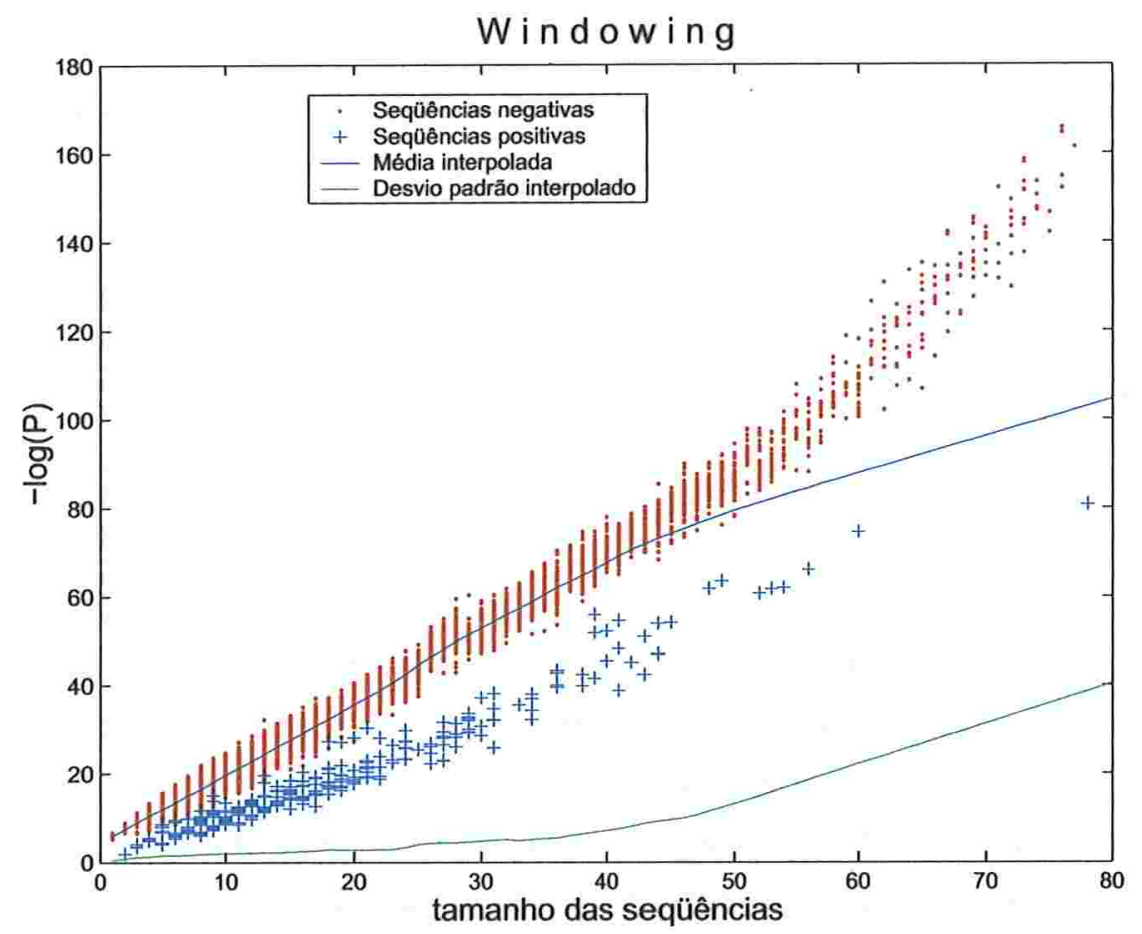

Figura 5.6: Técnica "Windowing" aplicada aos "NLL-score"s calculados por uma gramática inferida pelo algoritmo LAPFA.
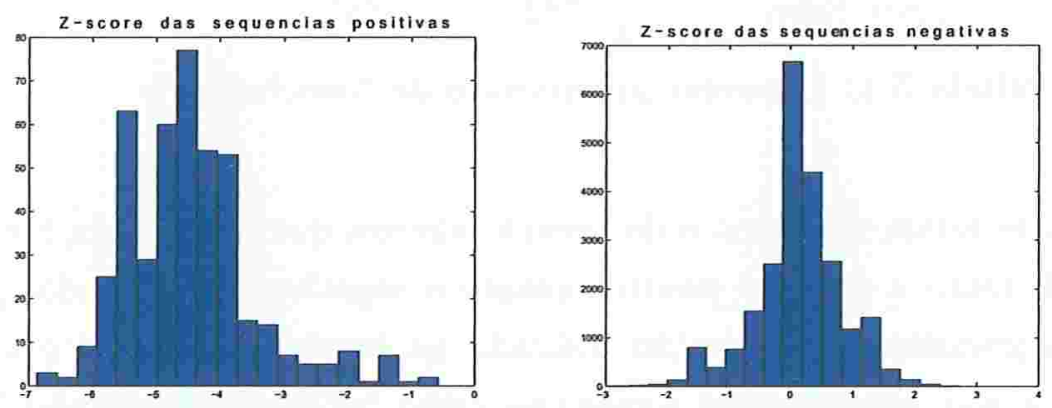

Figura 5.7: Na ordem da esquerda para direita: histograma do "z-score" das seqüências positivas e histograma do "z-score" das seqüências negativas. 


\subsection{Aplicação em Biologia Molecular}

Utilizando o laboratório de inferência gramatical, conduzimos uma avaliação inicial da aplicação dos algoritmos de inferência implementados no problema de definição de fronteiras iniciais e finais de éxons ("splice junctions"). Para que os resultados dos algoritmos de inferência pudessem ser comparados com outro preditor, escolhemos uma amostra de "benchmark" de "splice junctions" de humanos, disponibilizada pela Universidade da Califórnia, Santa Cruz e Lawrence Berkeley National Laboratory ${ }^{1}$.

Esse conjunto de amostras de "benchmark" contém seqüências de "acceptors", as fronteiras iniciais de éxons, e de "donors", as fronteiras finais de éxons. Todos os "acceptors" e "donors" têm um tamanho fixo de 90 e 15 bases de nucleotídeos, respectivamente. Numa seqüência de "acceptors" da amostra, as 7 primeiras bases de nucleotídeos fazem parte do éxon e as 8 bases seguintes fazem parte do íntron, que sempre começa com GT. Numa seqüência de "donors" as 70 primeiras bases de nucleotídeos fazem parte do íntron, o qual sempre acaba com AG, e as 20 bases seguintes fazem parte do éxon. O "benchmark" contém amostras de treinamento e de teste tanto positivas quanto negativas. A Tabela 5.1 mostra o número de seqüências de cada amostra.

\begin{tabular}{|l|c|c|}
\hline \multirow{2}{*}{ Tipo da amostra } & \multicolumn{2}{|c|}{ Tamanho da amostra } \\
\cline { 2 - 3 } & Donor & Acceptor \\
\hline Treinamento Real & 1116 & 1110 \\
Treinamento Falso & 4139 & 4658 \\
Teste Real & 208 & 208 \\
Teste Falso & 782 & 881 \\
\hline
\end{tabular}

Tabela 5.1: Tamanho das amostras de "benchmark".

Os classificadores foram construídos da mesma maneira que no teste da Seção 5.1.3. No caso do RPNI, tanto a amostra positiva quanto a negativa são utilizadas para que seja inferida uma gramática que é então utilizada na construção de um classificador binário. Este, por sua vez, classifica seqüências como pertencentes ou não à família representada pela gramática alvo em questão, de acordo com um limiar 0. No caso dos outros três algoritmos, para cada um deles, as amostras positiva e negativa são utilizadas

\footnotetext{
${ }^{1}$ A amostra "Representative Benchmark Data Sets of Human DNA Sequences" está disponível no seguinte sítio de internet: http://www.fruitfly.org/sequence/human-datasets.html
} 
para inferir duas gramáticas, $G_{+}$e $G_{-}$, respectivamente. Um classificador é construído a partir dessas duas gramáticas e classificará uma seqüência $s$ como pertencente à família se $p\left(s \mid G_{+}\right)>p\left(s \mid G_{-}\right)$ou não pertencente à família, caso contrário. Mais uma vez, pela falta de informação sobre as distribuições dos modelos positivo e negativo, supomos que $p\left(G_{+}\right)=p\left(G_{-}\right)$. Antes de aplicar os algoritmos, foi necessário determinar quais os valores dos parâmetros de entrada. Para tanto foi feito um teste de validação cruzada para diferentes combinações dos parâmetros. Os resultados das 2 melhores combinações da validação cruzada encontram-se na Tabela 5.2 para os sítios de "donor" e na Tabela 5.3 para os sítios de "acceptors".

\begin{tabular}{|l|c|c|c|c|c|c|}
\hline \multirow{2}{*}{ Algoritmo } & \multicolumn{3}{|c|}{ Parâmetro } & \multicolumn{4}{c|}{ Erro } \\
\cline { 2 - 7 } & $\mathrm{p} 1$ & $\mathrm{p} 2$ & $\mathrm{p} 3$ & \% Total & \% Falsos Positivos & \% Falsos Negativos \\
\hline LAPFA & 5 & 0,9 & 0,01 & 6,09 & 4,37 & 12,46 \\
& 8 & 1,0 & 0,001 & 6,39 & 3,67 & 16,49 \\
Alergia & 0,2 & - & - & 10,56 & 6,93 & 24,01 \\
& 0,3 & - & - & 10,85 & 6,26 & 27,87 \\
Amnesia & 0,3 & 6 & 2 & 24,09 & 24,18 & 23,75 \\
& 0,5 & 6 & 2 & 24,09 & 24,18 & 23,75 \\
\hline
\end{tabular}

Tabela 5.2: Desempenho dos algoritmos no teste de validação cruzada da amostra de treinamento de donors.

\begin{tabular}{|l|c|c|c|c|c|c|}
\hline \multirow{2}{*}{ Algoritmo } & \multicolumn{2}{|c|}{ Parâmetro } & \multicolumn{4}{c|}{ Erro } \\
\cline { 2 - 7 } & $\mathrm{p} 1$ & $\mathrm{p} 2$ & $\mathrm{p} 3$ & \% Total & \% Falsos Positivos & \% Falsos Negativos \\
\hline LAPFA & 5 & 1 & 0,01 & 6,38 & 5,11 & 11,71 \\
& 5 & 0,3 & 0,06 & 13,07 & 9,17 & 29,46 \\
Alergia & 0,1 & - & - & 30,95 & 22,03 & 68,38 \\
& 0,2 & - & - & 31,69 & 23,77 & 64,95 \\
Amnesia & 0,1 & 5 & 1 & 40,33 & 39,67 & 43,06 \\
& 0,3 & 5 & 2 & 40,66 & 40,90 & 39,64 \\
\hline
\end{tabular}

Tabela 5.3: Desempenho dos algoritmos no teste de validação cruzada da amostra de treinamento de acceptors.

A melhor combinação de cada algoritmo foi escolhida para que os algoritmos de inferência sejam treinados com toda a amostra de treinamento, e os classificadores construídos a partir das gramáticas inferidas sejam validados finalmente com a amostra de teste. As Tabelas 5.4 e 5.5 mostram esse resultado. 


\begin{tabular}{|l|c|c|c|c|c|c|}
\hline \multirow{2}{*}{ Algoritmo } & \multicolumn{2}{|c|}{ Parâmetro } & \multicolumn{4}{c|}{ Erro } \\
\cline { 2 - 7 } & $\mathrm{p} 1$ & $\mathrm{p} 2$ & $\mathrm{p} 3$ & \% Total & \% Falsos Positivos & \% Falsos Negativos \\
\hline LAPFA & 5 & 0,9 & 0,01 & 5,25 & 3,84 & 10,58 \\
Alergia & 0,2 & - & - & 12,63 & 8,82 & 26,92 \\
Amnesia & 0,3 & 6 & 2 & 22,32 & 21,99 & 23,56 \\
RPNI & - & - & - & 23,47 & 23,92 & 22,44 \\
\hline
\end{tabular}

Tabela 5.4: Desempenho dos algoritmos na identificação dos donors.

\begin{tabular}{|l|c|c|c|c|c|c|}
\hline \multirow{2}{*}{ Algoritmo } & \multicolumn{2}{|c|}{ Parâmetro } & \multicolumn{4}{c|}{ Erro } \\
\cline { 2 - 7 } & $\mathrm{p} 1$ & $\mathrm{p} 2$ & $\mathrm{p} 3$ & \% Total & \% Falsos Positivos & \% Falsos Negativos \\
\hline LAPFA & 5 & 1 & 0,01 & 6,70 & 4,20 & 17,31 \\
Alergia & 0,1 & - & - & 27,64 & 14,53 & 83,17 \\
Amnesia & 0,1 & 5 & 1 & 37,37 & 34,05 & 51,44 \\
RPNI & - & - & - & 31,46 & 28,11 & 45,50 \\
\hline
\end{tabular}

Tabela 5.5: Desempenho dos algoritmos na identificação dos acceptors.

A utilização desse conjunto de amostras permitiu uma comparação direta com o preditor de "splice junctions" NNSPLICE [RM97]. Essa ferramente, uma abordagem de Redes Neurais, foi treinada e avaliada com a mesma amostra de "benchmark" e obteve o seguinte resultado: $5.2 \%$ de falsos positivos e 6,8\% de falsos negativos para a identificação de donor e $3,1 \%$ de falsos positivos e $26,2 \%$ de falsos negativos para a identificação de acceptors.

Ressaltamos que os resultados obtidos pelos algoritmos de inferência gramatical são provenientes de um processo automático de escolha de parâmetros de entrada sem nenhum estudo detalhado. Mesmo assim obtivemos resultados comparáveis a um dos preditores de fronteiras de íntrons e éxons dentre os utilizados em Biologia Computacional. 


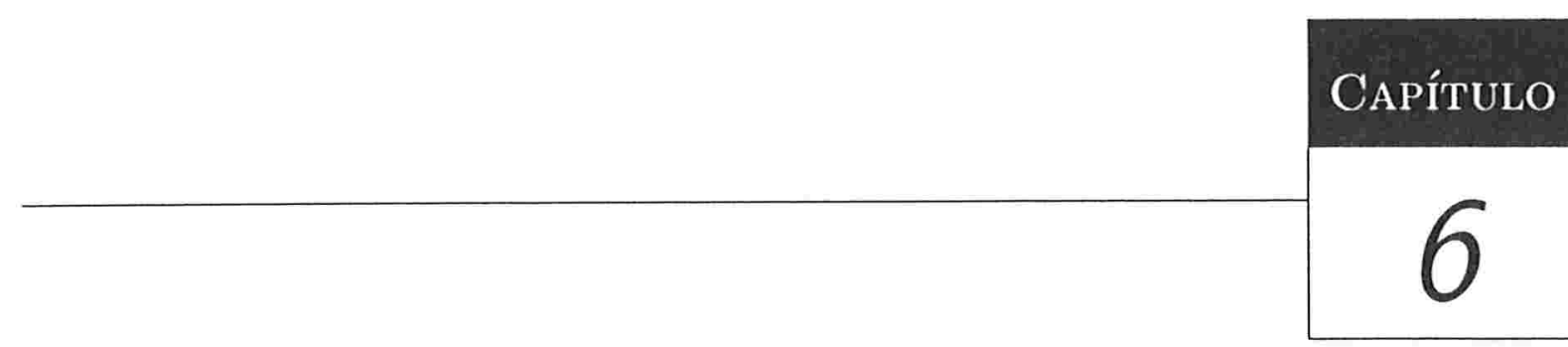

\section{Conclusão}

Neste trabalho, estudamos o campo de inferência de gramáticas regulares e a aplicação dessa teoria em problemas de Biologia Molecular. Como contribuições deste trabalho, podemos citar a implementação de 4 algoritmos de inferência de gramática regular (juntamente com sua descrição utilizando uma notação unificada), um estudo comparativo inicial destes algoritmos utilizando dados simulados e dados reais, o desenvolvimento de uma aplicação para a predição de "splice junctions" e um ambiente computacional que pode ser usado tanto para validação de algoritmos como para geração automática de classificadores obtidos por meio da inferência de linguagens regulares. Em particular, cabe destacar que em uma análise inicial nosso preditor de "splice junctions" obteve dados comparáveis aos melhores resultados do algoritmo NNSPLICE para uma amostra de "benchmark", mas com configuração automática dos parâmetros baseada apenas na amostra de treinamento, utilizando a técnica de validação cruzada.

O ambiente desenvolvido pode ser utilizado em trabalhos futuros como uma ferramenta de investigação da aplicação de inferência gramatical em problemas de Biologia Molecular. Apesar de nosso trabalho ter utilizado como ponto de partida o arcabouço 
desenvolvido por Ariane Lima [Lim02], melhoramos a estrutura existente acrescentando classes de suporte a inferência de gramáticas regulares, a implementação dos algoritmos de inferência de gramáticas regulares RPNI [Dup96], Alergia [CO94a], LAPFA [Ron95] e Amnesia [Ron95], um algoritmo para geração de gramáticas regulares estocásticas aleatórias, a modificação de um algoritmo de inferência de gramáticas regulares para a geração de inferência de gramáticas regulares estocásticas, um conjunto de programas para gerar testes de aprendizado em domínios de seqüências geradas por uma gramática alvo conhecida para aplicar a técnica de "windowing" a fim de classificar sequiências de tamanhos diferentes e para aplicar validação cruzada na busca de boas configurações para até três parâmetros em algoritmos de inferência gramatical (para gramáticas regulares ou não).

Na aplicação dos algoritmos na amostra de "benchmark", o fato de o algoritmo LAPFA ter desempenho equivalente ao do NNSPLICE, um preditor de "splice junctions" de domínio público, mostrou que a inferência gramatical pode ser utilizada como ferramenta na identificação de fronteiras de íntrons e éxons. Acreditamos que a continuação desse estudo inicial, junto a novas abordagens de testes, possam resultar em classificadores ainda melhores. Além disso, esse resultado indica que algoritmos de inferência de gramáticas regulares são promissores no reconhecimento de padrões em Biologia Molecular.

\subsection{Trabalhos futuros}

O Laboratório de inferência gramatical desenvolvido encontra-se disponível para novos experimentos empíricos. Destacamos a seguir algumas análises futuras que podem ser realizadas por meio dessa ferramenta.

Entre os algoritmos de inferência implementados, o RPNI é o único que não possui parâmetro de generalização. Em aplicações de Biologia Molecular, onde o custo de validação bioquímica é alto e por isso taxas baixas de falsos positivos são desejadas, uma ferramenta que controla a compensação entre falsos positivos e falsos negativos torna-se importante. Todavia, a variação de valores para o limiar dos classificadores construídos a partir de gramáticas inferidas pelo RPNI é uma alternativa para controlar a compensação entre falsos positivos e falsos negativos. A utilidade dessa abordagem poderia ser verificada por meio de testes com diferentes valores de limiar para um classificador. 
Nos problemas de Biologia Molecular, o volume de seqüências de amostras negativas é geralmente maior em relação ao volume de seqüências positivas. Um estudo pertinente é analisar o comportamento dos algoritmos em casos controlados em que os algoritmos são treinados com um volume maior de seqüências negativas do que positivas. Além disso, para esses testes seria necessário considerar as probabilidades do padrão das seqüências positivas e do padrão das seqüências negativas no classificador de Bayes. Nos testes realizados neste trabalho, suposemos que a probabilidade de ambos os padrões eram iguais.

Com relação à avaliação preliminar dos algoritmos de inferência utilizando a amostra de "benchmark", sugerimos os seguintes trabalhos futuros.

Como mencionado previamente, no contexto de um classificador de Bayes, consideramos a probabilidade do padrão da amostra positiva igual à probabilidade do padrão da amostra negativa. Uma nova abordagem para obter classificadores bayesianos melhores seria estimar esses dois valores de probabilidade.

Apresentamos na Seção 5.2 os resultados de classificadores gerados a partir de duas gramáticas, uma treinada pela amostra negativa e a outra pela positiva. Uma outra abordagem possível é a construção de classificadores gerados a partir de uma gramática inferida por um dos algoritmos Alergia, LAPFA ou Amnesia a partir da amostra positiva de treinamento.

Os algoritmos de inferência implementados foram comparados com apenas um preditor de fronteiras de íntrons e éxons. Outras comparações devem ser feitas aplicando a mesma amostra de "benchmark" em outros preditores ou aplicando os algoritmos implementados neste trabalho em outras amostras de "benchmark" disponíveis. Se os resultados obtidos nessa nova comparação forem positivos como os resultados obtidos neste trabalho, um preditor de "splice junctions" baseado no LAPFA deve ser desenvolvido para reconhecer fronteiras de íntrons e éxons em bancos de dados de seqüências de DNA. 



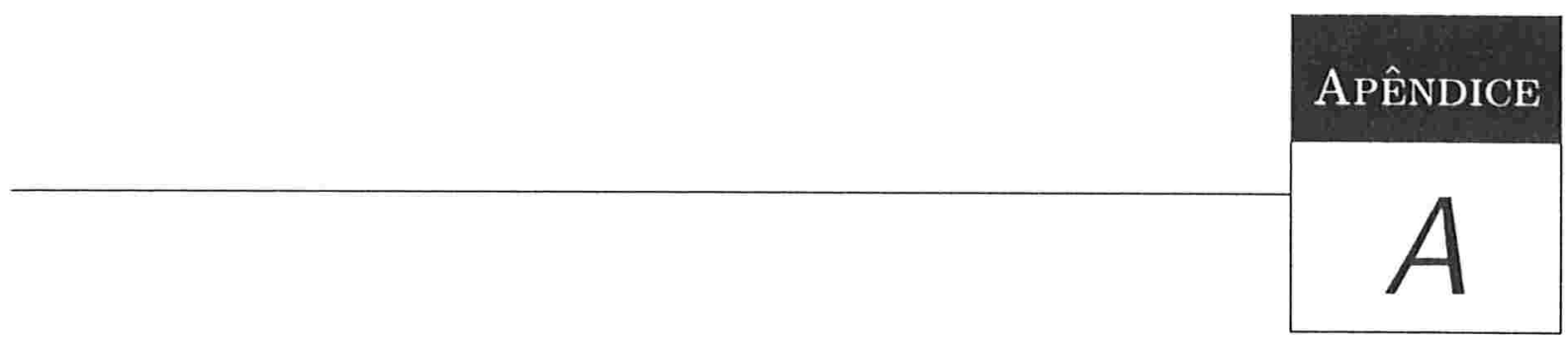

\section{Participações em Conferências}

- Apresentação de pôster na 6th Brazilian School of Probability em 2002.

- Apresentação de pôster no ICOBICOBI 1st International Conference on Bioinformatics and Computational Biology em 2003. 


\section{Índice Remissivo}

árvore de sufixos preditora (ASP), 48

ínfimo, 24

alfabeto, 12

algoritmo

de aprendizado, 6

amostra, 6

característica, 32

estruturalmente completa, 25

anticadeia, 28

aprendizado, 6

apresentação

completa, 21

positiva, 21

autômato, 11

ambígüo, 13

canônico, 13

canônico maximal, 25

compatível, 28

de árvore de prefixos, 26

de sufixo estocástico(ASE), 47

derivação de, 24 equivalentes, 13

finito, 12

finito determinístico (AFD), 13

finito determinístico (AFD) estocástico, 15

finito estocástico (AFE), 14

profundidade, 27

profundidade máxima, 29

universal, 26

Bayes

classificação, 9

cadeia de Markov oculta (HMM), 17

classificação de Bayes, 9

Classificação de Chomski, 12

conceito, 6

conjunto

de fronteira, 29

parcialmente ordenado, 23

conjunto de Caudas, 11

conjunto de estados finais, 12

espaço 
de conceitos, 6

de exemplos, 6

estado, 12

útil, 13

de reconhecimento, 13

inútil, 13

inicial, 12

exemplo, 6

função

de probabilidade do próximo símbolo, 15

de transição, 12

gramática, 11

estocástica, 14

gramática regular, 12

Gramática Regular (GR), 12

HMM, 17

identifica no limite, 21

limitante

inferior, 23

superior, 23

linguagem, 11

núcleo, 33

regular, 13

matriz de probabilidades

de emissão de símbolos, 17

de transição HМMI, 17

de transição AFE, 14

PAC

algoritmo, 8 modelo de aprendizado, 7

prefixo, 11

curto, 33

problema de consistência do AFD minimal, 28

produções

conjunto de, 11

quociente-direito, 11

reconhecimento, 13

relação de ordem parcial, 23

reticulado, 24

Booleano, 24

complementado, 24

completo, 24

de autômatos, 26

distributivo, 24

símbolo

terminal, 11

inicial, 11

não terminal, 11

sufixo

livres, 47

próprio, 47

supremo, 24

treinamento, 6 



\section{Referências Bibliográficas}

[Adi00] Said Sadique Adi. Ferramentas de Auxilio ao Sequenciamento de DNA por Montagem de Fragmentos: um estudo comparativo. Master's thesis, Instituto de Matematica e Estatistica da Universidade de Sao Paulo, 2000.

[AFvZ02] Pieter W. Adriaans, Henning Fernau, and Menno van Zaanen, editors. Grammatical Inference: Algorithms and Applications, 6th International Colloquium: ICGI 2002, Amsterdam, The Netherlands, September 23-25, 2002, Proceedings, volume 2484 of Lecture Notes in Computer Science. Springer, 2002.

[AKMSH94] M. Brown A. Krogh, I. S. Mian, K. Sjölander, and D. Haussler. Hidden Markov models in computational biology: Applications to protein modeling. Journal of Molecular Biology, 235:1501-1531, February 1994.

[Ang92] D. Angluin. Computational Learning Theory: Survey and Selected Bibliography. In Proceedings of the twenty-fourth annual ACM Symposium on Theory of Computing, pages 351-369, 1992.

[AS83] Dana Angluin and Carl H. Smith. Inductive inference: Theory and methods. ACM Computing Surveys, 15(3):237-269, September 1983.

[ASU86] Alfred Aho, Ravi Sethi, and Jeffrey Ullman. Compilers: Principles, Techniques, and Tools. Addison-Wesley, 1986. 
[AU73] A. V. Aho and J. D. Ullman. The theory of parsing, translation and compiling. Prentice Hall, Englewood Cliffs, N.J., 2, 1973.

[AW90] Naoki Abe and Manfred K. Warmuth. On the computational complexity of approximating distributions by probabilistic automata. In Proceedings of the third annual workshop on Computational learning theory, pages 52-66. Morgan Kaufmann Publishers Inc., 1990.

[Bar42] J. Barry. Probabilidade :um curso em nível intermediário. 1942.

[Cho59] N. Chomsky. On certain formal properties of grammars. Information and Control, 2:137-167, 1959.

[CO94a] Rafael Carrasco and Jose Oncina. Learning Stochastic Regular Grammar by Means of State Merging Method. Lecture Notes Artificial Intelligence, In Grammatical Inference and Application(862):139-152, 1994.

[CO94b] Rafael Carrasco and Jose. Oncina, editors. Proceedings of the Second International Colloquium on Grammatical Inference and Applications, volume 862, 1994.

[CO99] Rafael C. Carrasco and Jose Oncina. Learning deterministic regular grammars from stochastic samples in polynomial time. RAIRO (Theoretical Informatics and Applications), 33(1):1-20, 1999.

[DEKM98] R. Durbin, S. Eddy, A. Krogh, and G. Mitchison. Biological sequence analysis. Cambridge, 1998.

[DR96] Yoram Singer e Naftali Tishby Dana Ron. The power of amnesia: Learning probabilistic automata with variable memory length. Machine Learning, 25(2-3):117-149, 1996.

[Dup94] P. Dupont. Regular grammatical inference from positive and negative samples by genetic search: the gig method. Lecture Notes Artificial Intelligence, In Grammatical Inference and Application(862):236-245, 1994.

[Dup96] Pierre Dupont. Incremental regular inference. Lecture Notes Artificial Intelligence, 1147:222-237, 1996. 
[Fu82] King S. Fu. Syntactic Pattern Recognition and Applications. Prentice-Hall, Inc., Englewood Cliffs,NJ, 1982.

[Gol67] E. M. Gold. Language identification in the limit. Information and Control, 10:447-474, 1967.

[Gol78] E. M. Gold. Complexity of automaton identification from given data. Information and Control, 37:302-320, 1978.

[HAO93] Juergen Haas, Jeffrey S. Aaronson, and G. Christian Overton. Analogical reasoning for knowledge discovery in a molecular biology database. 1993.

[HK96] R. Hughey and A. Krogh. Hidden markov models for sequence analysis: extension and analysis of basic method. Comp. Appl. BioSci, 12(2):95-108, 1996.

[Hoe63] W. Hoeffding. Probability inequalities for sums of bounded random variables. Journal of the American Statistical Association, 58(301):13-30, March 1963.

[HS98] Vasant Honavar and Giora Slutzki, editors. Grammatical Inference, 4th International Colloquium, ICGI-98, Ames, Iowa, USA, July 12-14, 1998, Proceedings, volume 1433 of Lecture Notes in Computer Science. Springer, 1998.

[HSF97] J. Henderson, S. Salzberg, and K. Fasman. Finding genes in DNA with a Hidden Markov Model. Journal of Computational Biology, 4:121-141, 1997.

[KV89] Michael Kearns and Leslie G. Valiant. Cryptographic limitations on learning Boolean formulae and finite automata. In Proceedings of the Twenty First Annual ACM Symposium on Theory of Computing, pages 433-444, Seattle, Washington, 15-17 May 1989.

[Lan92] K. J. Lang. Random DFA's can be approximately learned from sparse uniform examples. In Proceedings of the Fifth ACM Workshop on Computational Learning Theory, pages 45-52, New York, N.Y., 1992. ACM. 
[Lan99] Kevin J. Lang. Faster algorithms for finding minimal consistent dfas. 1999.

[Lim02] Ariane Machado Lima. Laboratório de geração de classificadores de seqüências. Master's thesis, Instituto de Matematica e Estatistica da Universidade de Sao Paulo, 2002.

[MA92] N. Biggs M. Anthony. Computational Learning Theory - An Introduction. Cambridge University Press, 1992.

[MH96] Laurent Miclet and Colin De La Higuera, editors. Grammatical Inference: Learning Syntax from Sentences, 3rd International Colloquium, ICGI-96, Montpellier, France, September 25-27, 1996, Proceedings, volume 1147 of Lecture Notes in Computer Science. Springer, 1996.

[MKS94] Dana Ron Ronitt Rubinfeld Robert E. Schapire Michael Kearns, Yishay Mansour and Linda Sellie. On the learnability of discrete distributions. In Proceedings of the 26th Annual Symposium on the Theory of Computing, pages 273-282, New York, May 1994. ACM Press.

[MS97] Joao Meidanis and Joao C. Setubal. Introduction to Computational Molecular Biology. PWS Publishing Co., 1997.

[OG92] J. Oncina and P. Garcia. Inferring regular languages in polynomial update time. In N. Pérez de la Blanca, A. Sanfeliu, and E. Vidal, editors, Pattern Recognition and Image Analysis, volume 1 of Series in Machine Perception and Artificial Intelligence, pages 49-61. World Scientific, Singapore, 1992.

[Oli00] Arlindo L. Oliveira, editor. Grammatical Inference: Algorithms and Applications, 5th International Colloquium, ICGI 2000, Lisbon, Portugal, September 11-13, 2000, Proceedings, volume 1891 of Lecture Notes in Computer Science. Springer, 2000.

[PD94] L. Miclet e E. Vidal P. Dupont. What is the search space of the regular inference? In R. C. Carrasco and J. Oncina, editors, Proceedings of the Second International Colloquium on Grammatical Inference (ICGI-94): Grammatical Inference and Applications, volume 862, pages 25-37, Berlin, 1994. Springer. 
[Pit89] L. Pitt. Inductive inference, DFAs, and computational complexity. In K. P. Jantke, editor, Proceedings of the International Workshop on Analogical and Inductive Inference (AII-89), volume 397 of LNAI, pages 18-44, Berlin, October 1-6 1989. Springer.

[PY73] F. P. Preparata and R. T. Yeh. Introduction to Discrete Structures. Addison-Wesley, Reading, 1973.

[Rab89] L. R. Rabiner. A tutorial on hidden Markov models and selected applications in speech recognition. Proceedings of the IEEE, 77(2):257-285, February 1989.

[RM97] FH Kulp D Haussler Reese MG, Eeckman. Improved splice site detection in genie. Journal of Computational Biology, 4(3), 1997.

[Ron95] D. Ron. Automata Learning and its Applications. PhD thesis, Hebrew University, 1995.

[Sak95] Yasubumi Sakakibara. Grammatical Inference: An old and new paradigm. Lecture Notes Artificial Intelligence, 997:1-24, 1995.

[SDFH98] S. Salzberg, A Delcher, K. Fasman, and J. Henderson. A decision tree system for finding genes in DNA. Journal of Computational Biology, 5(4), 1998.

[Sea88] David B. Searls. Representing genetic information with formal grammars. In Proceeding of 7th National Conference on Artificial Intelligence, pages 386-291, 1988.

[Sea89] David B. Searls. Investigating the linguistic of DNA and definite clause grammars. In Logic Programming: Proceeding of the North American Conference on Logic Programming, pages 189-208, 1989.

[Sea95] David B. Searls. String variable grammar: a logic grammar formalism for DNA sequences. J. Logic Programming, 24:73-102, 1995.

[SMBMH94] Y. Sakakibara, R. C. Underwood M. Brown, I. S. Mian, and D. Haussler. Stochastic context-free grammars for modeling RNA. In Lawrence Hunter, editor, Proceedings of the 27th Annual Hawaii International Conference 
on System Sciences. Volume 5 : Biotechnology Computing, pages 284-294, Los Alamitos, CA, USA, January 1994. IEEE Computer Society Press.

[SV96] M.-F. Sagot and A. Viari. A double combinatorial approach to discovering patterns in biological sequences. In Proceedings of the 7th Annual Symposium on Combinatorial Pattern Matching, number 1075, pages 186-208, Laguna Beach, CA, 1996. Springer-Verlag, Berlin.

[Sza84] G. Szasz. Introduction to Lattice Theory. Academic Press, New York, 1984.

[TB73] B. Trakhtenbrot and Y. Barzdin. Finite automata: Behavior and synthesis. North Holland Publishing Company, Amsterdam, 1973.

[Tom96] Nina Sumiko Tomita. Programação automática de máquinas morfológicas binárias baseada em aprendizado PAC. Master's thesis, Instituto de Matematica e Estatistica da Universidade de Sao Paulo, 1996.

[Val84] L. G. Valiant. A Theory of the Learnable. Communications of the ACM, 27(11):1134-1142, 1984.

[YSRHKSH94] M. Brown Y. Sakakibara, I. Mian R. Hughey, R. Underwood Kimmen Slander, and D. Haussler. Stochastic Context-Free Grammars for tRNA Modeling. Nucleic Acids Research, 22:5112-5120, 1994. 